\title{
The International Journal of Screendance
}

VOLUME 1 • SUMMER 2010

ISSN 2154-6878

\section{EDITORS}

Douglas Rosenberg and Claudia Kappenberg

\section{EDITORIAL ASSISTANTS}

Virginia M. Piper

Dominique C. Bourg

Nathan J. Jandl 



\section{THE INTERNATIONAL JOURNAL OF SCREENDANCE EDITORIAL BOARD}

\section{ANN COOPER ALBRIGHT \\ Professor of Theater and Dance \\ Oberlin College}

\section{ELLEN BROMBERG}

Associate Professor, Department of Modern Dance

University of Utah

\section{DR. HARMONY BENCH}

Assistant Professor, Dance Department

Ohio State University

\section{DR. SIMON ELLIS}

Senior Lecturer (Practice-based)

Roehampton University

\section{DR. FRANK GRAY}

Director of Screen Archive South East (SASE)

University of Brighton

\section{CLAUDIA KAPPENBERG}

Senior Lecturer, Performance and Visual Art

School of Arts and Media

University of Brighton

\section{MIRANDA PENNELL}

Independent film and video artist

London, UK

\section{DOUGLAS ROSENBERG}

Professor of Art, Department of Art

University of Wisconsin-Madison

\section{THERON SCHMIDT, PHD}

Researcher

Queen Mary University of London

\section{SILVINA SZPERLING}

Director, Internacional Festival de Videodanza

Buenos Aires, Argentina

\section{DR. SARAH WHATLEY}

Professor of Dance

Coventry School of Art and Design

Coventry University

\section{MARISA ZANOTTI}

Senior Lecturer, Dance

University of Chichester 


\section{Cover and Publication Design}

Barry Roal Carlsen, University Communications, University of Wisconsin-Madison

\section{Cover Image}

Dickson Experimental Sound Film (Dir. William Dickson, 1894/1895)

\section{Design Research}

Julie VonDerVellen

\section{The International Journal of Screendance}

(ISSN 2154-6878) is published by Parallel Press,

an imprint of the University of Wisconsin-Madison Libraries.

Online: http://journals.library.wisc.edu/screendance 


\section{Table of Contents}

\section{EDITORIAL COMMENT}

Douglas Rosenberg

Claudia Kappenberg

\section{LETTERS}

\section{ESSAYS}

7 The Evolution of the 'A'Word: Changing Notions of

Professional Practice in Avant-Garde Film and Contemporary Screendance Chirstinn Whyte

13 In and Out of Place: Site-based Screendance

Kyra Norman

21 Falling ... on Screen Ann Cooper Albright

27 The Logic of the Copy, from Appropriation to Choreography Claudia Kappenberg

41 The Spectacle of Difference: Dance and Disability on Screen Sarah Whatley

53 Anti-Gravitational Choreographies: Strategies of Mobility in Screendance Harmony Bench

63 Excavating Genres Douglas Rosenberg

75 La Escritura Perpleja Susana Temperley

83 Perplexed Writing (English translation) Susana Temperley

91 When Dance is Imagined in Cinema: Disclosure in Dance Practice Marisa Zanotti

\section{INTERVIEW}

97 Bob Lockyer Douglas Rosenberg

\section{RE-VIEW}

107 Cutting Rhythms: A New Perspective on the Rhythmic and Choreographic Nuances of the Edit by Karen Pearlman Reviewed by Cari Ann Shim Sham*, MFA

\section{RE-PRINT}

111 Toward a Definition of Moving-Picture Dance Noël Carroll

\section{ARTISTS' PAGES}

127 Watching Simon Ellis

\section{CONTRIBUTORS}





\section{Editorial Comment}

\section{Screendance: The Practice in Print}

t $\mathrm{t}$ is with great pleasure that we introduce this first edition of The International Journal of Screendance, and share some thoughts about its intentions and parameters. The journal is a new, peer-reviewed publication; the first-ever scholarly journal dedicated to the growing area of the inter-disciplinary practice of screendance. It is an initiative undertaken by an international group of practitioners, researchers, and activists engaged with screendance, who wish to establish a forum for debate for all those interested in the intersection of dance and the moving image.

The International Journal of Screendance is hosted by the University of WisconsinMadison under the Parallel Press imprint and will be available in both digital (online) and printed form. The editorial board is formed from members of the International Screendance Network, based at the University of Brighton and funded by the Arts and Humanities Research Council, as well as scholars and artists from related fields of inquiry. Intended as an open international platform, and seeking input and participation from the larger global community, the journal seeks to foster not only a multi-cultural but also a multilingual discourse. To this aim, guest-editors from other cultural regions and adjacent fields of practice and inquiry will be invited to curate future editions of the journal. The journal will engage in rigorous critique grounded in both pre-existing and yet to be articulated methodologies from the fields of dance, performance, visual art, cinema, and media arts, drawing on their practices, technologies, theories, and philosophies, to develop and expand the scholarly debates around the practice of screendance. It will include original scholarship and historically pertinent, yet hard to find writings, as well as specially commissioned articles. Each issue will be edited around a particular set of questions that discuss and reframe current topics in the field of screendance, as a means of promoting and enriching critical dialogue.

For the purposes of the journal, we have chosen to use the term screendance to broadly describe a field, while noting that there are no hard and fast criteria for a definition of screendance. Over the history of this art form, there have been a number of terms used to describe the work, often limited to an indication of materiality (e.g. Video-dance, Cinedance or Dance film). The term we have chosen articulates a common denominator between all of the above. Through this journal, we aim to reframe screendance as a form of research that examines the interrelationships of composition, choreographic language, and meanings of body, movement, space, and time; this is done in the context of contemporary cultural debates about artistic agency, practice as theory, and interdisciplinarity.

Since the advent of optical media and the moving image, choreographic sensibilities, bodies in motion, and 'dance' have featured prominently within the frame. From Muybridge's motion studies to Eisenstein's groundbreaking cinematic language, via the 
Dadaists and Futurists, images of bodies in motion have been the object of exploration, through the media of still-photography, cinema, video, and digital technologies. Since the middle of the twentieth century, artists from the fields of dance and the moving image have developed a hybrid-practice, now commonly referred to as screendance. From the latter part of the twentieth century into the twenty-first, there were a number of curated events dedicated to screendance: the Filmdance Festival at the Public Theatre in New York City in 1983, curated by Amy Greenfield; Eyes Wide Open at the Dance Theatre Workshop in NY in 1989, curated by James Byrne; and events dedicated to scholarship such as the first conference on screendance at the University of Wisconsin-Madison in 1999, and at the American Dance Festival in 2006 and 2008. In the past two decades, there has been a rapid expansion of international interest in the field with conferences, symposia, and dedicated festivals, including: IMZ Dance Screen, Dança em Foco (Rio de Janeiro, Brazil), MOVES, International Festival of Movement on Screen (Manchester, UK), Dance Camera West (Los Angeles, USA), International Dance Film Festival (Yokohama, Japan), Agite y Sirve International Video Dance Festival (Mexico), ReelDance (Australia), Festival Internacional de Videodanza (Buenos Aires, Argentina), Dance on Camera Festival (New York, USA), the What If ... Festival (London, UK), and many more, too numerous to mention here.

This expansion in both exhibition and conference opportunities for screendance has not, however, been matched by an equivalent growth in written theorization, and there has been no dedicated forum for ongoing publication and dissemination of critical texts. The International Journal of Screendance aims to create a platform for the rigorous critical investigation of the myriad approaches to the practice of screendance and to encourage the development of a cohesive body of knowledge and scholarly texts. Additionally, the journal supports scholarship intended to expand the parameters of what may currently be considered screendance and apply a choreographic lens to screen-based and digital works that may not have been conceived of as part of this field, but which might contribute in some form to its practice.

It is important to acknowledge the efforts of numerous people and initiatives leading up to this moment. In 2006 Katrina McPherson and Simon Fildes, along with Karl Jay-Lewin, organized Opensource \{videodance\} at the Findhorn Foundation Community in the North East of Scotland. That undertaking brought together the group of artists and thinkers who would ultimately begin the process of creating this journal. A subsequent iteration of Opensource \{videodance\} was held in 2007, along with two publications about the symposia. In October 2008, Katrina McPherson, Claudia Kappenberg, and Douglas Rosenberg huddled by a fireplace in a remodelled pigsty behind Fildes and McPherson's home in Ferness, Scotland to clarify the concept of a new, dedicated journal of screendance and to begin drafting an editorial. In 2008, Katrina McPherson also worked with Claudia Kappenberg to secure funding from the Art and Humanities Research Council (UK) to establish the International Screendance Network. Numerous meetings and discussions between too many people to name took place over the next few years as support for the journal gathered momentum, bringing us to the present and this first issue.

We would also like to acknowledge the recent publication of Volume 5 Numbers 2 and 3 of the International Journal of Performance Arts and Digital Media, edited by Sherril Dodds and dedicated to screendance. For the edition of the journal, Dodds (whose own book, Dance on Screen: Genres and Media from Hollywood to Experimental Art (2001), was one of the 
first scholarly investigations of screendance as an art form) gathered a set of papers that explore screendance in the context of the performance arts and digital media. The publication points to the growing interest in scholarship about the art form, to which we intend to add.

This first issue of The International Journal of Screendance is dedicated to the proposal that screendance has not yet been invented. This is an appropriation of film theorist Andre Bazin's suggestion, in The Myth of Total Cinema (1946), that the reality of cinema had not yet embodied the ideal of cinema. Bazin's writing had been discussed in the first seminar of the International Screendance Network, together with Professor lan Christie (Birkbeck College, University of London), who had given the 2006 Slade Lectures under the title "Cinema has Not Yet Been Invented." The proposition that screendance has not yet been invented is intended as an incitement to the community to think about the art form in new ways, both critical and theoretical, and this journal aims to create a forum to sustain the debate.

A number of themes emerge in this first issue. The presence of Maya Deren is felt in a number of articles, as are ideas about genre, criticality, authorship, disability, performance, and the phenomenology of screendance itself. Chirstinn Whyte looks at amateurism and idea of "professionalism" in "The Evolution of the 'A' word: Changing Notions of Professional Practice in Avant-Garde Film and Contemporary Screendance." Gravity is explored from differing perspectives in two essays: Ann Cooper Albright rethinks the act of falling on screen as an instant in which new meaning can arise while Harmony Bench filters twentieth-century, modern and postmodern, dance techniques' shared faith in gravity and weight through a digital and electronic lens. Sarah Whatley raises questions about the portrayal of dance and disability on screen, and Argentine critic Susanna Temperley (in Spanish with English translation) addresses the role of the critic in screendance in "Perplexed Writing", while Kyra Norman explores ideas around the body, perception, and place in sitebased screendance. Claudia Kappenberg reviews notions of originality and authorship in "The Logic of the Copy", and Douglas Rosenberg proposes theories about genre and the diasporic nature of screendance.

In addition to in-depth discussion and theorization of particular aspects of screendance practices, each issue will include interviews and reflective writing by practitioners in the field. In this issue, we publish a transcribed interview with BBC dance for television producer Bob Lockyer. In an effort to reacquaint readers with out of print or hard to find extant articles, we will be including such texts in forthcoming issues, and we begin by re-printing a paper by film theorist and philosopher Noël Carroll entitled "Toward a Definition of Moving Picture-Dance."The paper was originally presented at the Dance for Camera Symposium in 2000 at the University of Wisconsin-Madison. In the paper and talk, Carroll, who has been writing about movement on screen since the 1970s, lays out an argument for a definition of the field in order to, as he states, "compare and contrast the various categorizations in play and to develop dialectically from them a comprehensive framework that makes sense of our practices and that resonates with our intuitions about its compass" (2, this issue). Finally, Karen Pearlman's recent publication, Cutting Rhythms, A New Perspective on the Rhythmic and Choreographic Nuances of the Edit, is reviewed by Cari Ann Shim Sham*. We trust that what results is a volume of pertinent, challenging, and enlightening material that will set the tone for future issues of the journal, which we intend to publish twice per year. Our wish is that this journal functions as a living space for 
serious, lively, on-going debate about the art form. We aim to encourage contributors to move freely between discourses while making screendance relevant to a broader field of art practice. We hope that this first issue inspires both intellectual debate and a sense of community.

Douglas Rosenberg and Claudia Kappenberg, editors

Letters, comments and feedback can be sent via screendancejournal@gmail.com.

Calls for papers for future issues will be circulated online. 


\section{Letters}

\section{Ave Screendance}

Although motion-picture dance is a thriving and exciting art form, it does not garner the respect it deserves. The reasons for this are primarily institutional. It is not seen on a regular basis, but only typically in one-off festivals and single-artist shows; it has not yet had its great critical voice; and, connected to that, it has not had a platform - a periodical or a publication - upon which such a critical voice could emerge. The arrival of The International Journal of Screendance is a valuable first step in remedying these shortcomings. It will provide a regular outlet for critical discussion of the historical and contemporary works of motion-picture dance. From that discussion, critical perspectives and critical voices will arise and mature. As the discourse surrounding motion-picture dance becomes increasingly sophisticated, an informed audience will grow and the demand for venues, perhaps online, where motion-picture dance can be viewed on a regular basis will expand. And with more eyes focused upon it, motion-picture dance will begin to gain the attention and respect that it justly deserves.

Thus, it is my pleasure to welcome this first issue of The International Journal of Screendance which promises to inaugurate the next stage in the development of motionpicture dance.

\section{Noël Carroll}

Distinguished Professor of Philosophy

The Graduate Center, City University of New York

\section{Dear Editors of the new International Journal of Screendance,}

I am so immensely pleased that this first issue of our long-dreamed of and discussed International Journal of Screendance is now coming into being. I would like to congratulate all those who have contributed to this brand new publication and look forward very much to reading the first issue.

As you are aware, I am sad that recent changes in my working circumstances meant that I was not able to be involved directly in this final manifestation of what was a shared vision for many years. I feel proud, however, that I was able to help it on its way, through various stages of its incarnation.

I have no doubt that with the calibre of contributors, writing and debate of the new International Journal of Screendance will go far in developing screendance as an art-form. This can be the much-needed public forum where ideas are exchanged, recorded, debated and disseminated. Well done for bringing it to life.

To the Journal's readership, I'd like to wish happy reading and say, if you disagree with what you find here, then please don't just snipe from the sidelines, write and send in your response. And if you really hate The International Journal of Screendance, publish your own! 



\title{
The Evolution of the ' $A$ ' Word
}

\section{Changing Notions of Professional Practice in Avant- garde Film and Contemporary Screendance}

\author{
Chirstinn Whyte
}

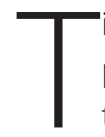
ime was in the world of screendance when we all knew where we were: in order to be professional, the dancers danced; the choreographers made up steps for them; and the producers and directors made the decisions. Such a model is most certainly no longer the sole option. In an indeterminate meshing of grey areas and interdisciplinary zones, demarcation lines have crumbled, fragmented and dissolved. Choreographic practice takes place on either side of the lens and at the keyboard and in the wider world, recessionary factors mix with new technological capabilities. Lightweight, hand held cameras liberate filming possibilities for dance-aware operators; editing software programs for domestic computers function as high-end industry standard, and rapid expansion of the specialist festival circuit provides a ready-made network of international screening outlets for often minimally funded work. Assessing this developmental arc, allows useful parallels to be drawn from within the traditions of filmic practice, which helps to disentangle an interrelated web of economic, operational and artistic factors.

Recent research by Patricia Zimmerman in the United States, and lan Craven in Britain, has focused on the historical and cultural impact of twentieth century amateur filmmaking. While artists such as United States-based academic and activist Melinda Stone are engaging directly with the community-oriented fora of camera clubs. ${ }^{2}$ Even as this model of amateur practice-undertaken as a pastime or hobby, and set apart from notions of commercial gain or career advancement-continues along firmly established lines, it can no longer be said to straightforwardly exist in opposition to a one-dimensional categorization of 'professional,', namely one set apart by specialist knowledge, and financially recompensed for labor. Dissolution of the professional/amateur dualism has attracted continuing reappraisal, with a highly significant strand of discourse emerging from mid-twentieth-century, North American avantgarde film. Artists including Maya Deren, Stan Brakhage and Jonas Mekas addressed the making practices of the amateur, with Deren The more one is dependent on circumstances exterior to one's own adaptability, the more discouraging the entire effort. One is not likely to take the time to arrange the angle and framing very precisely when either the clouds are mounting rapidly from the horizon, or the 'extras' are becoming thoroughly tired, bored, hungry and disillusioned about the 'glamour of film-making.' Under such pressure one hurries through, hoping that somehow it will turn out better than it does. It never does.

Maya Deren' noting that "the very classification [...] has an apologetic ring" (Stone 234) and Brakhage observing that it has been "hatched in criticism,' acquiring the currency of insult, equating to a term like 'Yankee' ("Amateur - Go Home")" (144). ${ }^{3}$ The Deren/Brakhage 
appraisal can be read as a corrective: a refusal to carry the categorization as a mark of artistic deficiency, with exemption from commercial concerns equated with enhanced levels of long-term developmental potential. Deren noted derivation from the Latin 'amator' or 'lover,' as 'one who does something for the love of the thing rather than economic reasons or necessity'" (17) and in an identification with this motivating spirit, Brakhage noted that over the course of his career, he attracted a variety of labels to describe his own role, including "professional," "artist" and "amateur," observing that "of those three terms, the last one-amateur-is the one I am truly most honored by" (Brakhage 142).

Deren's antipathy to traditional filmmaking practice is well-recorded. Characterized in highly negative terms, she cites a "collective monster" comprising "enormous personnel of assistant directors, cameramen, lighting men, actors and producers" as obstructions lying in the path of the artist in the realization of their ideas (20). Setting her own working processes entirely apart from externally-funded production models, Deren regarded the resulting operational parameters as requiring an opening up, rather than a restriction, of creative engagement specific to the medium (Deren 158). This entirely accords with what she characterizes as the single greatest advantage of amateur status, identified as "freedom - both artistic and physical" (17).

Brakhage also observed that "I have a growing conviction that something crucial to the development of the art of film will come from amateur home movie making,"4 and the Deren/Brakhage anti-industrial stance dovetails with recent developments in the field of moving image production. Film editor Walter Murch has acknowledged the transformative potential of digital technology to mainstream filmmaking practices, observing that "I can see down the road it's possible that a film crew will be a very, very small bunch of people" (214). ${ }^{5}$ Murch has further observed that the advent of digitization has the capacity to revolutionize the way in which all image-makers are categorized, likening its development to the introduction of money within the essentially agrarian economy of the Middle Ages. Murch asserts that "a media currency" has the potential to "create a kind of 'middle class' that's neither filmmaker nor consumer" (335). ${ }^{6}$ For screendance artists, using professionally-acquired skills to operate outside of traditional funding contexts represents a breach in the accepted, industry-sanctioned causal link between commission and production. Exploring creative and operational territories, characterized by Murch as inhabiting "the wide spectrum between home movies and feature films" (Behind The Seen 334) artists can find themselves adrift within a hybridized limbo of looking-glass economic models, effectively making on the indefinitely-deferred payment basis of the never-never, as the work itself attains the status of proto-currency: units of credit with the potential to be redeemed within an academic research economy, or accrued as notional capital with each curated festival screening. While this model can serve those securely footed on an academic or artsfunded career ladder, many choosing to explore alternative pathways can find themselves on the outside of a closed financial loop, requiring equally alternative solution-focused approaches.

Feeding into a counter-cultural stew of 1960s experimental filmmaking, the Deren/ Brakhage appraisal of amateur practice disseminated outwards, recognizably in the emergence of the low or zero funded independent filmmakers of the 1970s onwards. While many from this generational grouping subsequently assimilated into mainstream film production, the avant-garde filmmaking community retains a strong preoccupation with 
notions of amateur practice. Contemporary commentator Ed Halter has re-examined the issue noting that cultural ambivalence, characterized as a "simultaneous embrace and disavowal of professional status" pulls an increasingly career-focused artist into a Goldilockslike consideration of an aesthetic equation in which "amateur = too sloppy, professional = too perfect."7 Halter proposes use of the term "sub-amateur" in order to differentiate from what he sees as traditional level of non-professional filmmaking, and there can be little doubt that new thinking and terminology is required to adequately assess the breadth and complexity of contemporary creative and economic identities in the current outsourced era of portfolio careers and multi-jobbing.

Looking beyond the boundaries of roles clearly defined as "professional"can be particularly problematic for dance trained artists, who have traditionally faced a range of barriers to the recognition of their skills, experience and status. However, close examination of relevant discourse reveals a through-line from the aspirational ethos of the post-war filmic avantgarde, which can be read as feeding into the high watermark of cross-disciplinary activity at the Judson Church in late 1960s New York. In Britain, this lineage is traceable through the influence of New Dance of the 70s and 80s, and its legacy in the community dance movement, with each in turn calling into question the dominance of conventions often left to go unchallenged under the catchall banner of "professionalism." In particular, the latter has pioneered a model of inclusive practice fusing a concern with quality of experience and process-led creative strategizing which, at its most effective, can render hierarchical impositions of professional/community demarcation artistically irrelevant. Commissioned by the Foundation for Community Dance in 2001 and directed by dance artist Rosemary Lee, the screen project Dancing Nation illustrates four case studies mapping the effects and diversity of such practice. Lee's live dance work is strongly rooted in the notion of cross-generational, non-traditional participation, with screen works boy (1995) and Infanta (1998), co-created with Peter Anderson, constructed around the particular qualities of their respective central performers, rather than imposed as pre-determined, codified dance vocabulary to generically trained bodies.

By extension, the potential for screen-based work to bypass narrowly-defined notions of virtuosity as synonymous with "professionalism," has intersected with the emergence in Britain of integrated dance practice. Early examples of screendance commissioning in this field present a further problematizing of attitudes to, and expectations of, work presented within a professional arena, and include Victoria Marks' screen collaboration with CandoCo in 1993's Inside Out, and Liz Aggiss and Billy Cowie's integrated casting for Beethoven in Love, from 1994. More recently Katrina McPherson and Simon Fildes engaged with the movement worlds of sighted and visually impaired performers in 2001's Sense8, and adults with learning difficulties in 2005's There's Something You Should Know. Commissioned by Channel 4 television in 2004, Lloyd Newson's translation of his stage-based work for DV8, The Cost of Living, features physically disabled performer and CandoCo alumnus David Toole. As one sequence among a series of Newson's loosely strung narrative episodes, the relaxed dynamic pacing and easy shifts of weight characteristic of release-based work is used to explore and celebrate Toole's distinctive movement vocabulary of body weight supported by hands and arms. Non-naturalistic framing acts as a focal point for viewing engagement, as close-up shots of ground level hands follow feet, hips and torsos, in a continuous sea of movement, entirely filling the screen space. 
Brakhage observed that the term amateur was "most often used in criticism of the work I have done by those who don't understand it" (144). Tracking the often convoluted intertwined branching of contemporary professional identities, no longer necessarily presents as a straightforward task. My own status as a screen-literate, unfunded dance artist holding a mobile phone camera undoubtedly presents a challenge to any notion of discrete categorization, embodying a convergence of multiple genealogies often characterized as "alternative" or "independent" in the shifting lexicon of contemporary dance/ screen terminology. This hybridity translates into a mixture of highly specialist professional dance training and experience, combined with self-taught experimentation in the field of digitized moving image. Disentangling such a complex web of influence and approach requires careful consideration of a range of work recently created within the field, with professionally acquired skills and experience used to hold open a space for alternative perspectives.

Within the context of British screen culture, experimentation with longer form documentary has included work such as Patrick Keiller's London, from 1994, and Andrew Kötting's Gallivant, from 1996, with both playfully subverting notions a professionally distanced and supposedly objective stance. Shown within recent screendance festival programming, Alex Reuben's Routes, from 2007, similarly emerges explicitly from the personal preoccupations of its maker, engaged on a geographical and cultural exploration of the southern Unites Sates' intertwined folk traditions of music and movement. The works' improvisatory-oriented, non-linear arrangement is entirely reflective of its subject matter, while also drawing on Reuben's professional grounding in both visual art and music, highlighting a notion of choreographic screen practice as image composition, rather than straightforward translation of pre-made movement material.

A particular strand of professional experience, familiar to dance artists working within community and education-based contexts, has been transferred to screen with a great measure of integrity in the work of Bristol-based Lisa May Thomas. In The Elders, from 2006, Thomas makes use of poetic documentary form, interweaving the minimalism of formalized movement content within a larger framework of additional creative elements. From the following year, Challenge 59 threads together task-generated imagery communicating the experience of creative work with primary school age children in a way rarely presented within a festival context. Brighton-based artist Becky Edmunds' professional background in dance performance and documentation generates a subtlety of engagement with subjects, met on their own terms. El Fuego, filmed in 2007 in the expansive landscapes of rural Argentina, sets the weather-toughened face of a gaucho in late middle-age among black-burning smoke clouds. In its interrelation of single character to highly specific environment, the work can be seen to sit within a tradition including Orkney-based independent filmmaker Margaret Tait's Portrait of Ga, from 1952. Both works emerge from highly personalized, non-mainstream perspectives, involving a minimum of equipment and personnel. Deren observed that for filmmakers the most important part of your equipment is yourself: your mobile body, your imaginative mind, and your freedom to use both" (18). Thomas and Edmunds are dance-trained artists, undertaking a long-term shift into screen-based contexts. While no doubt retaining their professional economic and operational codes, these artists' engagement with lightweight, small scale, relatively low budget digital video production allows for a level of creative freedom within the arena of screen composition, 
which appears close to the aspirationally-oriented model of amateur practice as outlined by Deren and Brakhage.

A sideways glance at parallel practices reveals that for many involved in the music industry, a recording contract is no longer sole passage to a public profile, as Facebook and MySpace bypass the gatekeepers of A\&R as audience-building platforms. These developments can be seen as part of a large-scale wave of ongoing change in the processes of marketing and distribution, articulated by Chris Anderson in 2004 in a highly influential article for Wired magazine. Identifying the market potential of the remote consumer, Anderson put forward the theory that making available a greater range of options in the non-physical data space of the internet allows for a redefinition of potential audience base, noting that "many of our assumptions about popular taste are actually artifacts of poor supply-and-demand matching." However, translation of this expanded consumer base into revenue-generation is set against the demographic backdrop of the download generation's coming of age, with the attendant expectation that the fruit of cultural labor comes free of financial charge, and many image-makers continue to chase their own long tails through an ever-expanding series of yet-to-be-Monetized online distribution niches.

Walter Murch has recounted the experience of his first day at graduate film school in the mid nineteen sixties. ${ }^{9}$ He and many of his classmates, advised to abandon career plans for an industry in transition between the crumbling power-bases of the old studio system and the rise of television, decided instead to persevere and to experiment. Murch characterizes this mind-set as "the freedom of all bets being off" (328). It is not difficult to identify parallels between this era and the current state of digitized cultural flux. Now, as then, artists can find themselves engaging in multi-layered improvisational processes, in a constant state of adaption to rapidly changing circumstance, rather than following preestablished professional paths.

Contemporary notions of professional dance/screen practice present as a complex series of navigational processes, requiring skillful triangulation of rapidly shifting economic, operational and artistic factors. Worldwide recession and shifts in domestic policy agendas can leave arts funding or academic research budgets vulnerable, as a globally-homogenized entertainment industry promotes overwhelmingly commercially and aspirationally-driven models of achievement and success. While an unpaid artist_albeit an amateur by default when judged on economic criteria alone-can proudly adopt the status of "independent," re-examining the ideals of the mid twentieth-century filmic avant-garde can provide a range of alternative models for informed consideration, including "amateur" as locus of genuine creative exploration; as conscientious objector in the conflict zone of overriding commercial imperative and as representative of an ongoing lineage woven closely within the fabric of dance and screen culture. Regardless of the varying co-ordinates of individual pathways, acknowledging the egalitarian origins of "the amateur" has the potential to make fellow twenty-first century travelers of many. .

\section{Notes}

1. Deren, Maya. Essential Deren.Ed. Brian McPherson. New York: McPherson \& Company, 2005. 158. Print.

2. See Stone, Melinda. "If It Moves, We'll Shoot It': The San Diego Amateur Movie Club." Film History 15.2 (2003): 220-237. Print.

3. Brakhage, Stan. Essential Deren.Ed. Brian McPherson. New York: McPherson \& Company, 2005. Print. 
4. Brakhage, Essential Deren. 121.

5. Murch, Walter. The Conversations: Walter Murch and the Art of Editing Film. Ed. Michael Ondaatje. London: Bloomsbury, 2003. Print.

6. Murch, Walter. Behind The Seen. Ed. Charles Koppelman. Berkeley: New Riders, 2005. Print.

7. Halter, Ed. "After the Amateur: Notes." Rhizome News. 29 April 2009. Web. 10 Feb 2010.

8. Anderson, Chris. "The Long Tail." Wired. 12.10 (2004): 2. Print.

9. See Koppelman, Behind The Seen. 327-8. 


\title{
In and Out of Place: Site-based Screendance
}

\author{
Kyra Norman
}

et's begin by standing. Standing in the space. Focus for a moment on your breath. Its pace, its rhythm, its movement. Not changing anything, just noticing. The ground, gravity, weight, balance. Sounds, impulses, the sensations of the skin, the feel of the floor, and the fabric of your clothes. Now take this awareness further out, into the space around you. What do you notice?

When I prepare to dance, I prepare to see differently; to see space differently, shaped through an attention to how I experience this space physically. Exploring the role of the body in our perception of space leads us into rich areas of thought and action: from cognitive sciences to phenomenology and Merleau-Ponty, for whom "the perceiving mind is an incarnated mind,"(3)' from somatic practices in dance to Laura U. Marks' writing in the field of criticism, through which she works "to restore a flow between the haptic and the optical that our culture is currently lacking (xiii)."2 In preparing this paper, I have drawn particularly on writing by John Berger, Lucy Lippard, Gaston Bachelard, Tim Ingold, Miranda Tufnell and Chris Crickmay. I have woven a few threads of their texts into what follows, but these are only traces, and I warmly recommend reading these writers for a far more thorough discussion of their ideas.

It seems important to acknowledge at the outset that this paper can only scratch the surface, make a start, in looking at screendance and space, place, and site. Through this writing I hope to raise questions and provoke dialogue as to how we might further explore these issues in theory and in practice. I write from the perspective of an artist and researcher working within the field of screendance in the UK, and my intention here is to invite reflection on current thinking and practice in this field.

In his book, Ways of Seeing, John Berger writes of the activity of vision, a succinct reminder of the physical engagement that frames what and how we see. Berger writes:

We only see what we look at. To look is an act of choice. As a result of this act, what we see is brought within our reach - though not necessarily within arm's reach. To touch something is to situate oneself in relation to it. ... We never look at just one thing; we are always looking at the relation between things and ourselves. Our vision is continually active, continually moving, continually holding things in a circle around itself, constituting what is present to us as we are. (8) 3

Our sense of space begins in our own body: begins with, as dance artist Lisa Nelson has described it, "the body as both proscenium and performer,"4 simultaneously contextualising and enacting, framing and doing. Our perception of space-scale, symmetry, distance, texture, temperature-is informed directly by our own physicality. As MerleauPonty writes, "spatial forms or distances are not so much relations between different points in objective space as they are relations between these points and a central perspective — our body" (5). Through studio practice, dancers - and particularly those working with improvisation - draw on this experience to inform being in relation to space, allowing the space to invite action (or inaction). In this paper, my interest lies in what happens when 
dance-trained artists bring this physical engagement with space, and ways of seeing, to making work for the spaces of the screen. ${ }^{5}$

Screendances create, encounter, and are read through layers of space. We might include here the architectural, social spaces of the shoot and of the screening, the various spaces created by the camera and through the edit, the spaces of and between bodies. All of these spaces are contained within the space of the screen but as artists and as audience, we may pay more or less attention to each layer of space at different points and in different works.

In his essay, "Video Space: A Site for Choreography", Douglas Rosenberg observes that "video dance is a site-specific practice, that site being video itself ... This is where the work occurs and it is further the architecture against and through which the audience perceives the work. . . Site provides context" $(1,5) .{ }^{6}$ Rosenberg explains that he uses 'video' in this context as shorthand, encompassing the various processes of video production, including recording, transmission, and reception. Such a concept of site, unfolding through time, rather than being a fixed point in space, lends itself to a consideration of process-the work occurs in the camera, in the edit, as well as on the screen. Where terms such as 'cine-dance', 'dance film,' and 'video dance' have sought to categorize dance and moving image work through an attention to medium, the term 'screendance' brings all manner of screen media together, foregrounding the site and surface of the screen.

The screen is a site in the way Rosenberg speaks of video as site-a collection of processes, languages, and histories. This includes, but is not limited to, cinema, video art, television, computer gaming, and the Internet. It is also a recognizable site in spatial terms, and such a focus on space refers us back to the body and particularly to our own embodied experience of space. Having dealt a little with the 'screen' in 'screendance', it seems worth mentioning the 'dance' also. I am proposing here that dance is more than the subject of the screen work, it may also be a means of approaching, exploring and articulating screen space: bringing with it its own collection of processes, languages and histories.

In a moment, I will move from the general to the particular, and turn to three examples of artists whose work I see as doing just this: Angela Praed, Shahar Dor \& Amit Shalev, and Becky Edmunds. I will suggest that these artists draw on both dance-in particular site-based performance making — and screen processes and conventions, engaging in a practice that requires them to be both 'in and out of place.' By this I mean that, firstly, it is through a sincere attention to place in the moment of recording that the substance of the work arises; at the same time, this material is being shaped by an awareness of the space of the screen and a projection into the future, toward the edit, that screen space, and the future viewer. And, whilst these works may usefully be read through various screen lenses (e.g. documentary, documentation, video art) I will propose that the approach to place and space evidenced in these works is distinctive of a rich seam of improvised site-specific performance making, which can be traced through the history of dance, and leads us to significant questions about the exhibition and discussion of screendance.

First though, I will briefly address the way in which I am using the term 'place' in this writing. In his wide-ranging history of the line, anthropologist Tim Ingold contrasts "the line that goes out for a walk" in Paul Klee's terms — freewheeling, expressive and born of movement-with the geometric model of nodes and connecting lines that maps the modern world and is most often used to shape our understanding of transport and urban planning 
(72-84). ${ }^{7}$ The latter model brings to my mind the map of the London Underground: visually bold and coherent in overview but bearing little resemblance to the experience of navigating between these points at ground level.

I introduce this idea here because Ingold uses these contrasting lines to propose two distinctive ways of visualising place, in each case with significant implications for perception, movement, and the body. The first represents place with a hub-and-spokes model —each place is a clearly defined circle, from which radiate lines representing distinct travel routes or pathways. People are represented by dots, contained within a particular circle. The second model imagines place as a knot, made up of lines that represent the lifelines of each inhabitant, "bound together in the knot, but . . not bound by it" (Ingold 100). In an era characterized by movement, travel and change, it seems useful to conceive of place in this second way: as created by people crossing paths; but this crossing of paths need not imply constant motion, one can choose to remain, linger, dwell. I have kept this image of place in mind whilst thinking about the works discussed below.

Lastly, before turning to my three examples, I would like to, again, briefly, discuss the way in which, as a way into reading particular works, an attention to the layers of space that run through screendance offers an alternative means of grouping works together, placing them in dialogue with one another, and allowing us to interrogate screendance as an art form. For example, Harmony Bench's paper at OpenSource \{VideoDance\} (OSVD), in 2007, discussed a range of works created variously for cinema, television, installation and online viewing — set in what Bench described as 'no-place'-works where bodies seem to be suspended in, usually black or white, 'empty' space. Bench describes these "antigravitational choreographies [as] dance-based strategies of mobility developing alongside globalized imaginings of space, ground and body" (124). In the discussion following this paper, participants in OSVD talked about the way in which the bodies in many of these works seemed to lack not only physical gravity but also the gravity of memory. This came back to me recently when reading Lucy Lippard's The Lure of the Local, in which she proposes that "space defines landscape, where space combined with memory defines place" (281). ${ }^{9}$ Without memory, these bodies are out of place.

In screen terms, the 'no-place' Bench identifies is familiar to filmmakers as 'limbo.' It usually entails shooting in a blacked-out studio, with lighting arranged to create an impression of boundless space, without horizon. It seems important too that no-place alters sound-either amplifying it, distorting it, or cutting it out altogether. Sound colors our vision and shapes our perception of what we see as well as hear, and atmospheric sound contributes to the reading of place on screen. In an essay entitled "Losing Your Place," written as part of the work of Common Ground, Sue Clifford and Angela King describe the collection of atmospheric sound on a film shoot: "that elusive particularity, so often undervalued as 'background noise,' is as important as the stars" (7). ${ }^{10}$

So what of works that begin 'someplace,' then? Since this is an argument for particularity, let's look to the particular. "Place-specific (as opposed to drive-by) art begins with looking around" (Lippard 281).

In 2004, choreographer Angela Praed and dancers Robert Mennear and Lois Taylor undertook a dance research project, We're All The Same Height Lying Down, touring a 40-minute duet around the bedrooms of members of the public who had replied to their advertisement in a local paper, in Cornwall, where they live. Working in collaboration with Laura and David 
Travail, Praed subsequently produced the 12-minute documentary, The Bedroom Tour. Whilst each performance was witnessed only by a handful of people, in each case invited by the host and restricted in number by the intimate performance space, the documentary went on to be screened widely, including being shortlisted for the IMZ dance-screen documentary award in 2005. I am interested in what happens through this shift in context and conventions from live performance to screen, working into and out of place.

The choreographed performance, a dance duet between a young man and an older woman, takes place on the bed in each of the hosts' homes. We see recorded extracts in the video. It has been created for 'the bedroom' as a culturally specific, imagined location, and it is the hosts' homes and anecdotes that create the actual 'place' for the performance, coloring our reading of the performance on screen with intimate local detail and texture. Their responses to the performance are given time to unfold on screen. One host reminisces about her bed's construction by herself and friends, as students in the 1970s, from a pattern in Reader's Digest. Another talks about the contrast between his orderly work life and chaotic home life-with comic timing, at this point, and mid-sentence, the light cuts out (we presume a fuse or bulb has blown) and the scene is cast into darkness and laughter.

We see that each of the hosts reads the live work very differently, and their readings color our own. In this way, the performance of the set choreography, live before an audience, becomes an element in a highly complex work for the screen that includes the actions and opinions of the hosts as both audience and protagonists - their contextualization of the dancing they witness adds rich layers of ambiguity and narrative. The domestic setting frees the hosts' imaginations - one of the hosts is explicit in stating that whilst she has found this experience fulfilling and nourishing, it has not made her any more likely to visit a theatre. As Bachelard writes, "the house shelters daydreaming, the house protects the dreamer, the house allows one to dream in peace" (6). ${ }^{11}$ In the transformation to screen space, this shelter is lost, the dreamers exposed. Is a new form of shelter constructed through the adherence to documentary conventions, framing the hosts as characters in this new work? What is the responsibility of the artist to the live audience in the screen work, and to the screen audience?

Such questions are of a piece with Praed's original and sustained exploration around the role of the audience in site-specific performance and work for the screen. It is also in keeping with the screen conventions through which work is framed: that of a television documentary. The Bedroom Tour uses documentary as a framework to reflect on particular embodied experiences, documenting responses and memories-of the choreographer, performers and hosts - as much as the performance itself. In so doing, this process inevitably shapes these responses and memories. The use of camera, editing, location and speech presents the work in a style that is familiar from television documentary, bringing the live performance, with its theatrical conventions unfamiliar to the hosts, back into focus through a framework familiar from their own front rooms. In this way, the live work created for the specific site of people's homes becomes a work for the specific site of the screen.

To move now from Cornwall to Tel Aviv, to switch our gaze from rural and suburban houses to city streets. Lippard writes that "looking around in a city is visual overload. . . . Impressions are confused and chaotic. Longtime residents rushing here and there often forget to look at their surroundings while newcomers and visitors get lost and overwhelmed" (Lippard 197). 
Movement and performance artist Shahar Dor and cinematographer Amit Shalev together have developed a practice they call "Improvideo." They subtitle this process, "Spontaneous Dialogue." An improvisation-based method that aims to realize on film/ video compositions of performer, camera, and space, they describe their work as "a heightened interdisciplinary model that engages with questions around the body, performance, image creation, space and audience."12 I will use as examples here two works, No Conflict and John's Shoe, both made in their hometown of Tel Aviv.

No Conflict begins in motion, performer and camera walking down the street side by side. It is a city street scene; we see other people pass by, traffic, and shops. There are cuts, but the leisurely series of shots has the feeling of continuity, scenes from a single journey. Performer and camera vary their speed, sometimes one ahead, sometimes the other. They pass a boarded-up building covered in fly posters; the performer picks up and expands on movement material found in an image on one of the posters. The performer moves on, slipping between gates drawn nearly closed; the camera waits on the street side of the gates but through the narrow gap we have a sense of wider space, a parking lot, or a gap where a building used to be. The camera's view is restricted, whilst the performer has more room for maneuver.

When the performer opens wide the gate, he seems to invite the camera into the space, and the camera moves in. The two develop a duet of movement and rest, sometimes these states coincide; sometimes the camera moves past a stilled performer, sometimes the camera's gaze rests upon the travelling performer who then moves out of shot. In this space, there is no one else. Staying for a while in one place gives us time to register what we are seeing and to begin to see particularity rather than simply the idea of a city. As Lippard writes, "the light, the climate, the style, the materials, the flora and fauna (or lack thereof), the spaces and proportions, not to mention the demography and population, make cities and their neighbourhoods unique" (197). The performer leaves through the gate, and then the camera follows. They move off together back out into the street, and continue their walk, the performer's movement now interspersed with moments and qualities from the freer movement experienced in the enclosure. The camera moves in front of the performer, the footage slows, the screen fades to black.

John's Shoe begins with the performer side-on to the camera, sitting in the back seat of a parked car, door open, feet on the road, tying a shoelace. The opening sequence continues in short close-ups, cut together: the performer's face leaning down, filling the upper half of the screen, the hands on the shoelace. The camera then cuts further away to reveal the parked car's place on a residential city street, and the performer standing in the center of the shot, then walking out and away. Again, the performer and camera take a walk but this time the feel is more of montage, and as viewers we connect disparate places into one journey, rather than being shown the routes between them. Again, the performance opens out into a sort of 'clearing', this time a deserted sports ground, and the performer and camera develop a duet which seems to be led by a spirit of enquiry, the performer exploring and finding places to rest in the space, the camera exploring the body moving in space and finding moments to allow the gaze to alight, to come to rest.

Through a quick series of shots, we travel from this sports ground, back to the street, to the threshold of an apartment building with its double doors of glass bricks and come to rest once again in an overhead shot of a tree. The camera is static for some time as the performer 
circles and spirals around the tree, before adding a secondary layer of circling through a series of moving shots, tracking around the action in circles, sometimes travelling at the same speed and in the same direction as the performer and sometimes differently. A few more short, cross-faded shots take us out of this courtyard, out of the house to find the performer sitting on a wall, playing with his broken shoe. The sole comes loose, comes away and becomes almost a second character in front of the camera in an action-reaction shot sequence, then is chased up and down the curb, becoming an imprint, like the drawn footprints teaching a sequence of dance steps, an obstacle, a magnet, a toy: the scene cuts to black.

Merleau-Ponty writes:

We grasp external space through our bodily situation... Our body is not in space like things; it inhabits or haunts space. It applies itself to space like a hand to an instrument, and when we wish to move it about we do not move the body as we move an object. We transport it without instruments as if by magic, since it is ours and because through it we have direct access to space. For us the body is much more than an instrument or a means; it is our expression in the world, the visible form of our intentions. (5)

In both works, Dor and Shalev create duets between camera and performer, which open up the spaces they explore to the viewer. The body and the instrument work together to make visible the form of their shared intentions as they unfold. Berger writes that "soon after we can see, we are aware that we can also be seen. The eye of the other combines with our own eye to make it fully credible that we are part of the visible world" (9). Dor and Shalev fold this reciprocal act of vision into their process, and in so doing draw our attention to our own active vision in relation to the work.

Both artists take on the role of defining the performance space: sometimes Shalev frames space in a particular way and Dor fits his performance into this; sometimes Dor demarcates a particular space through his performance and Shalev fits his camerawork to that. In each case, the particularity of place sets the scene for action, and this action is simultaneously shaped by an anticipation of the screened image. Their, and our, attention moves in and out of place.

In The Poetics of Space, Gaston Bachelard writes that "space calls for action, and before action, the imagination is at work" (12). In improvisation, as here, the imagination is at work through action, rather than beforehand. It is this engagement with embodied, active imagination —instant composition — that improvisation brings to the screen. This composition comes from the body and its responsiveness to place. As director and choreographer Angus Balbernie writes, "the tuned body-in-landscape creates, and is offered, a resonant and responsive connection to core perceptual systems and expressive activity."13

In an interview with Chirstinn Whyte for Filmwaves, Becky Edmunds suggests that place has a very direct effect on her camera work. Where the built-up, densely populated SouthEast of England found her "addicted to close-up,"14 her experience of vastness in Argentina and subsequently Swedish Lapland invited a new way of working, a new interest in the use of extreme wide shots, and long takes. The outcomes of these instincts create works that, whilst visually and kinetically very different, are connected through their beginning in the body and its response to the particularity of place. These works are also about time: the artist taking time to experience place; the viewer taking time for the work to unfold. Edmunds has said: 
It is interesting that there are some technical decisions that working out in the landscape leads me to. I keep working with the zoom of the camera [in Swedish Lapland], which I never do in my normal working life-l avoid it normally, but out here it seems to be the only way I can find to express distance. I only work with wide shot out here. I have done no close ups at all - at least not of the body. I have close ups of twigs and icicles and snow, but the body seems to need to remain in the distance for me. ${ }^{15}$

Whilst I have so far chosen examples of artists_-Praed, Dor, and Shalev—working in their local neighborhoods, they and Edmunds are artists who work internationally. To return to Ingold's definition of place, they are bound together in the 'knot' of their home place but not bound by it. Not knowing too much about a place can allow us to see it, and ourselves, freshly. Lippard writes, "looking at land through nonexpert eyes, we can learn a lot about our own assumptions and about the places we live in and pass through" (125).

In each case, whether produced near or far from home, these are works that tread lightly on the earth: with only a few people and a minimum of kit, usually a single camera. Ingold makes what for me is a useful distinction between 'inhabiting' and 'occupying' a place (101). Referring back to Merleau-Ponty's idea of the body as inhabiting or haunting space, making space directly available to us, I see Edmunds'approach as to inhabit, to engage with space directly through the body, contrasting with the way in which a traditional film crew would move on to location, cordoning off a particular area, controlling action, focusing light, limiting sound. Inhabiting is informed by an attention to active vision and responsiveness to place: we come back to looking around.

When Lippard writes that "a lived-in landscape becomes a place, which implies intimacy," she is defining place as seen from the inside; landscape, from the outside (7). In one of the research pieces made in Swedish Lapland, stand-in, Edmunds places performer Scott Smith in the frame, where he remains, a static figure silhouetted as a black outline against a series of different spaces, until the final shot, where he wanders off screen. Again, the attention moves in and out of place, in two sites simultaneously: where Edmunds frames place in an embodied response to the moment, it is in screen space that Smith's series of stillnesses are connected, through the edit. Edmunds has spoken of how Smith is a stand-in for herself, and also for the viewer. ${ }^{16}$ He returns our attention to the surface of the screen and his stillness anchors us in relation to the shifting landscapes against which we see him. The small, still figure on screen connects us to our sense of wonder at vastness. For Bachelard:

Immensity is within ourselves. It is attached to a sort of expansion of being that life curbs and caution arrests, but which starts again when we are alone. As soon as we become motionless, we are elsewhere; we are dreaming in a world that is immense. Indeed, immensity is the movement of motionless man. (184)

From Cornwall, to Tel Aviv, to the Arctic Circle; from domestic interiors to metropolitan streets and spaces, to vast snowy expanses. The attention to place, and to the physical experience of space, evidenced in works such as those discussed above, calls for a similar thoughtfulness in creating contexts for these works to be screened and experienced by audiences. Whilst discourses around place may sometimes abstract issues around space, in witnessing screendance we read detail and specificity into the spaces we see, drawing on our personal embodied experience. In foregrounding place, I propose that screendance can speak to our shared humanity by articulating particularity and difference, in so doing, referring us back to our own bodies and our particular perceptions of space: 
It is through the sensuous world of the body, through our eyes, ears, skin, muscles, and organs, that we see, feel and respond to all that happens. The body is the ground from which all our knowing of the world begins. (3) ${ }^{17}$

\section{Notes}

1. Merleau-Ponty, Maurice. "An Unpublished text."Trans. James M. Edie. The Primacy of Perception: And Other Essays on Phenomenological Psychology, the Philosophy of Art, History and Politics. Ed. James M. Edie. Evanston, IL: Northwestern U P, 1964. 3-11. Print.

2. Marks, Laura U. Touch: Sensuous Theory and Multisensory Media. Minneapolis: U of Minnesota P, 2002. Print.

3. Berger, John. Ways of Seeing. London: British Broadcasting Corporation \& Penguin Books, 1972. Print.

4. Nelson, Lisa. "Composition, Communication, and the Sense of Imagination: Lisa Nelson on her pre-technique of dance, the Tuning Scores." Self interview. Ballet Tanz. Critical Correspondence, April 2006. Web. 10 Feb. 2010.

5. Dance training is, of course, itself a vast subject. Here, I am referring to a particular form of training in working with body, space and site through improvisation. See the following books for further information:

- Tufnell, Miranda and Chris Crickmay. Body, Space, Image: notes toward improvisation and performance. London: Dance Books, 2008. Print.

- Cooper Albright, Ann and David Gere, eds. Taken By Surprise: A Dance Improvisation Reader. Middletown, CT: Wesleyan U P, 2003. Print.

- Blom, Lynne Anne and L. Tarin Chaplin. The Moment of Movement: Dance Improvisation. Pittsburgh and London: U of Pittsburgh P, 1998. Print.

6. Rosenberg, Douglas. "Video Space: a Site for Choreography." Essays by Douglas Rosenberg. DVPG, n.d. Web. 4 Feb. 2010.

7. Ingold, Time. Lines: A Brief History. London and New York: Routledge, 2007. Print.

8. Bench, Harmony. "Anti-Gravitational Choreographies: Strategies of Mobility in Screendance." Opensource: \{Videodance\} 2007: Proceedings of the Second Annual International Opensource: \{Videodance\} Symposium, Findhorn, Scotland, 20-24 Nov. 2007. Nairnshire, Scotland: Goat Media, 2009. 116-125. Print.

9. Lippard, Lucy R. The Lure of the Local: Senses of Place in a Multicentred Society. New York: The New Press, 1997. Print.

10. Clifford, Sue and Angela King, eds. Local Distinctiveness: Place, Particularity and Identity. London: Common Ground, 1993. Print.

11. Bachelard, Gaston. The Poetics of Space. 1958. Trans. Maria Jolas. Boston: Beacon Press, 1994. Print.

12. Dor, Shahar. Improvideo Workshop :: London, UK.: September 2007. Artness: The Work of Shahar Dor, n.d. Web. 19 Feb. 2010.

13. Balbernie, Angus. On Shaping a Walk. AgnusBalbernie.com, n.d. Web.2 Mar. 2010.

14. Edmunds, Becky. "Hybrids: Becky Edmunds." By Chirstinn Whyte. Filmwaves. Filmwaves, 10 Dec 2009. Web. 15 Dec. 2010.

15. Edmunds, Becky. cold - vision, perception, production. Becky Edmunds, Mar. 2009. Web. 15 Dec. 2010.

16. Edmunds, Becky. The Screen as a Site for Choreography Research Event, University of Bristol, UK. April 2009. Speech.

17. Tufnell, Miranda and Chris Crickmay. A widening field: journeys in body and imagination. London: Dance Books, 2004. Print. 
$\mathbf{F}$

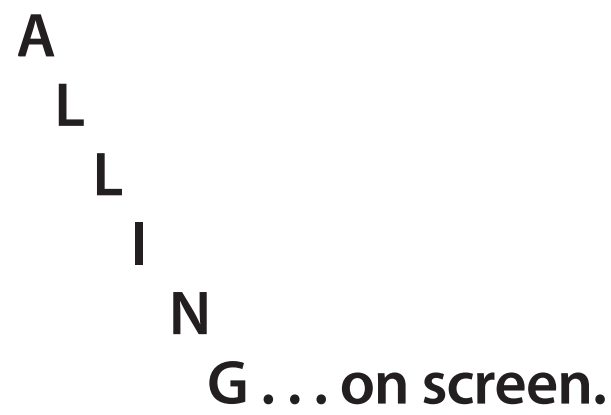

Ann Cooper Albright

The expression, "fall from grace," becomes an impossible statement when falling itself is experienced as a state of grace.

\section{- Nancy Stark Smith}

$\mathrm{B}$

$y$ the time she wrote these words as part of an editor's note for the fall 1979 issue of Contact Quarterly, Nancy Stark Smith had been practicing falling for seven years. From 1972 and the beginning performances of Contact Improvisation at the John Weber Gallery in New York City, until 1979, her body had learned to experience the momentum of a descent without clenching up or contracting with fear. She had internalized the trained reflexes of extending one's limbs to spread the impact over a larger surface area, and was able to adapt instinctually to seemingly endless variations of the passage from up to down.

This essay traces falling - that passage from up to down-on screens and in contemporary dance, by looking at examples of screendance from the last three decades of the twentieth century in order to think about the meaning of falling at the beginning of the twenty-first century. The genesis of my inquiry comes from a larger project on contemporary embodiment called Gravity Matters. In what follows, I focus specifically on the representation of falling as a state of being suspended between earth and air, the finite and the infinite. I am interested in how falling on screen can help us see the moments of a fall that are often unaccounted for in live performance and how the visualization of that "gap" can be theorized. As Nancy Stark Smith suggests:

Where you are when you don't know where you are is one of the most precious spots offered by improvisation. It is a place from which more directions are possible that anywhere else. I call this place the Gap. ... Being in a gap is like being in a fall before you 
touch bottom. You're suspended —in time as well as space-and you don't really know how long it'll take to get 'back.'

Because screendance is able to visualize that suspension in time as well as space, it may in fact, help us to think about aspects of falling off the screen, in situations where gravity really does matter.

What I share with my screendance colleagues, whose writing is included in this inaugural issue of The International Journal of Screendance, is an interest in delineating the interconnected spheres of screen technologies and dance. Indeed, the parallel development of early cinema and modern dance at the beginning of the twentieth century highlights their mutual influence. As many books and articles attest, both art forms shaped new ways of seeing the kinesthetic dimensions of a visual experience. Oddly enough, at the turn of this century, even as new technologies of editing and distribution were making screendance ubiquitous, an anachronistic nostalgia for the presence of a live, unmediated body took hold in some areas of the dance field and set up an unfortunate opposition between "real" dancing bodies and their filmed images. My research in both early- and late-twentieth-century dance has convinced me that this attitude does not account for the important and fruitful exchanges of movement information between the two genres. I believe that screens can influence how we think about live bodies, just as the dancing bodies have revolutionized movement on camera. One of my purposes here is to chart the ways that film and video help dancers see what they are doing, making visible moments of a fall that were previously unavailable to analysis. This iconography of the space in between up and down is elaborated by an approach to falling on screens that shifted historically from act (in the 1970s), to impact (in the 1980s), to suspension (in the 1990s), to a leveling out of the difference between up and down in the (2000s).

The evolution of Nancy Stark Smith's falling paralleled the development of Contact Improvisation. In 1972 when a crew of assorted college students and dancers (including Stark Smith) were experimenting under the guidance of Steve Paxton, Contact looked like an exercise in throwing and catching bodies that mostly crashed to the ground on the large wrestling mat. By 1979, the form had evolved into a major influence on contemporary dance, with a professional group of teacher/performers and an ever expanding collection of skills_falling being a primary one. During the week-long, tenth anniversary series of performances at St. Marks Danspace in New York City (1983), the signature virtuosic moves of Contact Improvisation - spinning shoulder lofts and falls that looped to the floor only to cycle back up into the air-were much in evidence.

Interestingly enough, much of this early work was documented by Steve Christiansen on video (open reel half-inch), and the edited complications of this material in Chute (1975) and Fall After Newton (1987) are well-known and widely distributed. Although each video has spoken narration by Steve Paxton, describing the development of Contact Improvisation, they differ radically from one another, both in terms of content and editing. Chute is essentially a ten-minute distillation of seventy-five hours of practice for the first Contact Improvisation concert in June 1972. ${ }^{2}$ The video is grainy black-and-white footage, shot close to the dancers. In this early collection of different exercises, we see a bunch of young people trying out the possibilities of launching one's body into the arms of a partner. These experiments with catching, falling, and dancing in physical contact often end up in awkward positions or clunky splats. The overall feeling of the work has a 
palpable sense of curiosity, a frankness with failed attempts that seems to say, "Well, that didn't work, let's try again."

Fall After Newton, in contrast, is elaborately and smoothly edited. The video traces eleven years of Contact through an almost exclusive focus on Nancy Stark Smith's dancing. ${ }^{3}$ The preface to the transcript of Paxton's authoritative narration (included in the commercial video) explains: "The great fortune of having video coverage of performances from the very beginning offered the possibility of examining one dancer's development and looking for corresponding growth in the dance form itself." The video begins with over a minute of Stark Smith perched on Paxton's shoulders as he spins quickly. This long sequence from 1983 sets up the implicit narrative of virtuosity, as both the text and the editing also showcase Stark Smith's spectacular dancing, particularly her falling. As the viewer is treated to an extraordinary series of smoothly layered shots of Stark Smith falling from the shoulders of Curt Siddall, Steve Paxton, and Danny Lepkoff, Paxton notes: "Higher momentum brings new areas of risk. In order to develop this aspect of the form we had to be able to survive it." Stark Smith's falls are looped together into one long sequence, phrases with regular pauses, and then in slow motion, before returning to real time.

The final section includes several slow repetitions of a particularly intense fall where Stark Smith lands directly on her back. Although the fall is slowed down to demonstrate Paxton's narration ("During this very disorienting fall, Nancy's arms manage to cradle her back, and this spreads the impact onto a greater area. And she doesn't stop moving. That helps to disperse the impact over a slightly longer time,") the viewer can still see the impact reverberate through her body, even as she rolls (now in real time) out of it and keeps dancing. Paxton's unintentionally patronizing comment "She doesn't seem bothered," elicits snorts and laughter from my students every time I show the video. And yet, the slow motion repetition, combined with Paxton's articulation of how to survive that moment of disorientation, really help my students to visualize the possibility of expanding their attention within a fall. As Stark Smith relates in her editor's note: "When I first started falling by choice, I noticed a blind spot. Somewhere after the beginning and before the end of the fall, there was darkness." Working backwards from image to sensation, viewers can learn how to stay in the light, from her example.

The slow-motion falling on screen that is a hallmark of Fall After Newton has a precedent in televised sports. From the early days of the Wide World of Sports, where the "thrill of victory" was always paired with "the agony of defeat" - a shot of a skier or runner wiping out in spectacular manner-to the almost animation-like effect of high definition instant replays, mediatized sporting events have always broadcast slow-motion falls. More and more, these shots, like the slow-motion gunshots in popular movies, transform something essentially awful into an abstractly beautiful effect. In sports, however, the camera usually returns to the live action, with scenes of the player being carted off the field, and pans to the worried look on the coach's or girlfriend's face, before cutting to a beer commercial. Slowmotion replays are now habitual in professional sporting events, especially in basketball, where even at live games, most of the viewers are watching the enormous screens to see what "really happened" in those split seconds before the foul. Early on in the development of the work, Steve Paxton once compared watching Contact Improvisation to watching sports, where you watch with a relaxed attention until some exciting move pulls you to the edge of your seat. 
This comparison between sports and dance, and their media legacies, is more than coincidental, of course. During the late 1980s and the 1990s, certain genres of contemporary dance (what I tend to call the Euro crash-and-burn aesthetic) highlighted a physically virtuosic, intensely driven body. Édouard Lock's company La La La Human Steps from Montreal is one well-known example of this approach to the human body, this side of the Atlantic. His main dancer, Louise Lecavalier, has the profile and attitude of a prima ballerina cum rock star, and it is her extraordinary dancing that drives his increasingly "mega" media extravaganzas such as Infante, C'est Destroy. Produced in 1991, (choreography is much too plebian a term for what actually transpires onstage) this "dance ' $n$ ' rock" event toured internationally for several years.

Throughout this nonstop seventy-five minute spectacle, Lecavalier's body-both its hardened aerobic energy and its filmed image-is continuously on display. Pitted against the pounding sounds of Skinny Puppy, Janitors Animated, David Van Tiegham, and Einsturzende Neubauten, her dancing uses the driving beat of the music to stretch dance movements to the outer limits of physical possibility and endurance. Over and over again, Lacavalier launches her body across the stage, flying through the air like a human torpedo. She gets caught by another dancer, thrashes around with him for a while, then vaults out of his arms, only to rebound back seconds later. Her body spends more time catapulting horizontally than it does moving vertically. Sometimes she is caught and guided to the floor by her partner (as in Stark Smith's falls), but most of the time her body is so tightly coiled that she practically bounces off the floor and back into another lateral vault.

In another context, I have analyzed with some care the heavy metal iconography and gender dynamic of Infante C'est Destroy. ${ }^{4}$ I return to this work now with a slightly different intent. For the purposes of this essay, I am curious about the contrast between Lacavalier's dancing and the filmed images of her naked body falling slowly through the space in the second half of the show. After we have seen Lacavalier and her various sidekicks slam their bodies relentlessly around the stage (think of the physical equivalent of a heavy-metal guitar solo), an enormous screen slowly descends across the front of the stage. At first, the film shows Lecavalier clothed in a medieval suit of armor, complete with sword (à la Jeanne $d^{\prime}$ Arc), and then later falling naked through a vast, bleak space. There is no coherent narrative in this short surreal film. Jump cuts inexplicably move her from a figure of power (the knight), to a woman bleeding, to a Christ-like transcendence. She is aggressor, victim, and saint; all the while imaged in larger than life celluloid.

Yet in the moments when she is falling through space, there is an otherworldly calm that envelops the audience. These moments are completely detached from the events onstage. Although her blond hair and alabaster skin are recognizable, Lacavalier's body is transformed on the film. She floats peacefully on screen, supported by the digital technology that allows her image to transcend gravity. She is falling on screen, but falling in such a suspended atmosphere that she seems to be evaporating. Then she lands. Shot from underneath a glass floor (à la filmmaker René Clair's Entr'acte), the impact is clear. We see her land on all fours, breasts bouncing, hair flailing. The shot is repeated, several times. Although the slow-motion editing mutes the jarring effect of her return to gravity, the audience still experiences a visceral reverberation of that jolting sensation whose effects are nonetheless clearly visible. What makes this sequence particularly eerie is the fact that we do not see the chain of events that led from her floating to landing. We see her suspended, 
but we don't see the real momentum of her fall, only the seconds before impact. It is like the story of Adam and Eve, without the apple. The image of her strong, yet vulnerable, naked body resting in air at one minute and then hitting the ground the next is both disturbing and bizarrely beautiful.

The American equivalent of La La La Human Steps is Elizabeth Streb's company Ringside. Over the past twenty-five years, Streb has been involved in making pieces that focus the audience's attention on how a human body (or bodies) interacts with various kinds of equipment such as poles, balls, hoops, plexiglass walls, a board-on-wheels, a coffin-like box suspended sideways in the air, two 4'x8' birch plywood panels, trapeze harnesses, various kinds of adult-sized jungle gyms, and a trampoline which can catapult people up to thirty feet in the air. Streb's dancers hurl themselves through space, slamming their bodies into the various pieces of equipment. Although the fierce physicality and built-up muscularity, as well as the way her dancers vault through the air, are analogous to the dancing in La La La Human Steps, Streb's work is much plainer, with a lot less theatricality, a lot less "attitude," and a lot less pretension than Lock's mega-spectacles. Typically in a Streb concert, one walks into the theater while the technicians are testing and adjusting the equipment. The dances start with the dancers casually walking on stage, shaking a limb here and there to loosen up, and preparing themselves as if for a race or some kind of sporting event. Once they have arranged themselves and glanced around to see if everyone is ready, the dancers launch into whatever physical challenge is being attempted in this particular dance.

More recently, Streb has been working with layering the movement tasks that are a signature of her work with real-time video projections. Her 2003 piece, Wild Blue Yonder, which was commissioned as part of a $100^{\text {th }}$ anniversary celebration of the Wright Brothers' first flight, juxtaposes the real flight of the dancers swan-diving off a large trampoline and landing on a thick gym pad with the manipulated images of their shadows. ${ }^{5}$ Like many of Streb's works, this dance focuses on bodies flying and falling though the air. The physical stamina of her dancers is breathtaking and yet the relentless repetition of their stunts tends to dull the impact of those extraordinary feats.

Wild Blue Yonder begins with the dancers entering the performance space and lining up on a ledge in between the scrim and the trampoline. As they jostle and adjust their spacing, the audience sees glimpses of their shadows projected against the twilight blue scrims. First one, and then another, and another dancer jump off the ledge and onto the large trampoline, which catapults them up high into the air. Arms spread out to their sides, the dancers swam dive down, bracing themselves at the last moment as they hit the crash pad. Their acts are spectacular, but it is the image of the dancers' shadows - those black alter egos - that is most riveting to watch. Suspended in the air for a moment, they really do look like airplanes.

Bit by bit, the dancers speed up, launching themselves one right after the other like the finale of the fourth of July fireworks. As more and more bodies take to the air, their shadows become erratic and unpredictable, often times staying on the screen long after the live body has landed. Sometimes the shadows will introduce a new movement motif, a flip or a pike turn, until eventually the images on screen take on a life of their own. This choreography of shadow and video image is infinitely more fanciful and varied than that of the live dancers, who must inevitably contend with the call of gravity that abruptly brings them 
back to the earth. Unfortunately, we never get to see images of this experience suspended in time, for the projected bodies never land, they only fade away. Predictably, the curiosity that fueled the Wright Brothers' ambition to fly keeps the audience gazing at the shadows floating in the sky, while the live bodies drop out of sight.

The context of my investigation of falling on screens is a deeper inquiry about the culture of falling post-9/11. Seeing Wild Blue Yonder makes me wonder: "Have the disturbing images of free falling bodies dropped out of our sight?" Are we overly comfortable with a technology that can suspend falling indefinitely such that we never are confronted with that final negotiation with gravity? What would it mean to use the technology of screens not to divert our attention from those spectacular falls at the beginning of the twenty-first century, but rather to examine the spaces in between that past and our future? In other words, how can we use screendance to teach us how to land a fall safely both physically and culturally? Ideally, I would be able to point to a recent screendance that realized a vision of falling that was both suspended and grounded. But that screendance has not yet been invented.

\section{Notes}

1. Contact Quarterly Spring/Summer (1987): 3. Print.

2. Chute. Narr. Steve Paxton. Videoda, 1972. Film.

3. Fall After Newton. Chor. Steve Paxton. Perf. Nancy Stark Smith and Steve Paxton. Videoda, 1987. Film.

4. Albright, Ann Cooper. "Techno Bodies." Choreographing Difference: The Body and Identity in Contemporary Dance. Hanover, NH: Wesleyan University Press, 1997. Print

5. Wild Blue Yonder. Chor. Elizabeth Streb. 2003. 


\section{The Logic of the Copy, from Appropriation to Choreography}

\section{Claudia Kappenberg}

$\mathrm{n}$ film, video, and fine art practices the appropriation of an existing public repertoire of
images, broadcast media and archives of all kinds is a well-established strategy for a critical
engagement with the everyday. By comparison, work that is made under the umbrella of screendance tends to be composed with new movement material. Both Appropriation Art and screendance are rooted in the technologies of reproduction and are part of the same history but they are pulling in different directions.

In the context of a first issue of The International Journal of Screendance, and hoping to encourage dialogues between screendance and other art practices, I will revisit the discussion on originality versus appropriation, which has underpinned developments in various areas of contemporary fine art practice. I will look at different approaches to appropriation and review the kinds of authorship that have emerged in the process. This includes an investigation into the logic of the copy inherent in these practices, wherein I will consider both the use of technologies of reproduction and the use of repetition within the work. In addition I will look at Appropriation Art through a choreographic lens and consider what screendance practices may be able to contribute to the debates on authorship.

For the purpose of my argument I will situate screendance in opposition to appropriation practices, even though that is problematic when you think about music videos (for example). They could be considered as a form of screendance in their emphasis

These works thrive on traditions of cultural commenting and recycling and freely combine, appropriate, remake, remix, spoof and parody. on choreographic sequences and moving dancing bodies, but they also appropriate and remix frequently from all kinds of cultural sources and media. The recent Video Phone by Beyonce (2009) and the remake by Lady GaGa (2010) come to mind, whereby both pop singers feature in each other's videos. Lady GaGa's remake inspired further spoof versions, performed, for example, by Him and Me TV (2010), all accessible on YouTube. These works thrive on traditions of cultural commenting and recycling and freely combine, appropriate, remake, remix, spoof and parody. Apart from music videos, though, much of screendance, and in particular the work that is shown in dedicated screendance festivals, is not explicitly engaged with the incorporation and appropriation of existing cultural material.

Appropriation as art practice rests on the idea of borrowing or copying rather than making something "new," that is, the incorporation of everyday objects and images into works of art or the copying of already existing works of art. Even though this may suggest a common methodology across different bodies of work, I do not want to argue for sameness between different appropriation practices, but rather explore the nuances and possibilities that distinguish different approaches. As Vera Dika argues in her book Recycled Culture in 
Contemporary Art and Film, we need to avoid generalities and simplifications in the discussions, as different appropriation practices cross different boundaries and explore various kinds of self-reflexivity (30).' To explore some of the operations at play, I will draw on different sources and points of view, mainly theorists Craig Owens and Margaret Iverson and anthropologist Verena Seremetakis, as well as my own experience in choreographic practices.

I will begin by discussing the video Snow (2003), a collaborative work by David Hinton and Rosemary Lee, which is above all a choreographic project and generally shown in the context of screendance, but which also draws on the tradition of Appropriation Art. The work sits therefore at a crossroads between screendance, visual arts and film practices. Following a discussion of Snow, I will broaden out to explore the work of artists who are associated with Appropriation Art and look at the aims and intentions of their different works. This will involve travelling backwards in time as the roots of these practices go back via the so called "Picture Generation" of the 1970s and 1980s to the use of the readymade at the beginning of the twentieth century. However, rather than drawing a map of Appropriation Art as such, my focus is on the correlation between appropriation and choreographic endeavours and the relation between making copies and making unique works of art.

I am writing this paper with a sideways glance toward Walter Benjamin's often quoted essay, "The Work of Art in the Age of Mechanical Reproduction"from 1936, in which Benjamin argued that the notion of the original and unique work of art was outmoded and that the technologies of reproduction, photography and film would allow for a new concept of art.2 His writing and the debates that followed proved highly influential in underpinning appropriation as an art practice. It will not be possible to fully review his argumentation in this paper but some of the issues discussed here will raise questions with regards to Benjamin's differentiation between the notion of the original and the copy.

\section{Series, playfulness and hard-core criticality}

The work Snow (2003) remixes black and white archive footage, dating from the 1890s to the 1960s, into a series of urban snow scenes (Figure 1, pp 30-31). The work begins with individuals vigorously flapping their arms and tapping their feet in an attempt to generate warmth, proceeds by cutting between groups skating and dancing on ice or shuffling through the streets, and ends with barely recognisable dark silhouettes braving violent snowstorms. The work is described as a "rhythmic choreography of gesture and actions on the slippery sidewalks and slopes of a bygone era" (Hinton and Lee, online). ${ }^{3}$

Snow brings a distant past into play with the present. Fragments of subjective histories and insignificant moments of the past are seen and remembered, perhaps for the first time. As a collection of out-takes huddled together on the screen, they have gathered sufficient mass to be noticed, attracting attention to what may have been lost otherwise. The grainy image quality of the archive footage further amplifies a sense of fragility in comparison to the video technology with which the work is screened. In a paper entitled "Resistance to Replication," given in the context of a debate on replicas at Tate Modern in London, Margaret Iversen discusses the effect of the presence of historical technologies in contemporary work: ". . just-obsolete technologies seem to condense both a promise for the future and a melancholic acknowledgement of the fading of those hopes. As 'found objects' they weave together past and future, memory and anticipation, and create a fabric of associations." ${ }^{\prime 4}$ 
Iverson highlights the changing status of the technologies of reproduction which, over time, have come to play very different roles. An example for the incorporation of obsolete sound technologies is Graeme Miller and John Smith's video, Lost Sound (1998-2001), which retrieves the sound of audiotape found on the streets of London and combines it with video images of the places where the tape was found. The work seeks out and replays, as if for the last time, a technology that encapsulates a whole era of sound making, constituting a remembrance as well as signalling its obsoleteness.

A similar dynamic plays out in Hinton's Snow, whereby outmoded film and contemporary video technologies are combined to invite a comparison between early amateur film footage and the contemporary equivalent. Whilst allowing for a nostalgic delight in archival footage, the work invites a reflection on ideas of technological progress that would have circulated at the time of early filmmaking.

In addition to this play on the material level in Snow, there are significant operations at work in the editing through the composition of a series of similar movement material. In this process the "historical" is detached from its original context, losing a sense of circumstance or narrative, and is embedded instead within a new structure, an accumulation built on formal qualities such as similar rhythm and corresponding shapes. This sort of operation is typical for work that appropriates existing material. It causes a shift from meaning that is located within the image to meaning that is created by the new series and the new context.

Exploring these compositional methods in works of art in the 1970s and 1980s, Craig Owens argues that the appropriation of found images is a Duchampian strategy dating back to the readymade, and also that it signals "a shift in elocutionary mode, from history to discourse" (75). ${ }^{5}$ The Duchampian ploy of taking an existing industrial object such as a bottle rack (Bottle Rack, 1914) and presenting it as art in an art context suffered a paradoxical fate: at first it confronted the traditional notion of an original art object and displaced the artists as the maker of the work. After the initial shock the readymade was, however, aestheticized very quickly by a homogenizing dynamic in the art market and reabsorbed into the exhibition space. Nevertheless, it could be argued that the readymade permanently destabilized the process of art making, shifting the attention away from the object to the cultural dynamics within which it was made, always and again highlighting an institutional context and its homogenizing mechanisms.

According to Owens this also caused a shift "from history to discourse," that is, a change from third-person narrative to direct address (75). Meaning as a certainty was replaced by a fluid and almost arbitrary process of an encounter between the art object and the viewer. Owens references this history in the context of appropriation practices of the 1970s because its practitioners began to systematically strip images and objects of their authority as carriers of meaning and articulated instead the processes through which meaning is assigned within a particular cultural context. Examples of this sort of practice include Sherrie Levine's appropriation of the work of other artists, as well as Dara Birnbaum's appropriation of TV material, both of which will be discussed further on.

Snow sits within this history and adds a chorographic perspective, bringing together archival film scenes from unrelated sources and appropriating them for its own choreographic purposes. The absence of narrative and original context creates a void that can only be filled by the viewer. As a formal sequence of fleeting moments, Snow invites the viewer to reflect on what we call "history"; as a choreographic endeavour, the work questions the 

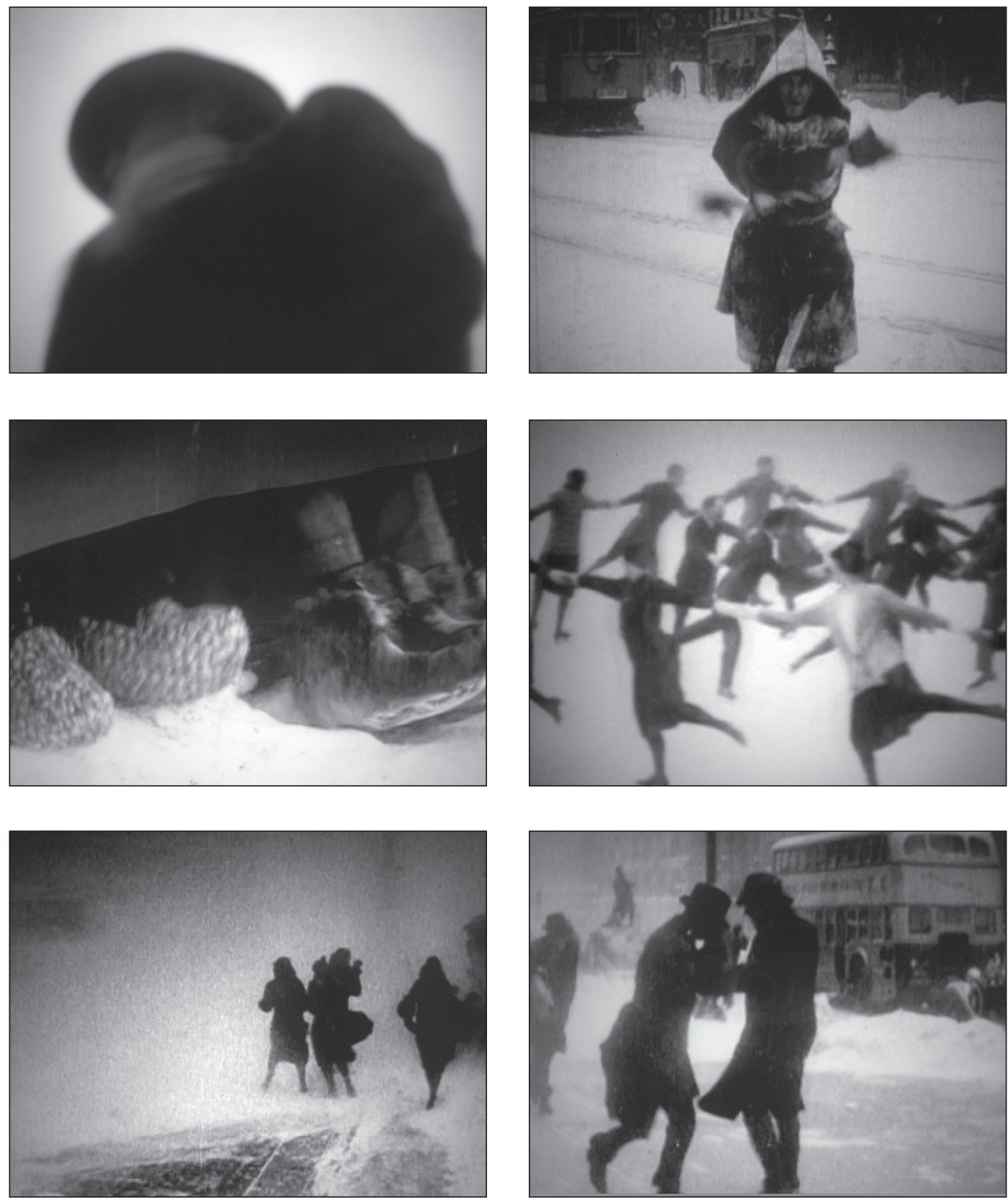

Figure 1: Snow (Dir. David Hinton and Rosemary Lee, 2003) 

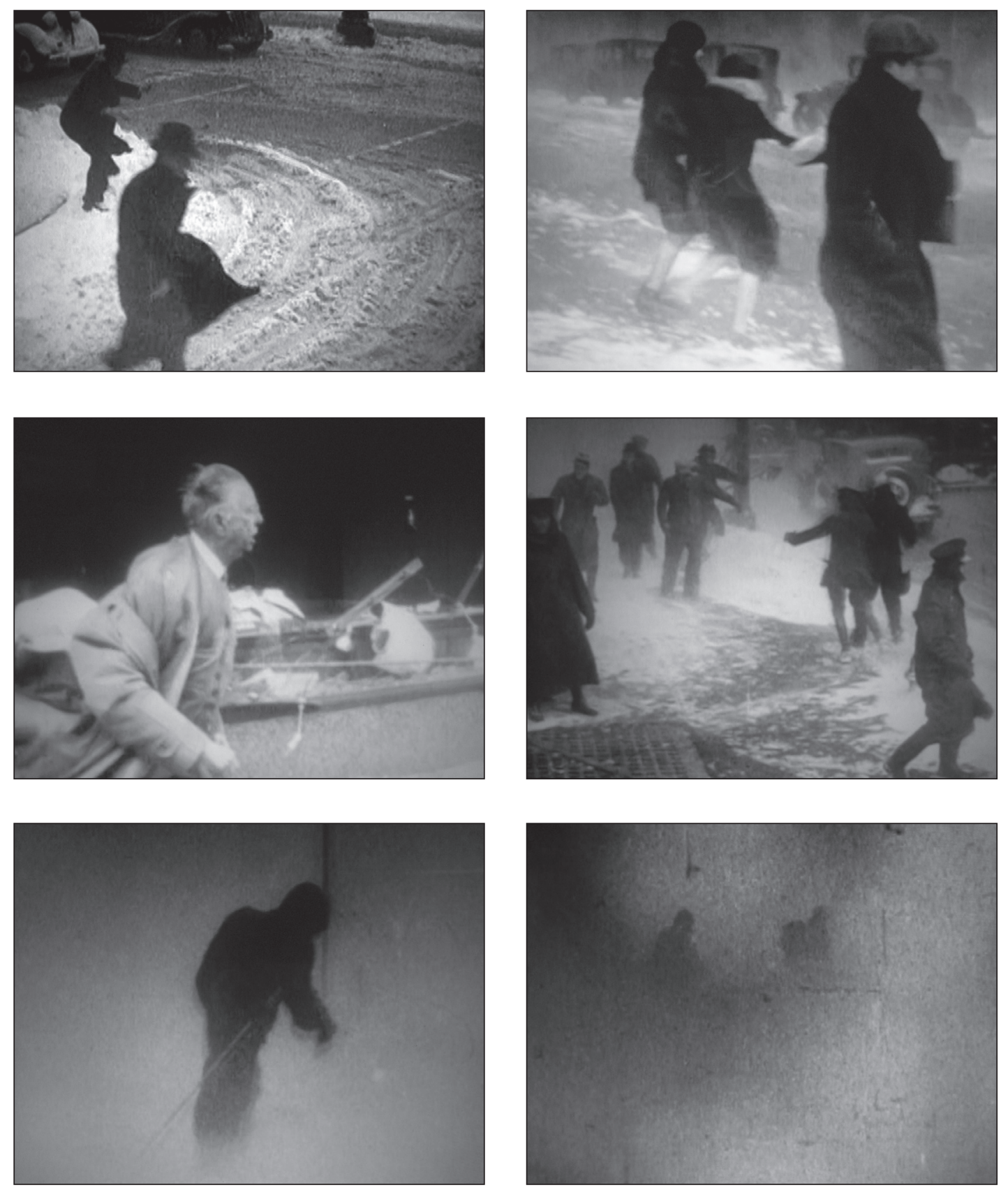
notion of the choreographic, as all the material was already in existence and no movement needed to be "written." The artist's "work" then consisted mainly in composing, in a sense, a response to what was already there, a process that is significantly different to the kind of authorship involved in making new material. In a work such as Snow, the author/maker/ choreographer does not claim a traditional form of ownership of the material and is more a disinterested kind of author figure.

The foundations for the model of the artist as disinterested figure had been laid by Duchamp through the readymade, as discussed above. In the late 1960s it was developed further by Roland Barthes in the essay The Death of the Author, in which Barthes argued strongly against the idea that an author could be the origin of a work of art and suggested that it was the work that was making the author. Barthes' essay was an invitation to re-invent authorship as a different kind of writing or making and emphasized the complexity of the process of making. In an essay entitled "From Work to Frame, or, Is There Life After'The Death of the Author'?" Craig Owens reviewed different kinds of authorship that subsequently emerged and that have tended to undermine the more traditional notions of authorship. ${ }^{6}$ | will not be able to expand here on the different threads in Owens' essay, but I would like to appropriate the title for my reflections of authorship in screendance. If I were to equate the author with the choreographer, I would call for the death of the choreographer, but I would like to try a different strategy in order to expand the notion of the choreographic and ask: "from work to frame, or, is there life after the death of the dancer?"

The point of a declaration of the death of the dancer is not to call for work in which there are no dancers - of which there are numerous examples-but rather to reflect on what it is that dancers represent within work and what role they are fulfilling with regards to authorship and the question of originality. Moving dancing bodies allow for the possibility of making "new" material and for a concept of the choreographer as the creator of the work, akin to traditional notions of authorship. This attempt to make original work is reinforced by the fact that individual bodies contribute a certain unpredictability on which the choreographer can draw to secure a uniqueness of the work. From this perspective, screen-based work without dancers would require the makers to relinquish some of the traditional claims to originality that are often inherent in choreographic project and located in the presence of moving bodies. In order to explore what authorship might look like without dancers, I will examine the work of a couple of contemporary appropriation artists, one with a playful and the other with a more serious approach.

Artist Christian Marclay works across visual art and sound art, taking artistic strategies from one field and applying them to the other. In some of his installations classic cinematic scenes and their sound effects are accumulated to expose the narrative conventions of film. In Quartet (2002), for example, cinematic moments such as telephones ringing and glass shattering are screened side by side across four large screens to create a hilarious comic-tragic soundscape. In Crossfire (2007), gun scenes from Westerns are edited into rhythmic series of increasing intensity. Shots of men in boots and cowboy hats facing the camera, reaching for their guns, pulling guns, pointing guns and finally shooting are edited into tight sequences with four variations of the same material projected simultaneously on four walls. Through the combination and pace of images and sound, the work bombards the viewer with cinematic tension from all sides. Crossfire could be described as a choreographic study of the cowboy, structuring the material in terms of movement and sound 
qualities, rhythm and framing, amplifying patterns and qualities of gestures. The work mocks cinematic representation and exposes a glorified emblem of masculinity.

Both Quartet and Crossfire seem quite close to their cinematic counterparts and very much the equivalent of cinematic spectacle within an art gallery. There is a strong sense of pleasure in looking and in the conventionality of the appropriated material. No matter how fragmented the material may be, the works acknowledge the importance of the little moments that flesh out the cinematic narrative-such as the ring of an old telephonewhich suggests that the artist is just as keen to fulfil to our desire for immersive experience as he is intent on introducing a critical distance.

Marclay fully embraces appropriation and exploits the processes across different media, working with film clips, strips of tape, record covers or old vinyl records. In The Sounds of Christmas (1999 and ongoing)he also invites other artists to make work with one of his collections, a large set of Christmas records, which travels from county to country and which he offers to local DJs and sound artists at Christmas time.

Marclay's work plays with repetition both on the level of content and technique, and he seldom "invents" material. His signature as an artist is to collect and copy and to create playful compositions with what he finds. In his discussion of Appropriation Art, Craig Owen argues that in this kind of operation fragments are piled up endlessly and "without any strict idea of a goal," a proposition that is drawn from Walter Benjamin's exploration of accumulation as literary process (Benjamin qtd. in Owens 43). ${ }^{7}$ The notion that there might not be a strict idea of a goal in the work highlights a disinterested kind of authorship, whereby the author lays no claim to making or breaking meaning. Instead of working with a sense of an origin and a destination, the artist builds on a process of replication inherent in contemporary culture and mass media and replicates this even further. By extension, the work crosses with ease between different media and traditions; thus a discussion on whether or not this work draws on choreographic sensibilities is of little consequence. By working with a process of replication the author does not need to secure any originality and can allow the work to unfold its meaning in relation to the cultural context from which it is appropriated. In this sense one could argue there is "no strict idea of a goal."

Marclay's broad, open framework can be seen as a response to the work of the 1970s and 1980s, when media artists demonstrated a more hard-core approach to appropriation, dealing explicitly with issues regarding gender, identity politics and capitalist ideologies. German artist Klaus vom Bruch made a series of works in the mid-80s which address the representation of self and identity. In Der Westen lebt (1984), vom Bruch uses rapid-fire video switching to juxtapose two very different scenes. One image shows the thrusting pistons of an oncoming train, the other a man and a woman kissing in a way that is at once erotic and violent, playful and disturbing. The high-speed editing creates a confused visual composite, with the effect that meanings bleed from one image into the other, juxtaposing the mechanical and the human as well as approximating the two. The sound of the train is edited into a hard, staccato rhythm and maintains the same tension throughout the work. Similar to Marclay's work, the composition builds on selected movement and sound qualities, but develops a more aggressive composition with a constant, staccato push and stop animation. The work comes across as a strong critique of a Western figuration of desire because of the single minded editing which pushes the male into the position of aggressive perpetrator and the female into a role as sexual object. 
In another of Klaus vom Bruch's works, Goblin's Chants (1986), a high contrast image shows a white male torso hovering in the middle of a black screen breathing rhythmically while a rotating tubular object is faded in and out over the chest. The movement on screen is accompanied by an Ethiopian call and response chant. Compared to the violence of Der Westen lebt, this video is seductive and hypnotic. The combination of elements is unsettling, however, and gives the impression of a strange, inexplicable ritual. How does an individual male torso relate to an anonymous technical structure and how does this pairing on a video screen relate to an African chant?

The uncertainty is the effect of a construct, whereby one fragment or layer is read through and against another layer. Appropriated for this work, each element clashes with the others and disparate cultural assets are collapsed into one frame. Owens argues that artists were "laying claim to the cultural significant and posing as interpreters," playing on the traditional role of creators of meaning but providing none of it" (54-55). ${ }^{8}$ Indeed, Klaus vom Bruch is not interested in making meaning but in making a critique of discursive conventions in popular media, advertising and television. Some material is taken straight from the media, such as the image of the train pistons or the Ethiopian chant; other material is made "in the style of," such as the scene of the man and woman kissing. Either way, vom Bruch uses an existing reservoir of images and gestures to expose them as constructs of a wider commodity culture. As a choreographic enterprise, the work copies from a limited cultural repertoire and highlights the limitations by staying within its boundaries.

Compared to Marclay's work this approach is minimalist and does not indulge the audience. A sense of duration and persistent repetition challenges the viewer and gives little opportunity for entertainment or visual pleasure, setting the work apart from the commodity culture that it is trying to critique. Considering the adherence to the principles of appropriation in this work, one might expect that there is not much of a sense of authorship, but that is not so. The author is palpable as a strict master of ceremony, in which all decoration has been removed and only the bare essentials remain. In appropriating a cultural repertoire, vom Bruch becomes the choreographer-director of this repertoire, re-staging well-known clichés and exposing them in the process.

Both Marclay and vom Bruch have an approach that is relatively disinterested, using and re-using existing cultural clichés, commodities and icons to make their point. On the other hand, and perhaps despite the exploration of already existing material, there is also a personal dimension to their work, and the artists seem to be quite at ease with this ambivalence. Their approach testifies to a certain criticality towards authorship but does not relinquish originality altogether. The work rather indicates an expanded notion of originality. I will proceed by discussing the work of two American appropriation artists from the so-called Picture Generation to further explore this point.

\section{The Picture Generation}

Artist Sherrie Levine is often called "the" appropriation artist. However, not uncommon for women artists of her generation, Levine is not keen to be drawn into the school of appropriation and even less to figure as its representative. She rather associates herself with the feminist discourses of the 1970s and their debates on notions of originality. In an interview 
for Arts Magazine in 1985, Levine was asked to comment on what originality meant to her. She responded:

It's not that I don't think that the word originality means anything or has no meaning. I just think it's gotten a very narrow meaning lately. What I think about in terms of my work is broadening the definitions of the word 'original.' I think of originality as a trope. There is no such thing as an ahistorical activity (I mean history in terms of one's personal history, too). ${ }^{9}$

By bringing in the personal dimension Levine references a feminist discourse that argued against universal classifications and narratives, and for a foregrounding of the local and the personal. The discourse supported a notion of subjectivity but problematized the concept of originality, arguing that there was no such thing as an artist who was not already embedded in a particular culture, economy and history. Levine does not, however, propose to abandon the concept of originality as has been suggested elsewhere, but argues that it needs to be reviewed and broadened.

Levine was part of a group of artists who came to prominence in 1977 through an exhibition at the alternative Artists Space in New York entitled "Pictures," curated by Douglas Crimp. Like Levine, artists such as Robert Longo and Jack Goldstein worked predominantly with film and photography, demonstrating a new fluidity between practices, genres and media and drawing on mass culture, television and advertising as much as the history of painting and minimalist sculpture for their own work. On the occasion of a review of the work of the Picture Generation at a show at the Metropolitan Museum of Art in 2009, curator Douglas Eklund reflects on the effects of the political climate and the mass culture on the production of art in the 1970s and 1980s. He describes it as a time of disillusionment and failed utopian promises of political and social transformations. Artists, he writes, were working "at the intersection of personal and collective memory, rummaging through the throwaway products of their youth ... in search of moments that both never existed yet were indelibly stamped in the mind." ${ }^{\prime 0}$ The statement foregrounds the fact that artists were deeply implicated as consumers of a proliferating visual culture whilst trying to find a critical voice from within. Eklund describes this culture of movies, television, popular music and magazines as a "sort of fifth element or a prevailing kind of weather," and the artists as scavengers of this image world (ibid.) As Margaret Iversen points out in her review of this body of work: "To appropriate, copy, replicate became the new, inverted, 'anti-aesthetic' values" (Iverson, online). This "anti-aesthetic"was above all a specific rejection of a Modernist tradition which advocated a separation between different media and genres and which celebrated the artist as creative genius. The new generation of artists inverted this aesthetic by replacing a process of creating with a process of copying and by replacing the separation between genres with a deliberate blurring of categories.

Levine's own take on appropriation constituted perhaps the most radical challenge to the notions of originality and authorship. Since 1977 Levine has copied and re-presented the works of other artists, showing for example photographs of natural subjects that had been taken by photographer Andreas Feininger (Owens, 75). In re-photographing and presenting the work of another artist the images fall somewhere between being "his" and "hers" and are neither the original picture nor simply a copy. Instead the works raise doubts as to the nature of authorship and the status of images themselves. In the interview for Arts Magazine, she explains: 
When I started doing this work, I wanted to make a picture which contradicted itself. I wanted to put a picture on top of a picture so that there are times when both pictures disappear and other times when they're both manifest; that vibration is basically what the work's about for me - that space in the middle where there's no picture. (Owens, 75)

As Levine points out, this work is highly contradictory and reflects a complex artistic process, calling into question the whole of the relation between artist and work. In this work we cannot locate the author but neither can we clearly identify the image inside the frame. The deployment of photography here is symptomatic in that a photograph is never an authentic, original object in the first place. Photography and film are always images of something and to ask for an authentic print makes no sense, as Benjamin noted in 1936 (218). Meanwhile a predominantly visual culture had lost interest in the notion of the original and Levine's re-produced pictures refuse to act as transmitter of cultural signification. According to Craig Owens such images "both solicit and frustrate our desire that the image be directly transparent to its signification. As a result, they appear strangely incomplete; fragments or runes which must be deciphered" (55). Instead of producing authoritative works of art, Levine undermines the reification of art objects by making work that is to some extent incomplete and which is neither her work nor that of the artist she is copying. In addition, Levine has only ever taken images of male artists to address a canon that has tended to privilege the male as artist, curator and recipient. Levine said: "A lot of what my work has been about since the beginning has been realizing the difficulties of situating myself in the art world as a woman, because the art world is so much an arena for the celebration of male desire" (Siegel, online). Her work plays a complex game of addressing gender politics, authority and the figuration of desire as male. In appropriating this "other" she has opened up a space in which there is no defined author and no classifiable work but a mode of operation all the same.

Levine's extreme approach to appropriation demonstrates a strong interest in questions of originality and authorship. It is interesting in this respect that after working through photographic reproduction she began to physically draw the work of male artists such as de Kooning, Piet Mondrian and Yves Klein, thereby re-introducing the hand and by extension her individual presence into the work. Through this introduction of physical trace the work became a curious hybrid, being both appropriated as well as original, pushing the boundaries of Appropriation Art and challenging the positioning of her as (appropriation) artist at the same time.

Levine's appropriation of other artist's work correlates to some extent with the work of Dara Birnbaum, who appropriates footage from television to create video loops, which replicate the clichés of television. An early work is Technology/Transformation: Wonder Woman (1978-79), an appropriation of sections of a popular TV series from the 1970s entitled '"Wonder Woman," and in which Birnbaum endlessly repeats characteristic moments of the main character such as her transformation from real woman to super woman.

The extracted clips are combined using a stuttering progression and persistent repetition to create a minimalist choreography consisting of running, spinning and saving a man's life. Through the repetition the images shift from being screen magic to pathetic looking effects, deflating the icon and turning Wonder Woman, almost literally, into a wind-up doll. In the process the original television series is revealed as a rigid choreography with a prescribed series of movements, limiting the main character to very tight parameters. 
Birnbaum's critique, however, was not as confrontational or as "hard core" as is sometimes assumed. In an interview conducted in the context of the "Talking Back to the Media" festival in the Netherlands in 1985, Dara Birnbaum speaks about her intentions in this body of work. Asked if her early work was about "talking back to the media," Birnbaum responds: "No, I think that never was the main subject. I wanted to talk about a form of representation and its issuance ... Rather than pointing the finger, rather than Talking Back at something, it is more important to Talk With" (Velthoven).. "Instead of an antagonistic artistic position her comments suggest something close and even intimately connected to the media. In isolating and re-editing the material the artist extends an invitation to the viewer to also look closely and to consider the image itself as well as any cultural subtexts to which it may refer.

In the same interview, Birnbaum talks about an acceleration in visual culture and television that is speeding up to the point of collapse. She says that to resist this development she has had to go slower, to make slower and slower tapes. Birnbaum describes how she was inspired by seeing Japanese prints in the Van Gogh museum in Amsterdam, which appeared to her like a "stop in TV time." Her comment suggests that she was searching for a different kind of visual experience than the one offered by television. Perhaps Birnbaum's work has always been an attempt to stop or slow down the pace of broadcast media, which tend to overwhelm the viewer with a continuous barrage of visual and audio material of any kind. The extraction and repetition of small snippets from television counteract this flow and the dramatic content of the material fades away with each repetition. Exhibited as loops, the work creates a reflexive interval, as if a stilling is the act that is performed here.

Anthropologist Nadia Seremetakis has developed a critique of dominant cultural modes from an anthropological point of view, commenting on a construed evenness and artificial sameness of cultural codes. Individual experience, Seremetakis argues, is, by contrast, uneven, regional, non-synchronous. She claims that representational modes need to be interrupted to "render the imperceptible perceptible" and to allow for different kinds of individual experience (12). ${ }^{12}$ Seremetakis proposes the concept of the "still act" as an interruption which would suspend at least momentarily a homogenizing culture that erases individual experience rather than articulating it (23). These still acts would not just be passive moments but an active and deliberate process, a paradoxical intervention that asserts a possibility of reflection and an artistic agency. This concept could be applied to Birnbaum's Wonder Woman, which plays with and against the language and rhythm of broadcast media to deconstruct its narratives and conventions.

"Readymade for the 20th century" was the title Dara Birnbaum gave to her video work from the 1970s in reference to artist Marcel Duchamp and in acknowledgement of a history that pushed aside the unique art object and replaced the artist-genius with a more detached author figure. The appropriationists discussed in this paper all seem to embrace this history and work with the copy as compositional strategy. On the other hand though, Birnbaum, Levine, Marclay and vom Bruch all pursue an art practice that is not entirely disinterested. A clear sense of signature emerges with each of the projects, indicating that some kind of originality has survived even in extreme forms of appropriation.

The authorship also seems multifaceted, with artists borrowing an infinite number of strategies to realize their projects, and the works described would perfectly make sense if they were screened in the context of screendance. Choreographic processes are at play even 
if they are not generally described as such; a work such as Snow demonstrates that there are no real boundaries between the two bodies of work, Appropriation Art and screendance. However, in spite of a proximity and resemblance in the work the artists are not at present exhibited in the same context, as if either party had sworn an allegiance, due to which they cannot cross an invisible line. The discourse on authorship as discussed above will account for some of the separation, but Benjamin's influential essay from 1936 must also play a part in this. I will review a few aspects of his essay to further explore the roots of screen-based practices and to outline the kind of authorship that screendance appears to be pursuing.

\section{Ebb and flow between the real and the copy}

First of all, it might be useful to recall that the strategy of the readymade, which was once radical and revolutionary, has over time become an accepted aspect of art making and that this development is due in part to the changing status of the technology of reproduction. Iverson argues that "these confident technologies that once participated in the shock of modernity now open themselves to reverie. The commodity fetish and advanced technologies of reproduction, now cast aside by the march of progress, become pensive."13 Iverson reiterates the fact that the environment around the art object has changed considerably in terms of familiarity and availability of technologies, and that this has affected the status of and response to reproduction in art. The shock of the readymade has turned into an easy acceptance of the technologies of reproduction, which in turn could explain why a seminal essay such as Walter Benjamin's "The Work of Art in the Age of Mechanical Reproduction" slowly fades into history. In this essay Benjamin claimed that the technologies of reproduction shattered the traditional authority of the art object which had been built on being unique and original, and that the arts needed to embrace the new technologies as a more adequate form of art practice for the twentieth century. He argued that this new kind of art was "lacking in one element: its presence in time and space, its unique existence at the place where it happens to be" (214). This "lack" and his text in general is usually read as a wholehearted endorsement of the new technologies and as a condemnation of the traditional value of presence of the unique work of art, or "aura" as he called it. Accordingly Benjamin's essay underpinned a categorical distinction between the traditional unique object and reproduction in art. In view of contemporary screen-based practices and with regards to audience experience this distinction is, however, difficult to sustain.

Screen-based work appears to facilitate a sense of space and time not unlike the encounter in real space, in particular when individual bodies are figured in relation to other bodies or in relation to particular sites. Hybrids like screendance are able to combine different practices and strategies, capitalizing on both the technologies of reproduction and the singularity of performance. The screen enables a paradoxical experience, in that it is always only an image but allows audiences an experience that compares to seeing live work or real objects. In a discussion on cinema as modern magic, film historian Rachel Moore explores this fundamental paradox of film and points out that the absolute separation from real space is exactly that which allows film to be perceived as real (86). ${ }^{14}$ Benjamin wrote that "the presence of the original is the prerequisite to the concept of authenticity" referring to the authenticity of the art object, but film allows for an experience of presence despite the fact that it is always only a reproduction. ${ }^{15}$ 
Presence must therefore be reconceived not as a requirement of the "object" but as an aspect of the experience offered by the work. Particularly in the case of screen-based work, presence may not at all depreciate with reproduction, as Benjamin suggested, but continue to exert the same presence across an infinite number of copies. Benjamin further proposed that "the authenticity of a thing is the essence of all that is transmissible from its beginning, ranging from its substantive duration to its testimony to the history which it has experienced" (215). Benjamin describes what he understands as the aura of a work of art, a combination of the particular of place and time, the unique history and the evidence of this history in the art object. One could argue, however, that this can be transferred from the art object to the object of representation, i.e. screen-bodies, through which a substantive duration and a history can be located within the work and experienced by the viewer. Screen-based work is therefore anchored through the detail or the screen body in space and in time and allows for an experience of presence and uniqueness on the part of the viewer in spite of the nature of the work as mechanical reproduction.

In the latter part of his essay Benjamin elaborated with excitement on the deepening of perception which had become possible through photography and film and his own writing appears to supports my argument. Benjamin writes:

By close-ups of the things around us, by focussing on hidden details of familiar objects, by exploring commonplace milieus under the ingenious guidance of the camera, the film, on the one hand, extends our comprehension of the necessities which rule our lives; on the other it manages to assure us of an immense and unexpected field of action ... The enlargement of a snapshot does not simply render more precise what in any case was visible, though unclear: it reveals entirely new structural formations of the subject. (229-30)

In this passage Benjamin explores the possibility of close-up and a revelation of detail without, however, considering that they could facilitate a sense of presence and uniqueness. He does not make the connection between the "auratic" experience that a traditional painting would have offered and the new kind of encounter that only a camera makes possible. And while he did acknowledge that the tasks of art forms, which are formulated within a body of work, are often only realized much later and within a new art form, he did not apply this to the presence of a painting and the presence that is invoked through the medium of photography or film. "I see this unreal thing exactly" is a quote from Epstein, which Rachel Moore brings into the debate to highlight the kind of experience that the new art forms facilitate. She argues that it is precisely this gap between the real and the representation which fuels the desire of the spectator (86).

We have therefore a history in which, initially, the technologies of reproduction displaced the unique art object in order to replace it with the logic of the copy prevalent in mass culture, and where, later on, the same technologies re-affirm the possibility of a continuity of the traditional values of presence and originality. In difference to most readings of Benjamin's essay, Iversen proposes that a wholehearted endorsement of a liquidation of a tradition may in any case be a misreading of Benjamin and that he did not actually dismiss our desire for the unique, or what he calls the auratic experience. This suggests a far more ambivalent situation, and Iverson proposes that the current "post-modern condition" might consist precisely of this ambivalence between a celebration of the copy on one hand and a desire for an auratic mode of experience on the other. Describing the same kind of ambivalence, Rachel Moore writes: "The pleasure of the spectator resides not in the pure fantasy 
of illusion but in providing a screen upon which to exercise the 'ebb and flow' between the real and the copy" (87). Moore proposes that the contemporary spectator seeks an art form in which the real and the reproduction coexist to allow for a flow between different modes of engagement.

It might be useful to position screendance within this paradox, as an art form that is rooted in technological reproduction and whose makers can both pursue this logic and seek to explore the unique and irreplaceable. Without an opposition between a notion of originality and the copy, a strict notion of disinterestedness on the part of the artist also appears redundant, and a more fluid concept of authorship seems more appropriate. I agree with Iverson in that there is "a need to complicate the tradition of disinterestedness and the displacement or effacement of subjectivity implied by the reiteration of the readymade."16 A complication would makes sense with regards to the relation between the copy and the unique presence within screendance practices and invite further reflection on the role of the body on screen as well as on spectatorship. As always bodies complicate the issues as they blur the boundaries between the author and the product, contributing as individuals whilst also being part of the "work." In this sense screendance may be able to offer exactly the kind of complication that Iverson calls for in order to advance debates on appropriation and authorship.

\section{Notes}

1. Dika, Vera. Recycled Culture in Contemporary Art and Film. Cambridge: Cambridge University Press 2003. Print.

2. Benjamin, Walter. "The Work of Art in the Age of Mechanical Reproduction." Illuminations. London: Pimlico, 1999. 211-244. Print.

3. Hinton, David and Rosemary Lee. Snow. London: Arts Council/ BBC 2003. Web. 25 March 2010. <http://empac.rpi.edu/events/2006/dancemovies3.html>.

4. Iversen, Margaret. "Resistance to Replication." Tate Papers Autumn 07, Issue 8. London: Tate Modern. Web. 25 March 2010.

5. Owens, Craig. "The Allegorical Impulse: Towards a Theory of Postmodernism, Part 2." Beyond Recognition, Representation, Power, and Culture. Berkeley: University of California Press. 1992. Print.

6. See Owens, Craig. Beyond Recognition, Representation, Power, and Culture. Berkeley: University of California Press, 1992. 122-139. Print.

7. Benjamin, Walter. "The Origin of German Tragic Drama," quoted in Owens 43.

8. Owens, Craig. "The Allegorical Impulse: Towards a Theory of Postmodernism." Beyond Recognition, representation, Power, and Culture. Berkeley, Los Angeles: University of California Press, 1992. Print.

9. Siegel, Jeanne. "After Sherrie Levine: An Interview with Sherrie Levine." ARTS Magazine, (Summer 1985). Web. 23 March 2010.

10. Eklund, Douglas. "The Picture Generation." New York: The Metropolitan Museum of Art, 2009. Web. 25 March 2010.

11. Velthoven, Willem. "Birnbaum interviewed by Willem Velthoven." Talking Back to the Media Festival. Mediamatic Magazine 1.1. Web. 7 March 2010.

12. Seremetakis, Nadia C. "Memory of the senses, Part I: Marks of the Transitory." Ed. N. Seremetakis. The Sense Still: Perception and memory as material culture in modernity. Chicago: University of Chicago Press, 1994. Print.

13. Iversen, Margaret. "Readymade, Found Object, Photograph." Art Journal 63.2 (Summer 2004): 57. Web. 7 March 2010.

14. Moore, Rachel O. Savage Theory, Cinema as Modern Magic. Durham: Duke University Press 2000. Print.

15. Benjamin, "Work of Art," 214.

16. Ibid., online. 


\title{
The Spectacle of Difference: Dance and Disability on Screen
}

\author{
Sarah Whatley
}

$\mathrm{T}$

he way in which disabled dancers appear in performance and are represented through performance has been the subject of discussion for a number of writers in recent years. 'These writings have drawn attention to how disabled performers challenge dominant views of disability as variously standing for less than, as other, as diminished, and as equated with loss. These writings, though relatively few in number, have been important for those working within the professional dance community. They have also stimulated further thought about how audiences view and form judgments about disability in performance and how disability presents useful challenges to the prevailing dance aesthetic. But, much of the existing writing is confined to addressing and critiquing the live performance event, whereas the focus for this essay is dance and disability on screen, which might raise different questions about how the viewer encounters and experiences disability, about the communion between viewer and screen and which also gives rise to a spectacular event: the spectacle of difference.

I am aware that looking at disabled dancers on film might usefully draw on different registers for sense- and meaning-making. As Sandahl and Auslander point out, disability is something one does rather than something one is (10). ${ }^{2}$ For people with disabilities, their experience of being 'out of the ordinary' and 'out of place' means that disability is already a kind of performance for them. By looking towards a broader theoretical framework, I want to explore what impact the framing of the screen has on the identities of those who dance with disabilities, how disabled dancers perform their own identities, and how this is read and interpreted by the viewer. So, my focus is on the screening of disabled dancers within dance films and how readings of disability on screen might generate a theory of looking; might disrupt a presumption of the relationship between screendance and mobility; and therefore make clear the political implications of screendance. In each of the screendance examples I refer to, the body itself is therefore fundamental to my reading and response.

Disability theorists Mitchell and Snyder discuss how the relationship between screen and viewer calls on particular notions of spectatorship. ${ }^{3}$ They interrogate the nexus between spectator and the filmed disabled body as a spectacle by delving into "the psychic structures that give meaning to disability as a constructed social space" (157). I acknowledge that I am not a neutral spectator. By writing from my own embodied, subjective position I accept that I am not writing as a viewer with a disability, ${ }^{4}$ and whilst I do not wish to ignore the viewpoint of audience members with disabilities, it is not the main purpose of this essay to explore what might be seen as a disabled gaze in relation to film. Nonetheless, I wish to distance this study from those projects that might treat disabled bodies as research objects of investigations: a position where "bodies marked as anomalous are offered for consumption as objects of necessary scrutiny-event downright prurient curiosity" (Mitchell and Snyder 157) and which place disabled people under a scientific gaze. 
I raise these points because my intention is to bring attention to how disabled performers contribute to visual literacy in relation to screendance and disrupt viewing strategies, thereby challenging the assumed mastery and domination of nondisabled performers. On one hand, viewers might experience the film as a medium that places distance between them and the disabled performer. In this case, bodily difference is experienced as "exotic spectacle" (Mitchell and Snyder 157). Viewing a film is not like attending a live performance in which the audience is at least in the same physical space as the performer, however remote and distant, and where there is the potential for a 'tactile' communion based on exchange between performer and audience. And yet, the viewer can be drawn into the film for a variety of reasons; film-spectator relations are always complex. Looking at disabled dancers on screen might well seduce the viewer into experiencing a range of bodily sensations that generate new kinds of appreciation.

If so, is this due to the medium itself (the film)? Or the subject matter? What is it that determines a particular mode of viewer engagement?

In an earlier paper, I postulated a range of viewing strategies that emerge from what I termed a presumption of difference when audiences view disabled dance performers. ${ }^{5}$ I argued that the viewer attends to dance that is performed by disabled performers differently; their critical framework is not the same as that which might be applied to a performance by non-disabled dancers. I am now reconsidering that theory in relation to this current project. Although the research that led to those categories was conducted directly with disabled dancers who gave voice to their own experiences, by proposing a categorization of viewing strategies, ${ }^{6}$ I assumed a privileged and non-disabled position for the viewer. I thus inadvertently positioned the disabled performer as other. Whether or not these strategies might be straightforwardly applied to screendance, screen theorist Richard Rushton offers what might appear to be a similar proposition, drawing on Deleuze's theory of spectatorship (1986) to consider the bodily mode of audience engagement with film (2009). ${ }^{7}$ Rushton observes that Deleuze "has no explicit conception of the cinema spectator," (47) and yet, he contends that a theory is implicit in Deleuze's Cinema books (1986, 1989). ${ }^{8}$ Rushton claims that Deleuze's spectator is created by the film and does not pre-exist it; there is no prior 'subject' before comprehending the film. The spectator is fused with the film. There is no spectator who watches/listens; subjects (subjectivities) are formed by the cinema, by the act of experiencing the film. Rushton builds on Deleuze's theory by suggesting that there is an important distinction in the spectator's relationship to any film, which he defines as a process of either absorption or immersion (48-49). Rushton then looks to art historian Michael Fried to propose that the mode of absorption is one in which the spectator is drawn into the film; s/he senses that $s /$ he is there in the film whilst acknowledging that s/he cannot be there. However, in the mode of immersion, the film comes out to the spectator so as to surround and envelop, to enter the viewer's own body (Rushton 51). Each of these modes provides the viewer with a different (bodily) engagement with the film.

Rushton's views, though not applied to any particular film genre, challenge the notion of there being two separate forces at play in watching dance on film: the film and the viewer. If they effectively meld together through the viewing-becoming a singular experience with neither existing independently of the other-then a taxonomy of viewing strategies, which exists prior to and independent of the viewer and the work, cannot be possible. It 
is in this respect that the series of viewing strategies I set out in relation to disabled dance in performance diverges from that proposed by Rushton. Nonetheless, I view these same viewing strategies as a provocation intended to call attention to the potentially destructive and unhelpful ways in which disabled performers are categorized, in order to prompt thought about spectator/performance relationships, which then can influence interactions beyond dance in wider society.

It may be that, in the case of screendance featuring disabled performers, the viewer is neither absorbed nor immersed in quite the way described by Rushton. Rather than the spectator being taken into the film or the film taking over the viewer, the spectator 'meets' the film in a complex space that allows for a shared somatic, kinaesthetic, intercorporeal, intersubjective, and visceral involvement, which invites the viewer to identify with the dancing human subject/s. But, depending on the bodily mode of engagement of the viewer, this identification might reinforce a notion of human difference, thereby allowing the viewer to "witness spectacles of bodily difference without fear of recrimination by the object of this gaze" (Mitchell and Snyder 157). Dancers with disabilities therefore have good reason to feel anxious about how their work is seen and evaluated in its own terms, prompting them to foreground their own experience of disability and their marginalization within an art form that has traditionally fixed the gaze on the sleek, perfect, flawless dancing body and which too often conforms to conventional notions of beauty. Often very aware of the politics of representation and their own agency (or lack of) in how they are portrayed and interpreted in performance, dancers with disabilities frequently contribute to the discourse of 'difference,' performing their own identity, making work about their own experience of disability. Disability becomes subject matter as well as material content.

There are relatively few dance films, readily available, that feature disabled dance artists. It may be that whilst there are many disabled dancers, they tend not to be regarded as professional artists unless they are members of the few established companies described as either disabled or 'integrated' - those where disabled and nondisabled dancers perform together. ${ }^{9}$ The filmed records of these companies show the scale of the incursion of disabled dancers into the mainstream (Smith 81). But labeling the company's work as 'integrated' poses another potential dichotomy. Already, the dance and therefore the experience of the audience are likely colored by an expectation of bringing together two different components or categories of 'normal' and 'other.' When applied to disabled people this can, according to Campbell,"suggest their categorization as sub-human, giving definition to their non disabled 'counterparts' $(27) .{ }^{10}$

Similarly, using the definition of 'screendance' offered by South East Dance as "dance made specifically for the camera, for presentation as a single screen film or video," it is worth noting that there are very few disabled dance and screendance makers: ${ }^{11}$ disabled dancers tend to be performers but less often choreographers or dance directors. ${ }^{12}$ Disability tends to be in front of the camera rather than behind the camera unless, as in the case of Laura Jones's Re: Bound (2008), she is in both roles. ${ }^{13}$ In Jones's film, disability is performative; her disability is both subject and subject matter. Jones self-directs a short self-portrait-in-film of her experience as a dancer who uses a wheelchair. Her close study of her relationship to space and time is sensitively worked into an intimate film. The camera plays with varying perspectives: sometimes filming from above, from below, and from all sides; sometimes with the dancer in full frame; and often close to the moving body, focusing on skin, muscle, 
breath, and the play between the textures of the dancer in her chair, which is set against the textured walls and floor of the studio setting. With a soundtrack of unaccompanied piano, the film is an exploration of a body that finds articulation within physical limitationsJones has full mobility in her arms and upper body but her legs are immobile-expressed clearly in the formulation of the title Re:Bound. These limitations are emphasized in the compositional journey she makes, beginning with small, detailed, rippling hand and arm movements through to spinning herself around in her chair. The camera follows her increasing speed, capturing only fragments of the dancer and her chair, blurred and indistinct, until she comes to almost stillness, performing 'near-exhaustion,'to remind the viewer that manipulating her wheelchair is hard work and requires stamina. She regains her breath and begins again. This cyclical structure tells us something of her efforts, her sense of her own corporeality, and her desire to find a medium; in this case film, which will allow her to find an expression to break through her physical boundaries.

To briefly return to Mitchell and Snyder's observation about the "exotic spectacle," distance between the disabled performer and non-disabled viewer may generate a different kind of viewing experience, determined by the viewer's perception of how far the disabled dancer appears to bridge the distance or overcomes disability in performance (157). By contrast, when a performer has become disabled through accident or illness, the experience of disability is often played out in the dancer's own performance. In Re:Bound, intimacy with the dancer through close camera work might reduce the distance between performer and spectator, but Jones seems to perform a 'longing' in her dance, implying a distance between her physical reality and that which she desires to be. The grace and fluidity of her upper body juxtaposes the immobility of her lower body. And yet the film's close attention on Jones' wheelchair as extension of her body, as much as tool to facilitate movement, softens the binary between ability and disability, diverting thought away from what might have been, or once was.

Some of the film records of professional disabled/integrated companies appear on YouTube and are documentary in style or serve as promotional material-some include short excerpts of works interspersed with commentary and touring information. The discourse of these documentary films seems intent on stimulating an emotional response. Frequent use of terms such as "tragic," "affliction," "confined," and "courageous" give shape to the commentary or text-line. Many portray the disabled body as filmic spectacle, focusing on gymnastic display despite disability, or on the dancer's ability to overcome the limitations of disability. Many of the comments posted by viewers confirm the spectatorial pleasure derived from these viewings.

More compelling are those videos that include the voices of those who dance. Catherine Long, a disabled dancer in the US-based Gimp project (which as a title deliberately foregrounds the offensive language that disabled people have to contend with) performs in Collision and talks about how performing enables her to take control. ${ }^{14}$ Whereas in the street, people will look at her, an event that she cannot control, in the theatre she is intentionally directing the viewer to look at her-something that is clearly empowering for her. This privileging of the disabled dancer's voice not only draws deliberate attention to the politics of disability but also explicitly foregrounds a cultural perspective informed by and within the phenomenology of bodily difference. Referring to phenomenology in this context draws attention not only to the capture of disability perspectives on film but also 
to the meaningful influence of disability upon one's own subjectivity and upon cinematic technique itself (Mitchell and Snyder 170).

The status of the disabled performer/choreographer means that there is perhaps little distinction between the disabled artist's experience of the live and the screen. When disabled dancers are involved, the distinction that Kappenberg makes between "body as tool" and "body as site" in screendance, is blurred if not removed altogether (96). ${ }^{15}$ The body is unavoidably a tool for inscribing a particular (and individual) experience of embodiment whilst also a site for the exploration of limitations and possibilities in a generic sense. Thus the individual body inadvertently stands for a collective body; a body as site for contemplation of a universally coded condition of disability. And yet the film of Catherine Long, as well as the film choices made by Laura Jones, brings attention back to the individual artist because of their control of how they are represented on film and in performance. Each dancer finds ways to control the viewer's gaze in order to speak beyond the visual text of her disability. Long uses the film medium to reinforce the control she experiences when performing in a live setting whereas Jones takes control through her editing choices. By controlling the filmic apparatus and the medium of their representation, they direct and perform their own individual bodily reality.

Other screendance films provide different representations of disability or represent the disabled performer differently because s/he is not in control of the film process in the same way; control lies with another. David Toole, a disabled, British, dance artist performs in The Cost of Living (2004) ${ }^{16}$ conceived and directed by Lloyd Newson, based on his earlier stage production. ${ }^{17}$ The film runs for thirty-five minutes and tells a story of two men who are street performers in an end-of-season English seaside resort. The locations are various and shift between urban, rural, domestic, and public sites. The narrative develops around the men's relationship, their encounters with others, their attempts to attract women, their vulnerabilities and insecurities, as well as their tactics for survival.

The film introduces several characters that display idiosyncratic behaviors, drawing attention to the way in which society's prejudices too easily position people as deviant or as outcasts. In this context, disability might be read as simply one more deviance. Dialogue traces the dynamics between the two central characters: Eddie and David. These are their real names; Eddie Kay and David Toole. Eddie has a tough, aggressive. and confrontational demeanor. He is not afraid to speak his mind. David speaks more through his movement and how he moves - or more specifically, how he either moves himself (propelled, supported, and animated through this arms) or is moved by others (carried, supported, lifted, or steered when in his wheelchair). David has no legs; his body ends at his torso/hips. ${ }^{18}$ Toole's physicality is very much a reality; there is no film trickery, implying that through the film, he performs his own narrative, his own authentic autobiography. The film as narrative thus blurs the boundary between fiction and reality, supported by the play between and juxtaposition of "real" and constructed locations. Although Toole is the only performer with an overt physical disability in the film, his extreme physicality and difference is less pronounced within a film that is concerned with excess and extremes of behavior amongst the other characters. The power of the film is located in bodies and bodily sensation that might be characterized as excessive (Mitchell and Snyder 139).

Paradoxically, several filmic and/or staging devices also effectively erase or diminish the reality of Toole's disability (he often appears behind open windows, seen only "from the 
waist upwards"). Then, when he comes into full view, the other players exhibit a matterof-fact attitude. The viewer is encouraged to see David's disability as just another bodily possibility. But at all times, he controls his own mobility, whether he moves independently or is lifted, carried, or pushed in his wheelchair by others in a functional, practical way. In a wheelchair, David is no longer a body without legs but a body seated, differently mobile but now subject to the many presumptions and preconceptions afforded to all those categorized as 'wheelchair users.'19

Despite the radical approach to "normalizing" disability within the context of the narrative, the radical and even shocking nature of David's disability points to the central motif and theme of the film. In one scene, David's own subjectivity is foreground. David is "sitting" on the bar, apparently "chatting up" the viewer or an imagined, invisible, other. We witness him confronting our own embarrassment and discomfort: "would you like to dance? Don't be embarrassed ... all of me or maybe just my arms ... can't be my legs ... I bet you're wondering what it's like... Well, I'll tell you ... It's small but it's peachy ... I saw you looking ... so would you like to dance? I'll be looking for you." In exposing the questions we might not dare to ask, he refuses to be emasculated by his disability, challenging how we might categorize him as asexual, freak, spectacle. In the same way that Catherine Long tells us on camera about her sense of being empowered when on stage, this reversal of power is turned into theatrical device as David takes control. Any discomfort he may experience at being looked at is turned back on the viewer who is made more uncomfortable by his direct questioning. Moreover, in this more intimate encounter, he confronts his own sexuality and dares the viewer to regard him as sex object.

The same device returns in a later scene, but this time the viewer is "twice removed"; the single lens of the camera is replaced by a double lens. This time the questions are not directed toward the viewer. David is subjected to an aggressive form of questioning by the cameraman, who with hand-held camera overshadows David, intrusively filming close-ups, and asking uncomfortable, personal questions. David is surrounded, pursued, interrogated, and seen close-up through the lens of the camera. He asks without wanting a reply "what happened to your legs, I want to know ... Have you ever been in a fight? If you hit me first it's OK if I hit you back isn't it because you're a man? Do you trust me? ... Because I don't trust you." As witness, the viewer is made uncomfortable, unable to intervene, and reminded of society's participation in the treatment of disabled people; how disabled people are stripped of their control, their dignity, their identity. And yet David is quickly back in control, heroic, undeterred by his encounter, leading the group into a fast moving, ensemble, group dance. Advancing like a military force, the dancers move together in a show of strength and solidarity, as a metaphor for the battleground that typifies David's day-to-day experience as a disabled man.

One scene within the work is posted on YouTube and has attracted many viewings and comments (one even asking if David's disability is camera trickery). The scene begins with the camera at ground level, filming close-up on ballet dancers'feet and legs within a dance studio setting as they move through barre exercises. It cuts to Eddie and David who look in from outside, seemingly unnoticed by the female dancers. ${ }^{20}$ David then enters the studio, unacknowledged, until he meets one dancer and they move together through a fluid duet. They begin a duet, in full camera frame, built around close contact and exchanges of weight, counterpull, counter balances, and seamless lifts. 
Conventional in form, the pas de deux upholds traditional dance values in its structure: combining strength, control, athleticism, and smooth, effortless performance. This spectacle of dancerly inventiveness (particularly due to David's very different physicality) is confused by the lack of attention given to the duet by the other dancers in the space. Do they choose to ignore the dance because it is unimaginable, distasteful — or is it, after all, just ordinary? Or is the duet actually a fiction, a fantasy shared by the two dancers? Ferris points out that "disability obscures the blurry lines that separate fiction and art from real life. Is disability 'fictional', or is it 'real'?" (56). ${ }^{21}$ In many ways, The Cost of Living continually blurs the line between fiction and reality and none more so than here, with the framing of the duet within a setting (the ballet class) that traditionally prepares the dancer for the fictionalized world of the theatrical performance event. So Newson's ironic divertissement plays on the conventions of the ballet.22 The duet challenges the dominant aesthetic of dance by appropriating the classical form and the duet device. By deliberately foregrounding and bringing together two extremes, two excesses, embodied by the classical ballet body and the disabled body, Newson forces the viewer to confront perfection and imperfection, those who cannot pretend and those who do not fit in.

The duet also takes time out from the narrative to further play with presumptions of what David can and cannot do. By positioning it within a context of "not noticing," the invasive gaze of the viewer, which marked the previous scenes, is neutralized. And yet, the camera gets close-up, offering the viewer a "private dance," an intimate encounter with disability to permit a form of communion with the dancers. The viewer is permitted to get close to a disabled body, a body more often concealed from public view, without fear of recrimination for looking, for staring. Mitchell and Snyder propose that this exacts a double marginality: "disability extracts one from participation while also turning that palpable absence into the terms of one's exoticism" (158; italics in original). Looking back to Catherine Long's comment, the theatre is a space where she feels empowered by having some control over the audience gaze. By placing her dancing alongside her comments on film, the viewer is both able to exercise curiosity by viewing bodily difference whilst at the same time hearing how she exercised her own agency within the performance.

The duet operates in different ways. Set within the context of the whole film, the duet provides a brief escape from the harsher reality of life beyond the relative safety of the studio. David's disability is not masked, neither is it compromised or exploited. It is not that he overcomes his disability, but rather he is allowed to challenge his own capability, demonstrating how he can dance on equal terms with his partner; much of the movement material seems to be sourced from his own body. Unlike disabled people who are made child-like in their frequent dependence on others, David asserts his autonomy through playing an equal part in the duet. Although David might be seen to be negotiating a selfimage with respect to a normative formula, in this case the well-established formula of the male/female duet, his dance leaves a "permanent mark upon 'normative' modes of embodiment" by shifting thought about what a male/female duet should be; because it is on film, as a "permanent record" and widely viewed (on YouTube), the duet becomes emblematic of what disability can stand for in dance (Mitchell and Snyder 169).

Campbell observes that at first, the scene "evokes pity for Toole, who seems too long to join the able bodied dancers, before surprising the viewer with the grace of his subsequent deeds" (28). But in her critique of this scene, she does point out that it can promote 
a patronizing image in which David is "watched as a heroic disabled dancer" (Campbell 28). She adds that such portrayals are unhelpful, "seeing the dancer is replaced by seeing the disability, and means that it lessens the importance of his artistic contribution deeds" (28). In the context of the film as a whole, David may well be viewed as heroic, but perhaps Newson invites this reading, forcing the viewer to confront the reality of the disabled hero by leaving David alone again at the end of the duet before he departs, unseen again by those around him.

The Cost of Living is rich with imagery, and although Toole is the only disabled performer in the film, it avoids a tokenistic approach to disability. We are left with many images of how David confronts, subverts, exploits, and overcomes his disability, both to further the narrative and to challenge the conventions of dance. Ultimately, Toole's agency within the film is somewhat ambiguous precisely because it blurs the line between fiction and reality. His motivation to perform may be motivated more by his desire to be recognized as fully human, to remedy the lack which he embodies, as a desire to take control of his own representation on film.

A quite different exploration of dance and disability is explored in StopGap's short dance film Chris \& Lucy (2008). ${ }^{23}$ Unlike The Cost of Living, the choreography is credited separately from the film direction, implying a separation between those who made the dance and those who are behind the camera and made the film. This two-stage collaborative process implies a fracturing between the "screen" and the "dance." But Chris and Lucy are again the names of the two performers in the film (Lucy Bennett and Chris Pavia), once more collapsing the distinction between the role and performer, and reflecting a wider trend in dance in the last decade towards personal narratives as subject matter. As before, the dancers might be seen to be performing their own individual stories. Another link is the seaside location, but there is no extended narrative structure. Whilst the work is clearly site-based, it does not attempt to develop a more developed relationship with or response to the site. Chris \& Lucy is a duet for a learning disabled man (Chris has Down's syndrome) and a nondisabled woman, and therefore might be seen to be "a creative collaboration that permits the full expression of individual subjectivity and experience for all involved" (Perring 177). ${ }^{24}$

The film begins with the dancers meeting and walking together to the beach with natural sounds as a backdrop. They appear to be alone. We see them facing out to sea with their backs to the camera. As they begin to dance, the camera moves around them, close up to their dancing, participating in their tactile exchange before moving further away, now looking from the outside in. As in the male/female duet in The Cost of Living, the duet follows a conventional dance duet format although it extends for a considerably longer period of time (approximately nine minutes). The two dancers move through a sequence emphasizing contact, sharing of weight, lifts, balances, and gesture. Their touch is functional yet suggests a caring and careful relationship. Chris tends to carry Lucy more, and Lucy carries her shoes. ${ }^{25}$ Each dancer has a short section in which they dance alone, momentarily isolated and separated — but the other is close by. There are brief moments of humor, but it begins and ends in a more melancholy mood. The close proximity of the two dancers focuses attention on the importance of the tactile sense in motivating movement; however, on screen the physical exchange between mover and watcher is absent. Moreover, the camera tends towards framing the dance as a theatrical event, reproducing 
the distance created between performers and viewers in a live, staged performance and detracts from what might have been an intensive communion between viewer and film if the camera stayed closer to the dancers' bodies. However, despite the public setting of a beach, the camera appears to be the only witness to their dance. Though simply constructed, the dancers seem to be liberated in this "natural" environment, away from the fear of the judgment of onlookers.

The separation from the reality of human relationships and encounters in Chris \& Lucy is a sharp contrast to the social world created in The Cost of Living. The simplicity and "naturalness" implied by the duet might be seen to play down the exoticism of this pairing between a learning disabled man and nondisabled woman. The freedom they find in their dance together suggests friendship, mutual support, and shared responsibility. But, because of the emphasis on equality as theme and Chris's apparent ability to overcome his disability to perform on equal terms with a nondisabled partner, difference (or more precisely its attempt to minimize difference) becomes subject matter. As an integrated performance, it tends to highlight the problem described by Campbell, who asks whether the pairing of disabled with nondisabled dancers projects an image of the disabled performer as a separate component that echoes the traditional dance partnership of female reflecting male (27). In this case, the male/female roles are reversed; Chris reflects Lucy and in doing so, the power relationship is inverted but separation and difference remain.

In looking closely at these two duets, in each case performed by a disabled male and a nondisabled female, I am interested in the extent to which these pairings disrupt normative gender ideologies. Dance as a discipline/practice is often plagued with preconceptions of the male dancer as homosexual. When the male dancer is a disabled dancer, might there be a different reading? Does disability signal that that sex is "off limits?" Manderson and Peake argue that "[s]ince masculinity is defined as able-bodied and active, the disabled man is an oxymoron" (233). ${ }^{26}$ In Chris \& Lucy, Chris is portrayed as gentle, easily supported, and led by Lucy, comfortable in his tall but soft body. Chris's masculinity and therefore gender difference are downplayed in the neutrality of their dress, in the sharing of movement material, and in the more protective and maternal role, played by Lucy. The partnership functions inter-textually in a quite different way in the duet in The Cost of Living. Newson explores issues of masculinity and femininity, partly through the narrative and partly through the way in which contradiction is embodied within the individual dancer. Toole's overt masculine physicality or "hypermasculinity" is expressed through his shaved head, and muscular upper body and arms but is abruptly contradicted by the absence of his lower body. He performs with agility and athleticism juxtaposed with softer and more extended movement. He deliberately plays with others' expectations of his own masculinity and he appears to enjoy exposing the ruse of Eddie's masculinity. He also confronts expectations of a disabled man's withdrawal from sex by deliberately raising the possibility through his speech in the film (Manderson and Peake 237). He seems to gain a newfound bodily agency and sociality in his performance of masculinity and sexuality (Manderson and Peake 237). In short, how gender is played out in the disabled body of David is important in how we read the representation of disability in the film.

My aim in this essay has been to explore how these dance films participate in the debate about difference and disability. Each work provides a different glimpse into how disabled people deal with being-in-the-world (Merleau-Ponty). ${ }^{27}$ I have variously argued 
that each accentuates or erases disability in different ways by using different filmic and choreographic devices. What is of particular interest in the context of this essay is the extent to which the medium of film participates in the representation of disability, either by providing the promise of generating interest in bodily difference as an exotic spectacle or by diminishing the distance and therefore the difference between viewer and disabled dancer (Mitchell and Snyder 157). At times, the camera brings the spectator closer to the reality of disability. Touch between dancers is captured and emphasized through the close proximity of the camera, reorienting the viewer's senses away from the visual to the tactile sense. The physical presence of the camera might be emphasized or conversely, the camera adopts a disembodied eye, as in classical cinema (Kuppers 157). ${ }^{28}$

The duets selected for detailed analysis tend to reinforce the dualisms and binaries that operate more widely within the frame of dance and disability: able/disabled, controlled/in control, passive/aggressive, and so on. A condition of "otherness" associated with disabled people tends to be emphasized by pairing disabled with nondisabled dancers. When the disability is marked as in the case of David Toole, this is probably unavoidable. And yet performance can demonstrate that disability can be beautiful, which helps to remove the automatic equation of disability with loss. As Campbell points out (with reference to Toole's performance in The Cost of Living):

Used in the appropriate context, Toole's graceful and unique style is a rejoinder that his physique permits him to dance in a way that the non-disabled can admire but not replicate: appreciation (and even envy) are likely to supersede sympathy. (29)

Importantly, the communion between viewer and performer when the dance is on film gives rise to a mode of visual consumption that finds room for different gazes. Viewers come to see disabled dancers through various filmed events and therefore different lenses. YouTube can be a powerful tool for providing viewers access to a range of video content. Mitchell and Snyder argue that a "complex space exists between images and their spectatorial reception by audience members" (158). But when viewed as a collective body of film content featuring disabled performers, and which is the principal vehicle for consumption by the viewer who comes to dance via the screen, a sense of separation or otherness is often reinforced, thus underlining a particular relationship between subject and viewer and that gives rise to a spectacle of difference.

\section{Notes}

1. See for example:

Albright, Ann Cooper. "Strategic Abilities: Negotiation the Disabled Body in Dance." Moving History/Dance Cultures: A Dance History Reader. Ed. A. Dils and A.C. Albright. Hanover, CT: Wesleyan UP, 2001. 56-66. Print.

—. Choreographing Difference: The Body and Identity in Contemporary Dance. Hanover, CT: Wesleyan UP, 1997. Print.

Benjamin, Adam. Making an Entrance: Theory and Practice for Disabled and Non-disabled Dancers. London: Routledge, 2002. Print.

Kuppers, Petra. Disability and Contemporary Performance: Bodies on Edge. London: Routledge, 2003. Print. - Sirens: Performance Technology, Community Dance and Disability Embodiment. Tallahassee, FL: Congress on Research in Dance, 2005. Print.

—. "Bodies, Hysteria, Pain: Staging the Invisible." Sandahl and Auslander, 147-62. Print.

Carrie Sandahl and Philip Auslander, eds. Bodies in Commotion: Disability and Performance. Ann Arbor: $U$ of Michigan P, 2005. Print.

Smith, Owen. "Shifting Apollo's Frame - Challenging the Body Aesthetic in Theater Dance." Sandahl and Auslander, 73-85. Print. 
Whatley, Sarah. "Dance and Disability: The Dancer, the Viewer and the Presumption of Difference." Research in Dance Education 8.1 (2007): 5-25. Print.

2. See note 1 .

3. Mitchell, David and Sharon Snyder. Cultural Locations of Disability. Chicago: U of Chicago Press, 2006. Print.

4. I acknowledge that it might be possible to see everyone as disabled and all of us probably have some disability, whether seen or "unseen" but at time of writing, I don't regard myself as having a disability.

5. See Note 1.

6. I proposed a series of five viewing positions as a means to determine the extent to which each either upholds or challenges conceptions of what dance is and what bodies are supposed to do in dance. I developed some of this thinking in a later publication. See: Whatley, Sarah. Moving Matters: Supporting Disabled Dance Students in HE. Coventry: CeMAP/Palatine, 2008. Print. Mitchell and Snyder consider critical modes of spectatorship in relation to disability documentary cinema, identifying some significant viewing relationships, but similarly state that they do not intend to imply that these are the only viewing positions available (158).

7. Deleuze, Giles. Cinema 1: The Movement-Image. Trans. Hugh Tomlinson and Barbara Habberjam. London: Athlone Press, 1986. Print. Rushton, Richard. “Deleuzian Spectatorship." Screen 50.1 (2009): 45-53. Print.

8. Cinema 1, see above.

—. Cinema 2: The Time-Image. Trans. Hugh Tomlinson and Barbara Habberjam. London: Athlone Press, 1989. Print.

9. Companies describe themselves in various ways: disabled, integrated, inclusive etc. In the UK there are a range of companies that include physically and learning-disabled dancers, including CandoCo Dance Company, Blue Eyed Soul Dance Company, Magpie, Anjali Dance Company, and Amici Dance Theatre Company.

10. Campbell, Fiona. "Reconstructing the Image of the Disabled Performer." Animated Spring (2009): n. pag. Web. 17 Mar. 2010

11. "Screendance." South East Dance. South East Dance: National Agency for the South East of England, n.d. Web. 17 Mar. 2010.

12. Notable disabled dance makers and company directors include Celeste Dandeker (co-founder, CandoCo Dance) and Judith Smith (Axis Dance Company). In the UK, there are initiatives to provide development support for disabled choreographers and dance leaders (such as the Transformations artist development program led by Blue Eyed Soul Dance Company) but there remain few established disabled choreographers.

13. Jones, Lucy. "Re:Bound."You Tube, 29 Sep. 2008. Web. 17 Mar. 2010.

14. Long, Catherine. "N.Y./Region: 'Collision' of Dance and Disability." Gimp. You Tube, 18 Mar. 2009. Web. 17 Mar. 2010.

15. Kappenberg, Claudia. "Does Screendance Need to Look like Dance?"International Journal of Performance Arts and Digital Media 5.2,3 (2009): 89-106.

16. Newson, Lloyd. "DV8 Physical Theater - The Cost of Living."You Tube, 29 Jan. 2008. Web. 17 Mar. 2010.

17. Newson is an established dance and performance maker with a long track record in making work for his company, DV8 Physical Theatre, which he named to make clear the emphasis on theatre, subject matter, and its ability to deviate from conventional views of dance. The film was commissioned by Channel 4 Television in the UK and received numerous screendance and screen Festival awards. The Cost of Living marked Newson's debut as a film director (previous dance films were made in collaboration with film directors).

18. Toole is well known in British dance, having established himself through a lengthy career working with several leading companies and building a reputation around his own particular and idiosyncratic movement range. As with other disabled dancers, his decision to perform may be motivated by his desire to be recognized as fully human, to remedy the lack which he embodies.

19. Both Albright (2001) and Briginshaw (2001) discuss the signification of the wheelchair in staged dance performances. Briginshaw is one of a number of commentators writing about disability in relation to dance who looks to Bakhtin's theory of the grotesque to explore the relationship between disability and excess. Briginshaw, Valerie. Dance, Space and Subjectivity. New York: Palgrave, 2001.

20. Different modes of looking; peering, staring, leering, recur throughout the film to remind the viewer of his/her own different modes of looking at screendance.

21. Ferris, Jim. "Aesthetic Distance and the Fiction of Disability." Sandahl and Auslander, 56-68. Print.

22. The divertissement in ballet is a familiar convention for providing a break from the narrative, an interlude or diversion from the main plot line. 
23. StopGap. "Chris and Lucy."You Tube, 29 Mar. 2008. Web. 17 Mar. 2010.

24. Perring, Giles. "The Facilitation of Learning-Disabled Arts: A Cultural Perspective." Sandahl and Auslander, 175-189. Print.

25. Lucy integrates carrying her shoes into the dance, which suggests that they signify both difference and similarity (Lucy having shoes but wanting to remove them to have the same tactile connection with the sand as Chris). Chris wears/carries no shoes. This difference between Lucy and Chris is rather curious and might carry more weight than is intended.

26. Manderson, Lenore and Susan Peake. "Men in Motion: Disability and the Performance of Masculinity." Sandahl and Auslander, 230-242. Print.

27. Merleau-Ponty, Maurice. The Phenomenology of Perception. Trans. Colin Smith. New York: Humanities Press, 1962.

28. Kuppers, Petra. "Bodies, Hysteria, Pain: Staging the Invisible." Sandahl and Auslander, 147-162. Print. 


\title{
Anti-Gravitational Choreographies: Strategies of Mobility in Screendance
}

\author{
Harmony Bench
}

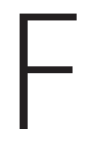

rom the perspective of the digital choreographies I discuss in this essay, twentiethcentury modern and postmodern dance techniques are notable for their shared faith in gravity and weight. From Doris Humphrey's Fall and Recovery, to Joan Skinner's Releasing Technique, and Contact Improvisation developed by Steve Paxton and others, twentieth-century, Euro-American dance techniques cultivate a weight-filled dancing body rooted to or in tensile relation with the ground. This ground, generally configured as a stable field for dancers to push away from, give in to, or move across, is only one option among many in choreographies for the screen, and is often rendered unstable in its appearance. Similarly, weight is treated as more of an aesthetic choice than a physical reality. In screendance, what I am calling anti-gravitational choreographies regard ground and weight with playful suspicion as they replace twentieth-century metaphors of groundedness and rootedness with levitation. Technologically unfixed, anti-gravitational dancers imagine an unpredictable ground over which they hover, glide, suspend, skim, and float; or else they do not imagine a ground at all. Such choreographies thereby give dancers back their lightness but not the gravity-defying escape velocities, for which early modern dancers roundly criticized ballet.

Mediations of dance, from print to film or digital video, offer frequent reformulations of dancing bodies' relationships to gravity and ground. They thus present opportunities for re-examining what cultural assumptions underlie the ways dancing bodies inhabit spacethey make visible what familiarity has rendered invisible in choreographies for the concert stage. In screendance, for example, exaggerated suspensions, interrupted falls, and other perturbations disturb the presumed solidity of the surfaces upon which dancers perform.

In this paper, I consider the anti-gravitational choreography in Richard Lord's interactive dance on CD-ROM, Waterfall (2002), ${ }^{2}$ Liz Aggiss and Billy Cowie's four-screen stereoscopic gallery installation, Men in the Wall (2004), ${ }^{3}$ and Mark Coniglio and Dawn Stoppiello's caffeinated, algorithmically-edited YouTube video, BKLYN (2007). I define anti-gravitational choreographies as the result of a dancer's detachment, excision, or disarticulation from his or her ground, which may be achieved through digital editing or by other means. Antecedents to digital anti-gravity can readily be seen in what Maya Deren describes as the "gravity-free" movements in her film The Very Eye of Night (1952-1959), and in Merce Cunningham's electronic suspensions in the video spaces of Blue Studio: Five Segments (1975), a videodance made in collaboration with filmmaker Charles Atlas. ${ }^{6}$ Even so, I argue that anti-gravitational choreographies, like the more common movement metaphor "flow," represent a particular strategy of mobility commensurate with this era of globalization.

When imagining dance without a ground, choreographers and filmmakers locate dance in an empty geometry that I call no-place. An attempt at creating a "neutral" site for dance, no-place is a void, an evacuated scene. Absent of spatial and political markers and 
relations, no-place is an anonymous, acontextual, blank space, often visualized onscreen as a smooth, empty field of white or a black abyss in which dancers float. For example, in Gina Czarnecki's experimental digital video Nascent (2005), luminous bodies unfurl across a blackened screen.' A dancer hangs from invisible wires, suspended in an endless white in Magali Charrier's Left or Right for Love? (2003). ${ }^{8}$ In Alex Reuben's Line Dance (2003), motioncaptured figures dance to Brazilian music while engulfed in a black that erases both the dancers' geographical as well as physical specificities. ${ }^{9}$ Cari Ann Shim Sham*'s Are You for Real (2006) situates a self-duplicating grey-bodied dancer in an unbounded white space. ${ }^{10}$ David Michalek filmed some 45 dancers at high speed against black backdrops and then decelerated their motion, suspending them in space as well as time in his multi-screen installation Slow Dancing (2007). " Sited in no-place, dancing bodies take on an inhuman mobility. They are unrestricted by physical or ideological boundaries and untroubled by forces such as gravity. Abstracted from built or natural environments that would contextualize their movement, bodies drift across the screen with an illusory freedom.

Of course, the lack of context represented in a screen-based no-place indicates a very specific context in which such abstract spaces may be constructed for dance. No-place is not the apolitical space it imagines itself to be. Elsewhere, I have argued that a colonial logic underwrites no-place and the erasures of topological specificity it substantiates.12 The enduring, flattening, colonial resonances are a crucial aspect of no-place, perennially instantiated in the even surfaces of dance studios, theaters, and screens that are the condition for dancers' unfettered movement in Western dance vocabularies. Nevertheless, I would like to focus in this essay on a secondary operation through which no-place enables dancers to appear in any other locale, here identified as any-place, in addition to the anti-gravitational modes of performance which carry dancers from site to site in Waterfall, Men in the Wall, and BKLYN.

No-place disentangles choreography from the site of performance; it disarticulates dancers from the grounds on which they stand. In dance onscreen, once dissociated from a particular location, dancers access a heightened, media-enabled, anti-gravitational mobility. No-place surreptitiously slides dance into new screenic sites by erasing the specificities of locale. While no-place is visualized in the above examples as monochromatic screenscapes, no-place functions as a pure, transparent spatiality, revealing whatever image lies behind. Unbounded, anti-gravitational dancing images ease themselves into any available site. Their recurring transitions are smoothed by no-place, which sits between locations and renders all potential sites conveniently available. ${ }^{13}$ Dancers extracted from place can exist nowhere and everywhere at once. Radically dis-located, dancers installed in no-place are thus able to move into any-place whatsoever. ${ }^{14}$

Waterfall, Men in the Wall, and BKLYN follow dance's dislocation into very different technologies and viewing conditions, maintaining the abstraction of a transparent no-place while placing topographically-detached bodies in disparate settings. Their focus is not on portraying a dancing body in an empty space, like the films and videos mentioned above, but on superimposing images such that dance can be made to appear anywhere: Waterfall stages modern dance choreography on top of rivers and cresting waves; the performers in Men in the Wall seemingly travel the world in the space of a condensed day; and BKLYN rapidly cycles through a number of shoot locations throughout Brooklyn, New York.

Although their aesthetic, technological, and experiential differences are pronounced, these three works all open geographic sites to dance's aesthetic incursions. As transitory and 
contingent sites, any-places appear receptive to dancing bodies. However, merging dance with new locations does not produce a seamless fusion in any of these pieces. Whether deliberately or inadvertently, Waterfall, Men in the Wall, and BKLYN reveal the tensions that arise when uprooting dance from one place and transposing it into another. They produce anti-gravitational choreographies where dancing image and screened environment interface, calling attention to their disjuncture. In portraying hyper-mobile performers who move freely from place to place, the artists have also choreographed their performers' unmooring, which, I argue, encourages only the most superficial of connections to place. The dancers' uprooting depicts not a multi-locationality of transnational movement, but rather a dubious form of nomadism.

\section{Waterfall}

In Waterfall, dancer Emma Diamond sensuously engages water through various explorations: walking along a grassy and windy beach, feeling water pour through her fingers or drip onto her face, and splashing barefoot in puddles. As a CD-ROM, Waterfall invites computer users to participate in the piece's explorations by clicking anywhere in the window to activate dancing images or new scenes. Their tactile interactions are incorporated into the onscreen worlds, establishing an intimate, if highly-mediated exchange between viewer and work.

One particular section of Waterfall interests me here, where Diamond's luxurious and focused task-like investigations give way to water studies of a different kind. Lord recorded Diamond in what appears to be a dance studio or black box theater and extracted her dancing image, which is projected onto watery environments through which users navigate. Lord has cleverly matched Diamond's movement to each background, suturing them together to encourage an illusory integration of dancer and scene. Diamond snakes backwards over river rapids (see figure 1); rolls in with an ocean tide and washes out with its surf; skips through a cresting wave; and gently glides across an icy glacier. She also walks on a calm lake, dances below an ocean's surface (see figure 2), and alights on tree branches in a rainforest to the accompaniment of chirping monkeys and other jungle sounds.

With his cut-and-paste technique, Lord insinuates dance into places in which "dancing," at least of the sort in which Diamond engages, could not actually occur. Yet, the photographed sites have no identity except as unlikely venues for Diamond's performance. The nameless bodies of water seem to have been chosen for their formal properties rather than geographical significance and thus only signify
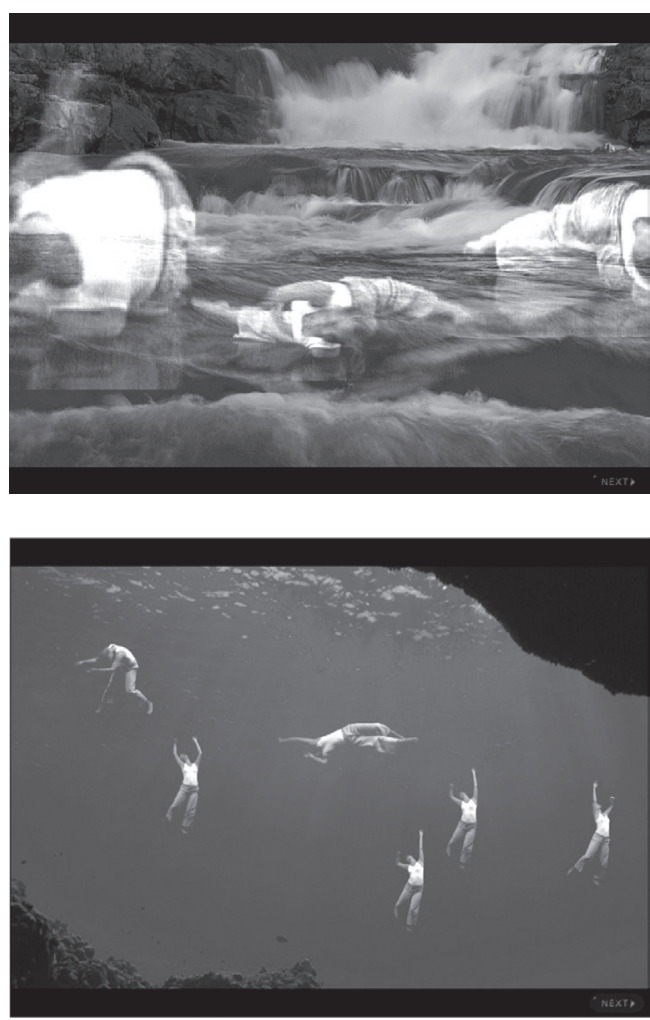

Screen shot. Waterfall. Dir. and chor. Richard Lord. Perf. Emma Diamond. CD-ROM. Prod. Big Room Ventures. 2002. 
generically in Lord's romanticized portrayal of dance and nature. "Arriving" in each new environment, Diamond offers a new choreographic interpretation of the water's movement. While she dances with abandon, however, the oceans, lakes, and rivers behind her remain disturbingly stationary. Confronted with neither the force of moving water, nor that of gravity, Diamond maps the liquid motion onto her body. She does not dance in any of the places represented onscreen, which, in their postcard-like perfection, have already ceased to be places. Rather, she dances in a limpid no-place set atop the various waterscapes.

Even with Lord's careful compositing, Waterfall struggles to maintain a seamless connection between Diamond and each body of water portrayed. This tension is due in part to the uncharacteristic stillness of each site, but it is also a result of the environmental extraction that allows Diamond to appear against each background. Lord aligned his camera angles to those of the photographs, but the water still repels Diamond, refusing to fully integrate her. Though Lord tightly cropped the footage of Diamond's dancing, residues of the black floor on which she originally danced show through. Her reflections in the shiny surface undermine Lord's photographic sleight-of-hand, reminding viewers that Diamond is located not in the watery venues portrayed, but somewhere else, in some other erased space. Ultimately, Diamond sits in no-place, like a cutout on a collage, a dancing image hovering over emptied imaginations of any-place. Lord's hyperdance operates under the assumption that dance and dancers can be imagined independent of context-that dance, existing nowhere in particular, can appear everywhere equally.

\section{Men in the Wall}

Whereas Lord tries to unify dancer and scene within the spectator's visual field, Men in the Wall undermines the continuity that Waterfall simulates. Located "in the wall," the men provide viewers with the convenient architectural metaphor of the window, which brings the outlying landscapes into view but keeps both men and audience separate from them. Having been filmed against a green screen, the men clearly dance in no-place, excised from one performance context and projected into another. Liz Aggiss and Billy Cowie further situate the men in a liminal space, neither inside nor outside, neither here nor there, but in between.

Four men of different nationalities_-or so their caricatured, accented English would seem to indicate-talk, sing, and even dance together over the course of the twenty-fiveminute piece. The men remain in separate frames, one man each to four florescent green and yellow boxes projected across a single wall. Viewed through 3-D glasses provided to spectators, the flat stereo projections merge into vistas imbued with depth. Morning, noon, and night, beautiful and inclement weather, urban cityscapes and tropical paradises; the men in the wall find themselves traveling the world, from one scenic but unidentifiable location to another, without leaving the safety of their technologically-rendered window frames. (See figure 3.) Sitting in the gallery, viewers likewise remain safely enclosed in a white box, peering into nameless, people-less any-places just beyond.

While Waterfall gestures toward the technological merging of Diamond and the environments in which her dancing appeared, Men in the Wall plays with the discontinuity between each man and the image behind him. It does not take long for viewers to realize that Men in the Wall accomplishes more than the vertigo-inducing novelty of stereoscopic dance-media. Perhaps one man's oddly-crumpled pant leg will provide the clue, or 


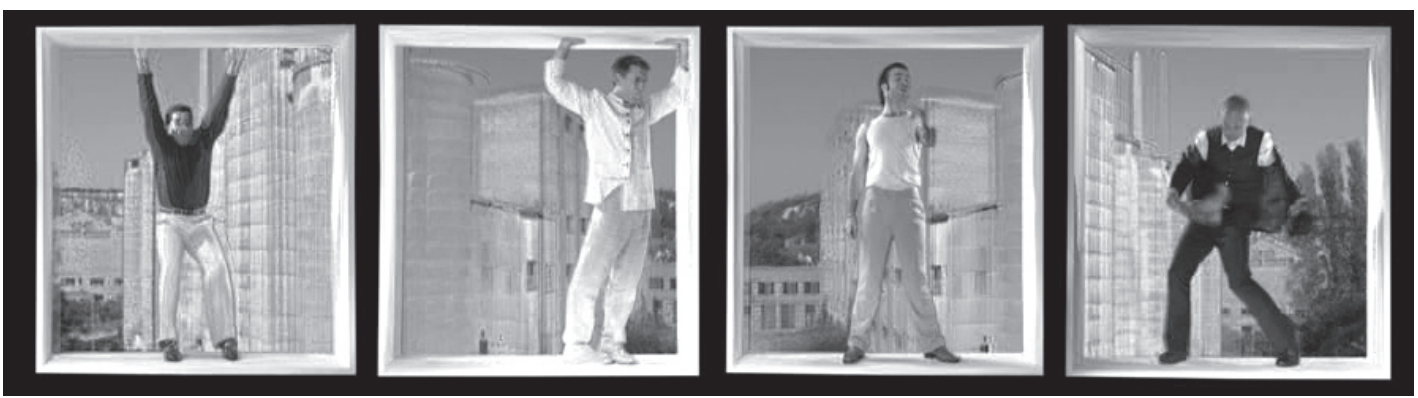

Photograph of multi-screen video installation. Men in the Wall. Dir. And chor. by Liz Aggiss and Billy Cowie. 2003. Photo used with permission.

another's awkward turn, or yet another's less-subtle suspension from the top of his frame. Whatever the telling detail, at some point, viewers will recognize a disconnection between the background images of mountains and buildings and the men in front of them. While the background environments maintain their verticality throughout the piece, presumably corresponding to the verticality of the viewer, the men are disinclined to regard any particular direction as a stable up or down. Aggiss and Cowie have unfixed the performers from standard directionalities, reshaping the relationship of each performer to his ground. They constantly reorient the men along unpredictable horizons, preventing the relative stability of the scenic backdrops from having any grounding effect.

The men forge their own directionalities within the confines of their fluorescent containers, unraveling the magic of their global travels with a heavy dose of irony. The men float across the top and slide down the sides of their boxes. Despite their anti-gravitational dislocation and suspension, the men do not seem disoriented and give no indication that they have lost their bearings. Viewers may try to sort out the directions from which the men were filmed, to realign the men's vertical and horizontal positionings, but they remain defiant. They are not rooted to anything, least of all to the anonymously idyllic views of remote and expensive real estate that remain out of reach for the men perched in the wall. Not that they seem bothered by it; Men in the Wall is not a class critique. Indeed, the performance-oriented men remain mostly frontal, doing little to acknowledge the landscapes beyond. Rather, through the men's detachment, Men in the Wall questions the very possibility of a stable and uniform ground. Aggiss's and Cowie's gravitational challenge extends beyond the projected images to include the viewers, whose spatial orientations and perceptions are also reconfigured. Donning the requisite 3-D glasses, audience members experience the dizzying effects of artificial depth and become sympathetically ungrounded alongside the men onscreen.

\section{BKLYN}

BKLYN likewise overturns the gravitational mandate of modern dance, but dancer Hillary Nanney's release from gravity and place is much more violent than Men in the Wall's gleeful upside-down and sideways performers let on. At most, the men in Aggiss and Cowie's piece look uncomfortable, while in BKLYN, Mark Coniglio's algorithmic editing inflicts technological whiplash on Nanney's body as she epileptically jerks around the screen. Like Waterfall and 

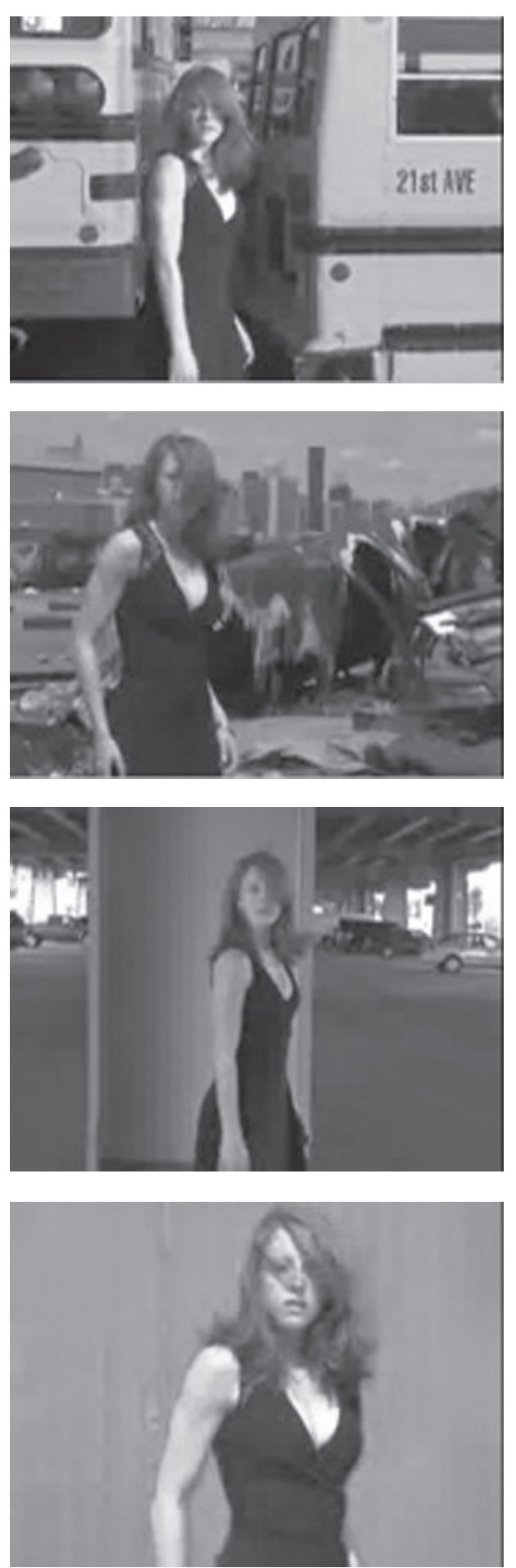

Above figures are screenshots of one sequence of BKLYN. Chor. Dawn Stoppiello. Algorithmic editing Mark Coniglio. Dir. of photography Ruth Sergel. Perf. Hillary Nanney. YouTube. 2007.
Men in the Wall, BKLYN locates dance in multiple sites, here distributed throughout Brooklyn, New York. However, $B K L Y N$ introduces each site at a much faster rate than either Waterfall or Men in the Wall. It begins with few edits but as it progresses, the cuts between locations dramatically increase. Their density gives viewers a sense that Nanney performs her phrase of choreography simultaneously throughout the borough, which can only be shown linearly as a rapid cycling through each of the sites. The editing thus both creates an impression of Nanney's simultaneous performances, and at the same time organizes her ubiquitous presence into a set of sequentialized images. It further tests viewers' capacity to track a phrase of movement across rapid cuts, multiple environments, and fragmented gestures.

The piece never gives viewers smooth or "organic" movement but offers instead a stuttering phrase that persists across the rapid cuts, advancing only after repeating a few frames in each new site. One step backward, two steps forward. Only Nanney's presence onscreen prevents the images from dissolving into a soup of color and light. Even when the choreography dis-integrates into modules of movement without transitional steps, Nanney's coherence and consistent appearance in each frame carries the movement across the densely-spliced piece. Further, the integrity of her dancing image as the only constant against the swiftly changing scenes radically foregrounds her, pulling the choreography out of the shots as the speed of the edits increases. Nanney becomes isolated from the environments in which she dances through the constant juxtaposition between her image and the relentlessly changing backgrounds. (See figures 4-7.) As with Waterfall and Men in the Wall, the sites in BKLYN remain fairly anonymous - a bus yard, a parking structure, a gas station, a sidewalk in front of a red fence, a park, among other places in which Nanney performs Dawn Stopiello's choreography. Shots that might successfully communicate Brooklyn as such-a brownstone-lined street, for example, or a view of Manhattan island, pass too quickly to carry much semiotic weight when not accompanied by other similarly distinctive images.

In the first minute and a half, Nanney skims the surface of each site, riding across the cuts until she pauses for a few counts at a gas station. BKLYN's second 
half further distances Nanney from each site by moving into tighter shots that frame only her upper body. Disarticulated from her ground and distributed across an anonymous, changing landscape, she is no longer geographically instantiated in each of these Brooklynbased sites, but teased out, excised from what are now merely backdrops. As Nanney turns to face the scenes behind her, she mirrors a spectatorial position, and the images seem to hit her body with the same violence and intensity with which they assault our eyes.

Levitating out of the background scenes, Nanney moves from a ubiquitous presence to a singular one, an onscreen duplication of the viewer. But BKLYN's choreographic disarticulation proves more complex than that of Waterfall and Men in the Wall. Nanney's anti-gravitational choreography operates in proportion to the rapidity of cuts between sites and in relation to her framing. As the edits slow or pause, and as the piece returns to full-body shots, Nanney is pulled back into the bus yards, sidewalks, and gas stations. BKLYN makes the relationship between dancer and ground explicitly elastic. Whereas Diamond floats above watery surfaces in Waterfall, and the men hover above rotating grounds in Men in the Wall, in BKYLN, Nanney levitates and then settles. She modulates among possible relationships to the sites in which she performs-now grounded, now gliding, now severed, now re-instantiated, now here, now everywhere.

Nanney's hyper-mobility is marked by a policing of the sites in which she dances, however. Even though the artists have chosen everyday shots rather than iconic images of Brooklyn, they depict a curiously depopulated city. Accustomed to theatrical evacuations of local identities in dance, viewers may not notice the absence of people until an errant man accidentally wanders into the frame. Someone, perhaps Coniglio, can be heard to the side of the camera shouting "Hey!" and the man quickly exists the shooting area upon realizing his intrusion. The shout and the man's astonished and apologetic expression appear repeatedly as the algorithm cycles through its edits. His aberrant presence is a glitch that reveals the assumed emptiness of the sites in which Nanney dances. Through him, a broader Brooklyn-based social landscape momentarily seeps into the any-place constructed for the screen. The artists' inclusion of the clip is an admission of the desire for an empty performance area, a no-place even in a public space. Paradoxically, the clip is also an acknowledgement of the impossibility and perhaps even undesirability of such evacuation. This double maneuver is commensurate with BKLYN's anti-gravitational choreography, which allows Nanney to rush across multiple sites but requires an occasional pause to ground and reorient, and which depicts her dis-instantiation as perilous rather than idyllic.

Waterfall, Men in the Wall, and BKLYN supply a number of sites against which dancing images are projected, none of which provides a "home base" for performers. They do not isolate any particular site as the one that enables continuous relocation from one place to another. That site, I argue, is a transparent no-place, which invites the projection of anonymous and interchangeable backdrops into its emptied milieu. Dancers disarticulated from their grounds hover and suspend indifferently in sites evacuated of context and meaning. These any-places are never specific places with proper names but approximate stock images retaining the anonymity of generality: not this rainforest but a rainforest, not this island but an island, not this gas station but a gas station. It does not matter which; any site will do to frame the dancing images floating therein.

Articulating strategies of mobility alongside globalized imaginings of space, body, and ground, the anti-gravitational choreographies in the pieces I have discussed in this essay 
elaborate upon digital visual media as sites through which twenty-first century bodies access remote or disparate geographies. In so doing, they represent ungrounded, ubiquitous, and transposable dances and dancers. The artists' portrayals of globalized subjectivities do not include disaffected or alienated dancers, however. Rather, the performers are merely indifferent-but without resorting to apathy. Indeed, if read in conjunction with current debates surrounding global warming, Waterfall could be seen as a politically-motivated nostalgia, a protest against deforestation and pollution. BKLYN too could be read as a critique of the ongoing gentrification and suburbanization of Brooklyn. Yet, to one extent or another, each piece depicts a de-differentiation of sites that promotes their serial substitution. Places lose the contours of distinct local identities. They are replaced by any-places over which dancers hover as they perform their anti-gravitational choreographies.

The primary question that these pieces collectively raise for me is thus not how do anti-gravitational choreographies revel in or subvert the technological displacements spurring globalization, but rather, how does the inability to differentiate, or the lack of concern regarding such differentiation, lie at the core of Western dance practices' ability to travel the globe historically as well as currently? In pursuing that question, what movement strategies will emerge in addition to the anti-gravitational choreographies I have described here? What kinds of grounds do they imagine? What are the ethical and political ramifications of their choreographic strategies, the dancing bodies they imagine, and the sites in which they appear? And what roles do media technologies play in visualizing, creating, or commenting upon those bodies, grounds, choreographies, and sites?

\section{Notes}

1. Hillel Schwartz argues that modern dancers reacted against balletic ideals of weightlessness and rediscovered gravity and dynamism. They insisted, Schwartz states, on effort, weight, and torque as forces behind their movements. Their project thus stood in opposition to that of ballet dancers whose "delusions that the law of gravitation does not apply to them" modern dancers disdained. See Schwartz: "Torque: The New Kinaesthetic of the Twentieth Century." Incorporations. Ed. Jonathan Crary and Sanford Kwinter. New York: Zone, 1992. 71-126. Print.

2. Waterfall. Dir. and chor. Richard Lord. Big Room Ventures, 2002. CD-ROM.

3. Men in the Wall. Dir. and chor. Liz Aggiss and Billy Cowie. Perf. Jeddi Bassan, Sebastian Gonzalez, Thomas Kampe, and Scott Smith. 2003. Premiere 23 Feb 2004. ICA, London. 18th Street Arts Center, Santa Monica. 20 June 2007. Installation.

4. BKLYN. Chor. Dawn Stoppiello. Algorithmic editing Mark Coniglio. Dir. of photography Ruth Segel. Perf. Hillary Nanney. YouTube. 2007. Web. 1 Oct 2008.

5. The Very Eye of Night. 1958. Dir. Maya Deren. Mystic Fire, 2002. Film. See also Maya Deren: "Adventures in Creative Film-Making." 1960. Essential Deren: Collected Writings on Film. Ed. Bruce R. McPherson. Kingston, NY: Documentext, 2005. 163-185. Print.

6. "Blue Studio: Five Segments." Merce by Merce by Paik. Dir. and chor. Merce Cunningham and Charles Atlas. Videodance, 1975-76, 1978. Film.

7. Nascent. Dir. Gina Czarnecki. Chor. Garry Stewart. Prod. Forma and Australian Dance Theater, 2005. DVD.

8. Left or Right for Love? Dir. Magali Charrier. Chor. Maria Lloyd. Prod. Amanda Lloyd; Linda Jasper, South East Dance; Caroline Freeman, Lighthouse 2003. DVD.

9. Line Dance. Dir. Alex Reuben. Chor. Afua Awuku and Alex Reuben. Prod. Margaret Williams; Caroline Freeman, MJW Productions 2003. MySpace. Web. 20 Jul 2007. [http://vids. myspace.com/index.cfm?fuseaction=vids.individual\&videolD=2001607725]. 
10. Are You for Real? Dir. Kyle Ruddick and Cari Ann Shim Sham*. Chor. Cari Ann Shim Sham*. Eyestorm, 2006. YouTube. Web. 15 May 2008.

11. Slow Dancing. Dir. David Michalek. Prod. David Michalek and Moving Portrait, Inc. 2007. Installation.

12. For a more detailed explanation of the parallels between colonial expansion and the imagination of a no-place for dance, see my essay: "Media and the No-Place of Dance." Forum Modernes Theater. 23.1 (2008): 37-47. Print.

13. In this regard, no-place is similar to the non-places Marc Augé delineates. See for example: Non-places: Introduction to an Anthropology of Supermodernity. Trans. John Howe. London: Verso, 1995. Print. See also Michel Foucault's discussion of adjacency and convenience, The Order of Things: An Archeology of the Human Sciences. Trans. Richard Howard. New York: Vintage Books, 1973. Print. And Giorgio Agamben's short meditation on ease and substitution in The Coming Community. Trans. Michael Hardt. Minneapolis: U of Minnesota P, 1993. Print.

14. The phrase "any-place whatsoever" should not be confused with the Deleuzian concept of an any-space-whatever, which is specific to his analysis of post-war film. Instead, it should be read alongside Agamben's notion of "whatever singularities." As "whatever" places, any-places are in-different and non-specific, neither universal nor particular, but of a type. 



\title{
Excavating Genres
}

\author{
Douglas Rosenberg
}

$A^{s}$ s screendance in its institutionalized form-and more specifically in its nascent academic form-becomes historicized, and as that knowledge subsequently informs the practice, the field benefits from theoretical disruptions that question and disturb the received knowledge, replacing or augmenting it with alternative modes of inquiry. In this instance it is my goal to put forth ideas that counter the narrative of screendance as monolithic and without distinction as to genres, medium specificity, or identifiable differences that flow from formal or substantive approaches and concerns. By examining screendance alongside the structure of other art forms, I intend to suggest that the discourse around screendance would be made stronger by excavating and identifying its generic sources, which would in turn push screendance into a broader and more vital interdisciplinary dialog.

Screendance is a diasporic culture, one that constantly migrates through host cultures and assumes various vernacular elements, while often struggling to maintain both its empirical elements and the identity of its "cultures of origin." At the core of this dynamic is the fact that the techniques of representing images on screen also flow from preexisting genres, and so have material specificity that is readable as well. Both dance's and media's contingent origins thus conspire to create meaning that emerges from the cumulative effect of their grafting: traversing both temporal and physical geographies, dance and media absorb something of the landscape and culture of each, thereby generating communities of practice that share both common languages and stylistic elements. These "imagined communities"1 exist across international borders and are linked via a diasporic family tree that may be read through the cultural objects they create. It seems accurate to claim, finally, that if both disciplines that make up the whole of a screendance have traceable affiliations with genres, then we should also be able to name the resulting genre into which the new work falls. In other words, screendance may be thought of as the product of a lineage that can be articulated in various ways, including: the provenance of the dance language within the work; the materiality and history of the media by which it is created; and also the complex cultural diaspora of its makers and its references.

That is not to say that genres are necessarily fixed, however; indeed, it is my observation that as dance is mediated within the site specificity of camera space and further by the material cultures of film, video or digital technologies, it tends to assume the characteristics of that mediation. In other words, in the diaspora of dance through the culture of media, dance becomes more like film or video than vice versa. Dance conforms to the space of media, to its pace, to the patterns of viewership and the way in which media objects are consumed. From a critical viewpoint, meanwhile, the discursive language of dance tends to persist, as the genre's normative viewership is most often within the context of a dance audience. The way in which dance on film or screendance tends to be discussed and critiqued thus depends on the point of origin of the speaker. If dance and its diaspora are privileged by the speaker/viewer, the language of dance will be the currency by which 
the work is critiqued. If the speaker/viewer privileges film or video (and its diaspora), it is likely that the language of the moving image will lead the discourse away from issues of kinesthetic and/or choreographic observations.

In the last decade at least, the screen has clearly become a well-understood site for dance. However, it is always a site that is doubled: the initial layer is the built environment or landscape in which the body (dance) is located; the secondary layer is the media by which the performance is inscribed, bonded into one screenic image. In short, the visual culture of screen-based dance cannot be separated from the signifiers present within the frame itself and in the device by which that frame is created. Meaning flows from the entire image as well as its fragmented parts, often exposing the numerous tensions between the two and the competing desires of each.

On screen, dance seems simultaneously to resist and to adapt to the space of media, to its pace, to the patterns of viewership and to the way in which media objects are consumed. In this capitulation, one tension that arises is the way in which the language used to describe the co-habitation of dance and media tends to also describe a servicebased relationship. For instance, the often-used phrase, "dance for camera" (a common festival title) ${ }^{2}$ implies that it is dance that is being staged at the pleasure of the camera, for the express purpose of the camera's desire. ${ }^{3}$ It also implies that the camera is a spectator or receiver of the dancing body as opposed to a space in which dance flows with the agency of a collaborator. Thinking laterally, it would seem odd to use a phrase such as acting for camera to describe a similar hybrid, for instance a "narrative film," unless it was in the context of a course on the practice. Dance for camera does not imply a course, but rather a course of action, a privileged performance made specifically for the viewership of the camera-eye.

The use of the word for-as opposed to with -in this regard is fraught with meaning. It implies a slavish relationship in which it is the camera for which all is performing, a hierarchical suppression of dance as a method of communication with its own agency and desire and a casting of camera space as a kind of colonial space for which dance is simply another subjugated citizen. In this case, both dance and the camera ultimately suffer. Indeed, these linguistic constructions tend to reinforce the difficulties in critiquing such hybrid forms, as they maintain a material binary by continually re-stating their cultural and material affiliations. Dance/camera, camera/dance: either way, such terminology allows for the viewer/ consumer/critic/theorist to attach their gaze on either solely dance or solely the camera, virtually piercing and eliding the hybridity of the form before their eyes.

Some of the information needed to unpack and describe individual works of screendance may be found in the terminology and language offered by its makers and presenters. To fully realize difference as well as to construct a narrative of related screendance communities and genres requires a closer reading of the practice, as well as some knowledge of the intent of the authors. In his book On Criticism, philosopher and critic Noël Carroll points out:

One very important access road to the intentions of artists has to do with the fact that artists produce works that belong to acknowledged categories. That is, in general, artworks belong to categories — like genres, styles, movements, periods, oeuvres, etc. - and/or they have lineages and traditions. We can locate the pertinent kind or combination of kinds to which the artwork belongs by, among other ways, calculating the number and salience of features that the work being criticized has in common with members of the prospective class of artworks which we suspect it belongs. $(72)^{4}$ 
Following Carroll's logic of artistic intention, it is clear that by cataloguing the relative attributes of artworks within a greater context, we can both derive further meaning and also partake of a larger cultural dialogue catalyzed by each work of art. However, genres do not readily announce themselves, and this is where the process of excavation must be undertaken. While the quantitative methodology that Carroll cites is integral to the way in which the art world (as well as the world of film, music and other practices) functions as an evolving intellectual community, screendance has been resistant to most efforts to articulate its genres and categories of practice, even given the thoughtful and considered attempts to do so over the last decade. ${ }^{5}$

Manifesting precisely this desire for a more rigorous viewing of the field, dance scholar Sherril Dodds published Dance on Screen: Genres and Media from Hollywood to Experimental Art in 2001, in which she carefully articulated a number of screendance genres. Dodds quotes screendance makers and directors who point out influences for their work that come from sources outside the dance world. She notes, for instance, that the director "[David] Hinton's fascination with the possibilities of movement on screen does not derive from a dance tradition, but from popular action films" (25). ${ }^{6}$ In this case, Hinton appears in a spectrum of artists whose work flows from very particular genres with equally particular esthetic and material concerns. It subsequently falls to those who consume and circulate the resulting work to further articulate the meaning of those concerns when they are attached to a particular dance vocabulary in a film or video hybrid. ${ }^{7}$

Dodd's book articulates theoretical paradigms that have gone largely unchallenged since its publication. In a recent essay called Does Screendance Need to Look Like Dance, however, Claudia Kappenberg speaks back to Dodds, suggesting a number of alternatives to parsing the field into genres and noting that "a limited vocabulary for the discussion and critique of such work has continued to tie screendance practitioners and ambassadors to the pre-existing disciplines" that Dodds articulates (91). ${ }^{8}$ It may be that the screendance community lacked sufficient critical mass to mount a response to Dodd's challenges for a higher degree of criticality; regardless, though, as the practice has grown in the last decade and as more exhibition venues have appeared, there has been a persistent resistance to adopting the same rigor found in the larger art world by which the community creates a vocabulary to articulate its process and practice.

In live dance, on the other hand, though citations of genre may not be common, they are certainly present. In dance historian Sally Banes' Terpsichore in Sneakers (1977), she notes as early as the introduction that:

When Yvonne Rainer started using the term "post-modern" in the early 1960's to categorize the work she and her peers were doing at the Judson Church and other places, she meant it primarily in a chronological sense. Theirs was the generation that came after modern dance, which was itself originally an inclusive term applied to nearly any theatrical dance that departed from ballet or popular entertainment. By the late 1950's modern dance had refined its styles and its theories, and had emerged as a recognizable dance genre. (xiii) ${ }^{9}$

The articulation of dance by forces both inside and external to the creative circle of practitioners aids us in honing the field into sharp-edged focus in regard to how works of dance circulate and how they are received culturally. It also allows for critics such as Banes and Michael Kirby to refer to "the theory of post-modern dance" as early as $1975 .{ }^{10}$ And it allows for artists working with other methodologies to distance themselves from the theory 
of post-modern dance in order to articulate their own theories and practice. Indeed, Banes (in Terpsichore) goes on to parse dance into even smaller and more precise subgenres of practice and to recount the manifestos of each. These lineages and subgenres of dance are primarily embodied via a dancer's training and performance histories, as well as more overt political choices that that dancer may make as to her affiliations with a particular area of practice. By indexing the salient aspect of dance as they pertain to genre and categories, Banes helps to create a discourse about the culture of dance itself.

Thinking laterally, and taking as an example a common art world methodology, both video and performance art were part of a movement in the mid 1960's that was catalyzed by concerns about the body as a site of resistance and by new technologies of representation and witnessing. Both were originally attached to a master narrative stemming from the Fluxus movement, among others, until a critical mass of practitioners began to name their aims and concerns and to contextualize their creative output in more specific terms." Early video art in many ways mimicked the practice of experimental film, yet in articulating both the material and contextual differences from film, video artists and curators were able to begin a discourse specific to the desires of video as an independent art form. Performance art was in its early days often termed "body art," thereby clearly locating the substance or material of the practice within the site of corporeality, inseparable from the body itself. And while body art or performance art might be confused with dance or theater, it was evidently the intent of its practitioners to distance themselves from those narratives and traditions, thus creating a space in which to address their own concerns.

If aggregate areas of art practice are delineated by master categories and further articulated by genres and subgenres, then by the same logic, "dance" is a master category that includes the genres of modern, ballet, tap, contact, and so on. Each of these genres creates its own literature, both by theory and by practice, which defines it as separate from other genres. The literacy of each is thus more or less refined by its practitioners and also by its critics (and historians), who collaborate in articulating its provenance and its relationships to other categories and genres of other forms of expression. Though screendance (known also by its various other titles: video dance, dance for camera, etc.) defines itself in name and through festivals, screenings and touring programs, there remains a considerable lack of literacy and scholarship or critical writing about the particular and differing formal and content-based approaches to the practice. In its stead, there is a reliance on shorthand and inferred meaning via the numerous names by which the practice articulates itself.

For instance, while the term video dance is used to describe a number of activities involving dance and the moving image, it is, from a linguistic perspective, both quite specific and simultaneously vague. The term implies that the method of recording involves a particular technology (video), which has a documented history both as a sub-set, of the visual arts (video art), and as a technology that flows from a particular historical moment (the mid-1960s). Those particularities place whatever may be referred to as video dance in a specific discourse situated in the continuum of the visual arts and a larger discourse around video culture in general. At the same time, the referent dance makes the term less precise. "Dance" tells us very little about the provenance of the movement vocabulary, its place within the history of choreographic strategies, or its politics in general. It does not name its place in one of the many specific techniques or schools of movement nor whether it is contemporary or modern, historical or ballet. Therefore, while video dance is a term that is 
widely applied, the term ultimately does little to illuminate the nature of the work in question. Moreover, other terms are equally misleading or misrepresent the actual materiality of the hybrid of dance and its mediated image in common usage. To move forward with this argument, then, I will restate the idea that, like dance itself, screendance is a master category with numerous genres and subgenres flowing from it.

Screendance, being a hybrid practice, contains at least two disciplines: dance and screen-based, technologically mediated methods of rendering. In this capacity, it is an overarching master category: screendance implies that the endpoint of the endeavor is a mediated image of dance on a screen, any dance on any screen. Indeed, by design and intent, screendance does not imply the materiality of rendering, nor does it describe a particular genre of dance practice. It could be shot in film or video, or manifest in a cameraless digital environment. The choreographic language of the work could be modern, post-modern, jazz, ballet or any other kind of dance. In order to particularize a discussion about a work of screendance, then, it is necessary to further articulate both form and content-both the method of rendering as well as the choreographic language. In this way it becomes possible to extrapolate meaning from the common and/or accepted shorthand that is used to describe a range of screendance practices.

We know that the category of visual art has numerous genres and subgenres. Film has genres, dance has genres; therefore, progressing logically, hybrids of any two of the above would result in both a genre and have beneath them numerous subgenres. By virtue of the fact that screendance is already a hybrid it may be thought of, then, as either a category or a subgenre of two or more parent genres. As in the case of film and other categories or parent genres, screendance would then propagate its own subgenres as well. These subgenres, given enough of a critical mass may then become a movement. Movements in turn catalyze new genres and are the product of a group of artists who agree on certain general principlesand create both artwork and literature that support those principles.

For an example of these phenomena in the film world, we can look to Dogma 95, a manifesto-driven provocation and movement that included the Danish director Lars Von Trier, Thomas Vinterberg and others who formed the Dogma film collective. The group produced what was called the "Vows of Chastity," a list of ten prescriptions in exacting language that described what a filmmaker could and could not do in order for the film to be considered a Dogma 95 film. ${ }^{12}$ As with most manifestos, it had a short-lived but intense existence. However, the manifesto catalyzed a movement that spread beyond film circles into other areas of practice including the screendance community. Shortly after the "Vows of Chastity"appeared in print, Katrina McPherson, Litza Bixler and Deveril Garraghan, dance filmmakers based in Great Britain, responded to the Dogma 95 manifesto with their own screendance-specific manifesto, Dogma Dance:

YES to the development of dance technique for film-YES to a sharing of knowledge between dance and film-YES to the development of choreographic structure in filmYES to technology which aids rather than hinders - YES to human dancers - YES to the creation of a new genre-YES to safe dancers-YES to the encouragement of dance filmmakers-YES to a new hybrid form.

$\mathrm{NO}$ to unsafe dancers - NO to the primacy of equipment and technology over human creativity-NO to the breakdown of choreographic structure- NO to purposeless hierarchies_-No to unbalanced wages_NO to the dominance of film in Dance film. ${ }^{13}$ 
Dogma Dance's stated intent was to "offer a challenge to dance-film-makers to make their work within the frame-work of 'artistic and production rules', evolved to encourage the radical development of the medium and the individual's own approach to making work."14 Illustrating their provocation was a curated screening in London called Under Your Skin. ${ }^{15}$ The Dogma Dance manifesto has echoes of numerous other such statements of purpose in all areas of arts practice, most particularly Yvonne Rainer's NO manifesto from 1965, but also manifestos by the Futurists and other twentieth century movements that utilized such texts to both provoke and catalyze artistic production within a narrowly defined set of parameters. ${ }^{16}$

Manifestos and genres are a way to initiate the organization of data into manageable systems of intellectualized units. The early part of the twentieth century saw countless manifestos from the Dadaists, Surrealists, Futurists, Fluxus artists and others, which by midcentury had given way to a more coherent naming of styles and genres. Styles and genres such as Abstract Expressionism, Pop Art, and later Video Art and Performance, had traceable lineages that led back to the manifestos of the earlier part of the century. The manifestos of Dogma Dance and others mentioned above extend the legacy of artists defining their communities and subsequent experimentation. Screendance, however, as previously noted, has vigorously resisted the kind of scrutiny that comes from naming styles, genres and approaches to an area of practice.

Ironically, naming such affiliations does not necessarily close down a practice, but rather tends to open it up to new ideas and manifestations. The art historian Henry Sayre refers to the post-modern avant-garde as an art "founded upon contingency, multiplicity and polyvocality." That is to say that even lacking a coherent and/or recognizable style, art works made in the post-modern era are recognizable and "eminently amenable to a formalist approach [of critique]" (xii). ${ }^{17}$ Screendance, being a hybrid and performance-based form, would certainly fit under Sayre's description. If we are to include screendance in the discourse of post-modern art practice, however, the task then is to begin to determine how to approach works of screendance in order to read them, name them, critique them, and begin to have a meaningful dialog about them.

Scholar Mark Franko, in "Aesthetic Agencies in Flux: Talley Beatty, Maya Deren and the Modern Dance Tradition in Study in Choreography for Camera" offers a reading of Maya Deren's dance film works that give us a glimpse into the possibilities of viewing such "classic" works through contemporary theoretical lenses. ${ }^{18}$ Franko proposes that in Deren's film, both the presence and absence of the dancer Talley Beatty is a "product of the film's manipulation of time and space as well as the vehicle wherein the film itself attains movement." He goes on to say, "This is what Deren identifies as film dance:'a dance so related to camera and cutting that it cannot be performed as a unit anywhere but in this particular film"' (141). Deren's definition of film dance has been the default standard for dance on screen that is not documentation, most likely since it was first uttered. However, that definition cannot be depended on to speak for all works in which movement codified by some metric as "dance" and the technologies of screen media intersect. Franko, in reflecting on Deren's dialectical view of choreography and film goes on to say:

For Deren, the limitations of dance arise from the limitations of architecturally defined space germane to live performance. The mobility of the camera and the manipulations of editing disrupt such limitations and transfigure them. Through the agency of camera and 
editor, "a whole new set of relationships between dancer and space could be developed." (141)

This statement, though of importance to the form, overemphasizes the dialectic of dance and media. This dialectical understanding or view of dance and film is rooted in what Sayre describes above, as being "eminently amenable to a formalist approach [of critique]." It neutralizes any of the diasporic traces that are brought to bear in either the dance or the media elements resulting in a visuality that is in the end a method of conforming to Deren's prescription at its lowest common denominator. Furthermore, it almost completely effaces issues of race, gender, and all of the diasporic flotsam and jetsam that attaches to both sides of the dialectic: the choreographic language and its provenance, the cinematic history and materiality of the methods of inscription. In short, the family tree of such work -its generic heritage - is rendered invisible in favor of a reductive, modernist reading of its formal qualities.

Given the evolution of theoretical discourse in the arts beyond screendance, however, it is no longer adequate to define a work for the screen by those formal qualities that simply imply that the work could not be created as a live event. Rather, it seems necessary to define new models and critiques related to works of screendance, ones which take into account the commitment of makers to defining the practice in novel and often eccentric ways. In addition, these models should facilitate a deeper understanding of the context by which the work becomes a part of a larger collective discourse on the body's representation on screen, as well as innumerable other concerns that attach to the arts in a contemporary world.

The methodology for analysis that I would like to suggest in order to probe the practice and to excavate its genres looks at a work's screenic ${ }^{19}$ attributes as well as its vernacular, choreographic attributes. In other words, what are the qualities of the work that are "of the screen"? What are the contingencies that tether the work to the screen and what are those histories and theories that attach to the work in the process? What are the formal qualities of the rendering (which may include style, genre, materiality), and what are the formal qualities of the choreographic language (which may include schools of movement, choreographic vernacular, lineage and other material associations)? What is the intent of the work - that is, what can we divine from the way in which the work is described by title, by the meta-data and by formal designations such as video dance, dance film, screendance, etc.? And finally, what is the content of the work, what are the inferences that can be read by the performance contained within the frame of that which we are consuming, what are the politics of the work?

Putting these rhetorical suggestions into practice, we can look to Viking Eggeling's Diagonale Symphonie (1924) ${ }^{20}$ as an example of a film that might be probed for its screenic qualities in order to excavate its characteristics, and thus assign its relationship to a particular genre. Diagonale Symphonie is a silent film in which no humans appear, and yet the film's stated intent is an exploration of the depiction of movement. Eggeling himself called it an "abstract film." To more accurately contextualize the film's relative value and to locate the film in a larger interdisciplinary, intertextual discourse, however, we need to also consider the diaspora of Eggeling from Germany to Zurich, Switzerland, where he became associated with the Dada movement; the surface qualities of the film (paper cut-outs and tin foil figures photographed a single frame at a time); and also his artistic associations 
(Hans Richter, Jean Arp, Tristan Tzara, and others). In so doing, we will be able to index those aspects of the film that both separate it from and attach it to other work that flows from a similar set of historical and material circumstances.

As another example of this process, we might examine Hans Richter's Rhythm 23 (1923), a silent black and white study of movement through objects, which comes out of the postWorld War I cinematic avant-garde that originated in Germany and was composed mainly of painters and photographers. ${ }^{21}$ Richter's artistic and political affiliations are evident in his own writing at the time, but also in the visuality of his films. Without elaborating on the diasporic history of Dada and Cubism that is attached to Richter's sense of cinematic materiality and spatial understanding of film, it becomes less possible to accurately place this work within a conversation about screendance. Thus, while neither Diagonale Symphonie nor Rhythm 23 are works of screendance per se, an activist curator ${ }^{22}$ might include these films within an exhibition of screendance works in order to demonstrate the flexibility of a particular subgenre of screendance practice.

The above examples demonstrate that in order to understand and articulate screenspecific works, it is of value to know the meta-narrative of the work and to "read" both the surface qualities of the film and the meta-knowledge one can attach to the discourse around the work. The films of Eggeling, Richter and others of the time were materially unlike any other art form. While there is a resemblance to drawing or graphic design, theirs is a set of visual images that is more filmic (or screenic) than graphic. The sequential appearance of discreet shapes and forms is so deeply embedded in the surface of the film that they are irretrievable as graphic objects in their original form.

To compare two simple subgenres useful to the discussion of screendance, we might examine the dialog between narrative and poetic forms. These classifications are broad yet simultaneously specific. A work in one category may seep into the other, but it is a starting point by which to address both the intent of a work, (as Carroll describes) and the result of the work. Erin Brannigan's recent essay offers an insightful discourse on the use of the close-up in screendance using Miriam King's film, Dust as an object of contemplation.23 Brannigan states:

... one of the projects of dance in the twentieth century has been to reactivate or investigate exactly this function of the body: the body as receptive surface and responsive organ which can articulate, through the most subtle micro-movements, the registration of flows of energy, sensory activity and exterior stimuli which occur through and upon the body. When applied to dancefilm, this calls for a reworking of the dominant theories of the cinematic close-up. (126)

While I agree with Brannigan in theory, in "reading" the works she cites as well as others that conform to her theory of micro-choreographies, I would suggest that the use of the close-up in screendance is most often encountered within a kind of discreet narrativity, one that while not explicit (though often so) it is rather implicit, made so by an opening combination of shots and edits that lay out a series of juxtapositions by which all subsequent images are referenced.

I would propose that it is the rare work of screendance that does not begin with a series of shots that are implicitly narrative. In other words, projects that begin and end with the body in motion (or "stillness"), offering no other juxtaposition of place, inanimate objects, locative devices or musical overlays that contain in and of themselves multiple 
layers of implied or inferred meaning. In her reading of Miriam King's Dust, and subsequent contrasting with Amy Greenfield's Element, Brannigan says, Dust begins with a close-up of sand particles blowing across surfaces, creating patterns as they dance and scatter, then hard sand cracks and a hand emerges. This begins a series of close-ups of performer Miriam King's body; her back, fingers crawling across the sand, her eyes which are covered by goggles. King's body emerges through fragments until we see it as a whole, attempting to swim across the sand dunes. The first full close-up of King's face is followed by a close-up of a ticking watch, and then various odd angles render her face strange and unfamiliar. The second half of the film features King's body parts in close-up submerged in black water, the solid form of the figure dissolving in the dark liquid and play of light (Figure 2). This sequence recalls Amy Greenfield's body struggling in thick black mud in Element (1973), emerging and disappearing in a study almost entirely shot in close-up. Greenfield's pioneering work in the 1970s combined close-ups of the moving body with intensely motile and loose camera work that 'ungrounded' the figure to a radical degree. In both films, the drama is spread across various surfaces, substances and the body of the performer equally, with detailed movements of fingers, limbs and back muscles filling out their intensely visual tales. In such dancefilm examples, the performing body and the closeup have combined to create a new mode of filmic performance. (126-127)

Brannigan's detailed reading of the two works illuminates the inherent difference between a work that relies on external cinematic devices to ground its meaning and one that does not waver from or capitulate to film's desire for narrative strategies outside of the body's own landscape. The opening of Brannigan's description of Dust states that it "begins with a close-up of sand particles blowing across surfaces, creating patterns as they dance and scatter, then hard sand cracks and a hand emerges." Before we even encounter King's body and are allowed to begin our own relationship with its corporeal meaning, we are set up by a series of shots designed to foreground a very particular narrative. She goes on to describe the fact that "the first full close-up of King's face is followed by a closeup of a ticking watch." Again we are brought out of our relationship with the body that Brannigan eloquently describes in her exposition of King's film, and into a consideration of the concept of time via a shot of her wristwatch.

Brannigan then notes that "The second half of the film features King's body parts in close-up submerged in black water, the solid form of the figure dissolving in the dark liquid and play of light"; and also that "This sequence recalls Amy Greenfield's body struggling in thick black mud in Element (1973), emerging and disappearing in a study almost entirely shot in close-up." The difference here is not without consequence. The use of close-up in Dust conforms to a historical use of the technique designed to enhance narrativity and thus impose meaning in a manner that is closely aligned with the way in which literary devices are used to tell a story. In Dust they are used as a kind of steering device to keep us, the viewer on track. In Element, no such external narrative is present, no literary devices, no juxtapositions of the visual culture of objects or the kind of editing techniques that suggest a narrative outside of the body's experience with itself and its environment. The use of the close-up to contrast the wide shot in Element is always limited to the body and the site it inhabits. No other signifiers are present in Element; thus, we are free to imagine our own metaphors for the engagement of Greenfield's body to the landscape and her performance within it. In illustrating or engaging in the process of excavating the salient features 
of a work of screendance, and given the evidence of difference exemplified by the above examples, it becomes possible to parse these works into subgenres that are themselves contained by the larger category of screendance. I would therefore name King's Dust as narrative and Greenfield's Element as poetic, again keeping in mind that these delineations are meant as a catalyst for both curating and critical discourse.

At this juncture, there are two points that I will make that might seem to be counterintuitive: the first is that the visual culture of work that transpires at the intersection of dance and screen media is often more dance-like than film-like; that is, it looks like dance. The second is that it seems like film. Even the most abstract or "pure" (i.e., non-narrative) choreography tends to capitulate to the desires of cinema, to the desire to be narrative. As Claudia Kappenberg observes, "Almost 30 years after [Amy] Greenfield and 50 years after [Maya] Deren, much of screendance remains rooted above all in dance traditions ..." (qtd. in Brannigan 93). That is to say, dance resists the nature of cinema or video and maintains its identity even if edited and temporally altered. Though embedded in the site of film or video, dance as a realistic technical performance tends to maintain its own nature: again, it still looks like dance, or at least the visual culture of dance. However, often the presentation of the visual culture of dance is embedded in the narrative structures of film in a way that telegraphs a kind of mistrust of the body's ability to transmit its own stories without additional signifiers. Greenberg's Element is a possible answer to the rhetorical question that Kappenberg poses: Does Screendance Need to Look Like Dance?

To achieve the sort of hybridity that other interdisciplinary art world practices have achieved, it would seem that dance must necessarily become more screenic and more conscious of its own diasporic wanderings. At the same time, to begin to create a linguistic apparatus by which to articulate the relationships between works would open new territories of critical thinking in the field.

\section{Notes}

1. See Benedict Anderson's Imagined Communities (New York: Verso, 1983. Print.)

2. The festival that I direct at the American Dance Festival is called "Dancing for the Camera: International Festival of Film and Video Dance." It was so-named more than 15 years ago.

3. Dance on Camera, a slight variation, has similar resonance, though the probable meaning here is a combination of dance for camera and dance on screen. Claudia Kappenberg notes that, "The home page for the annual 'Dance on Camera Festival' in New York demonstrates this legacy, stating that since its creation in 1971, its mission has been to facilitate the preservation of dance, encourage documentaries on dance and further screen adaptations. I would argue that all three categories are representative of a 'dance for film' approach in that the film-making and its technologies are predominantly put at the service of the dance" (93). See note eight for full citation.

4. Carroll, Noël. On Criticism. New York: Routledge, 2009. Print.

5. Such attempts have been made via conferences which focus on screendance as early as 2000 .

6. Dodds, Sherrill. Dance on Screen: Genres and Media from Hollywood to Experimental Art. New York: Palgrave, 2001. Print.

7. Marcel Duchamp writes: "All in all, the creative act is not performed by the artist alone; the spectator brings the work in contact with the external world by deciphering and interpreting its inner qualifications and thus adds his contribution to the creative act." (Kepes, Gyorgy. The Visual Arts Today. Middletown, Connecticut: Wesleyan University Press, 1960. 111-112. Print.)

8. Kappenberg, Claudia. "Does screendance need to look like dance?" PADM 5.2 and 3 (2009): Print.

8. Banes, Sally. Terpsichore in Sneakers. Hanover: University Press of New England, 1977/1987. xiii. Print. 
10. Banes, Sally and Michael Kirby. "Introduction." The Drama Review 19 (1975): 3. Print.

11. See for example Rose Lee Goldberg's Performance Art: From Futurism to the Present, Revised and enlarged ed. (New York: Harry N. Abrams, 1988. Print.)

12. 1. Filming must be done on location. Props and sets must not be brought in. If a particular prop is necessary for the story, a location must be chosen where this prop is to be found.

2. The sound must never be produced apart from the images or vice versa. Music must not be used unless it occurs within the scene being filmed, i.e., diagetic.

3. The camera must be a hand-held camera. Any movement or immobility attainable in the hand is permitted. The film must not take place where the camera is standing; filming must take place where the action takes place.

4. The film must be in colour. Special lighting is not acceptable (if there is too little light for exposure the scene must be cut or a single lamp be attached to the camera).

5. Optical work and filters are forbidden.

6. The film must not contain superficial action (murders, weapons, etc. must not occur.)

7. Temporal and geographical alienation are forbidden (that is to say that the film takes place here and now).

8. Genre movies are not acceptable.

9. The final picture must be transferred to the Academy $35 \mathrm{~mm}$ film, with an aspect ratio of $4: 3$, that is, not widescreen. Originally, the requirement was that the film had to be filmed on Academy $35 \mathrm{~mm}$ film, but the rule was relaxed to allow low-budget productions.

10. "The director must not be credited." (Purity and Provocation: Dogma 95. Eds. Mette Hjort and Scott MacKenzie. London: British Film Institute, 2003. 199-200. Print.)

13. "Dance Dogma." Left-luggage.co.uk. Eds. Katherine McPherson and Simon Fildes, 18 Aug. 2007, Scottish Arts Council and University of Dundee's School of Media Arts and Imaging. Web. March 2010.

14. Garraghan, Deveril. "Dogma Dance." Dance and Technology Message Board Archive. Scott Sutherland, 20 Oct. 2000, Web. March 2010.

15. Garraghan, "Dogma Dance."

16. See Douglas Rosenberg's 1999 manifesto in Purity and Provocation, 173.

17. Sayre, Henry M. Object of Performance: the American avant-garde since 1970. Chicago: University of Chicago Press, 1989. Print.

18. See Franko, Mark. "Aesthetic Agencies in Flux: Talley Beatty, Maya Deren and the Modern Dance Tradition in Study in Choreography for Camera." Maya Deren and the American AvantGarde,. Ed. Bill Nichols. Berkeley: University of California Press, 2001. 131-150. Print.

19. This use of the work "screeninc" was introduced to the screendance network in discussion by Harmony Bench. It has also appeared in common usage in places such as N. Katherine Hayles'"Print Is Flat, Code Is Deep: The Importance of Media-Specific Analysis" (Poetics Today 25.1 [2004]: 67-90. Print.) Hayles writes; "In the computer, the signifier exists not as a durably inscribed flat mark but as a screenic image produced by layers of code precisely correlated through correspondence rules, from the electronic polarities that correlate with the bit stream to the bits that correlate with binary numbers, to the numbers that correlate with higherlevel statements, such as commands, and so on. Even when electronic hypertexts simulate the appearance of durably inscribed marks, they are transitory images that need to be constantly refreshed by the scanning electron beam that forms an image on the screen to give the illusion of stable endurance through time" (74).

20. Diagonale Symphonie is viewable at: <http://www.ubu.com/film/eggeling.html>.

21. See Richard Suchenski's "Hans Richter." Senses of Cinema 49 (2008): n. pag. Web. Mar. 2010.

22. See Douglas Rosenberg's "Curating the Practice/The Practice of Curating." PADM 5 (2\&3): 75-87. Print.

23. Brannigan, Erin. "Micro-choreographies: The Close-up in Dancefilm." International Journal of Performance Arts and Digital Media 5.2\&3 (2009): 121-39. Print. 



\title{
La Escritura Perpleja. Hacia Un Posible Uncuentro Entre Crítica Y Videodanza
}

\author{
Susana Temperley
}

as líneas que siguen no buscan hablar sobre videodanza sino sobre escritura de videodanza. El interés en este tópico se origina en algo que comienza a perfilarse como un problema: el hecho de que la videodanza ha encontrado un lugar de emplazamiento y crecimiento prolífico en Latinoamérica y sin embargo, no ha logrado aún despertar el interés de los críticos.

El caso es que la crítica, uno de los metadiscursos más importantes para la vida de géneros y lenguajes, ${ }^{1}$ puede definirse como el extremo del desfasaje entre producción y teorización de videodanza. La existencia aún muy incipiente de textos críticos se hace palpable en comparación con la vitalidad que ha adquirido su objeto de estudio. Se pueden establecer parámetros de este estado de hechos al considerar el contexto de emplazamiento del arte contemporáneo en general, donde la posibilidad de permanencia y de validez del museo como espacio de difusión de las obras consiste en uno de los tópicos de discusión más actuales. En el caso de la crítica, en cambio, la cuestión de validez como medio de difusión no parece formar parte de ningún debate.

Así, ante el palpable retiro de la crítica puede formularse una pregunta que contribuya a abrir el debate: los formatos de la crítica y los interrogantes que ella plantea ¿la habilitan a seguir funcionado como parte del dispositivo metadiscursivo del arte contemporáneo? La ausencia de crítica, aún de forma solapada, sobre artes hibridas como la videodanza puede estar diciendo algo al respecto.

Por otra parte, encontramos la escritura de los propios artistas. La palabra reflexiva de los creadores de videodanza se hace cada vez más frecuente (y fecunda) y se orienta a indagar en la propia obra o teorizar sobre el lenguaje de la videodanza convocando disciplinas como filosofía, epistemología, historia del arte e incluso política. El hecho es que en diferentes circuitos de difusión de las obras (especialmente los festivales) han empezado a abrirse espacios paralelos, destinados solamente a la discusión teórica que, por ahora, se da entre los mismos artistas.

Hoy en día, resulta de suma importancia la existencia de estos textos ya que conforman el único metadiscurso existente sobre videodanza, al tiempo que señalan una carencia estructural de escritos externos a la vorágine de la producción de obras. Podemos hablar así de la teoría proveniente del campo de producción artística como un modo de expresión que si bien es necesario, tiende a generar un hermetismo estructural en el circuito de difusión de obras (a pesar del fluido intercambio a través de páginas web y blogs). En consecuencia, aún se está lejos de la posibilidad de un "mercado" de videodanza, y si bien muchos artistas se encuentran presentando su obra de manera independiente o a través de festivales (cada vez más sofisticados y completos) y muestras itinerantes, los consumidores de videodanza que se generan por cualquiera de estas vías, siguen siendo los mismos artistas. Esta es una de las diferencias cruciales con respecto al Videoarte en general que, de alguna manera está 
siendo explotado en circuitos más "rentables" abiertos por grandes corporaciones del mundo tecnológico (de telefonía principalmente) a través de un neo-mecenazgo que, si bien genera controversias, parece hacerse cargo de un lugar antes vacío. ${ }^{2}$

En síntesis, existe un espacio de teoría desocupado, pero también existe otro, que ha comenzado a madurar y sistematizarse. El punto crucial se encuentra en que la proliferación de escritos provenientes del mismo campo de producción de arte conlleva ciertas ventajas pero no puede reemplazar a la crítica en la especificidad de su rol. ${ }^{3}$

Parece crucial la existencia de una Crítica que abra el campo hacia una reflexión profesional o al menos renovada. Es por eso que en la búsqueda de discusión sobre este tópico surge otra pregunta: si existiera una crítica en videodanza, ¿qué papel le tocaría jugar ante este lenguaje artístico complejo y aún controvertido? Para intentar contestar esta pregunta habrá que tener en cuenta que la existencia de crítica determina en gran medida la importancia de un modo de expresión artístico en la cultura, pues contribuye a la designación de status de lo que critica y lo circunscribe como un espacio autónomo de efectos estéticos.

\section{Ser crítico en videodanza ¿qué significa?}

\subsection{Resolver}

De acuerdo con Danto, las consideraciones estéticas que gobiernan nuestra relación con las obras, e incluso el mismo concepto de Arte, no son ahistóricos y en la actualidad nos encontramos en un momento de cambio radical: "Deberíamos pensar en el arte después del arte, como si estuviéramos emergiendo desde la era del arte a otra cosa, cuya exacta forma y estructura resta ser entendida." ${ }^{4}$

El autor acepta que el arte es paradigmáticamente impredecible pero además, particularmente en este momento, estaríamos frente a una estructura en la que "todo es posible." Así, el arte contemporáneo es demasiado pluralista en intenciones y realizaciones como para permitir ser capturado en una única dimensión y, por ende, la crítica de arte debería ser tan pluralista como el mismo arte posthistórico. ${ }^{5}$

¿Qué tenemos que entender entonces por crítica "posthistórica"? O al menos cabe preguntarnos si es posible postular líneas de abordaje para las obras contemporáneas que permitan seguir definiendo a la crítica como género. ${ }^{6}$ Si la crítica tiene por tarea determinar a qué estructura histórica pertenece la obra que critica, qué significados carga y cuáles son las intenciones que satisface, de entrada se evidencia un efecto de incertidumbre pues estamos frente a una estructura histórica en la que todo es posible, es decir que carecemos de una narrativa maestra que sirva como referencia al crítico para contestar a estas cuestiones.

\section{Pero Danto realiza una salvedad:}

Hoy todo es posible en el sentido en que ciertas cosas no eran posibles para un europeo o un africano en 1890. No obstante estamos encerrados dentro de la historia. No podemos tener el sistema de creencias exclusionistas que impedían a los artistas europeos hacer ídolos y máscaras (...) Pero no hay formas que nos estén prohibidas. Lo único que nos está prohibido es que ellas tengan la especie de significado que tenían cuando nos estaban prohibidas.? 
De acuerdo con esta tesis, la emergencia de una crítica especializada en lenguajes posthistóricos como la Videodanza, se enfrentaría a un objeto de estudio caracterizado por la libertad formal y la novedad e imprevisibilidad en cuanto a su "significado", mientras que la misma crítica sería impensable por fuera de este régimen de creencias del "todo es posible".

Esta posición tan incómoda que se presenta al crítico de arte de la actualidad (llámese contemporáneo o posthistórico, da igual), se evidencia en su propia reflexión. Tal como lo menciona el crítico mexicano Cuauhtémoc Medina:

[El arte actual] tiene que ver con un territorio que asumió (como herencia) el cambio de las posibilidades creativas y de los dilemas entre esas posibilidades creativas y los discursos, imágenes, sonidos y estructuras sociales (...) Los que estamos dentro de este territorio (la crítica) no entendemos más que los que están afuera. Es, más bien que estamos dispuestos a la experiencia de tener que construir nuestra relación con estos objetos una y otra vez, encontrándole placer a ese momento de extrañamiento y aprendizaje.

Nadie nos enseña como elaborarlo. Los llamados especialistas nos quedamos tan perplejos como los demás. A lo mejor ni siquiera podemos hacer algo con lo que se nos está presentando y precisamente en territorio donde podemos establecer diálogos entre nosotros, donde compartimos nuestras excitaciones, donde se montan los discursos, es ese territorio de perplejidad... pero no estamos en la posición de rechazo ante la condición de prácticas que no están aferradas a algún dispositivo ya conocido. ${ }^{8}$

En este escenario, el crítico de videodanza, al asumir su rol, se enfrentaría en primer lugar con la necesidad de "resolver" el dilema de su propia posición pues es posible que no pueda hacer/decir algo con lo que se le presenta como objeto de reflexión y al mismo tiempo no estará en condiciones de rechazarlo para volver a lugar seguro, al de las artes definidas por un dispositivo tradicional.

\subsection{Escribir}

\section{LOS CONCEPTOS}

Ahora bien, el medio donde el crítico resuelve su lugar es la escritura. Y aquí ya aparece otro problema.

Barthes describe el acto de escribir como una suerte de gesto paradójicamente trágico:

Sin duda puedo hoy elegirme tal o cual escritura, y con este gesto afirmar mi libertad, pretender un frescor o una tradición; pero no puedo ya desarrollarla en una duración sin volverme poco a poco prisionero de las palabras del otro e incluso de mis propias palabras. Una obstinada remanencia, que llega de todas las escrituras precedentes y del pasado mismo de mi propia escritura., cubre la voz presente de mis palabras. Toda huella escrita se precipita como un elemento químico, primero transparente, inocente y neutro, en el que la simple duración hace aparecer poco a poco un pasado en suspensión, una criptografía cada vez más densa. ${ }^{9}$

El asunto es que la crítica de videodanza se enfrenta a la tarea de "acompañar" y valorizar cierto objeto - que vive siempre en un presente caracterizado por la ausencia de límites en lo formal- y como ya vimos debe hacerlo dentro de esa misma estructura histórica. El crítico debe efectuar una escritura de su tiempo, de un tiempo que es el mismo que el del artista, ${ }^{10}$ pero por medio de signos que se resisten a decir lo que nunca antes fue dicho. 
La escritura es un lenguaje endurecido que vive sobre sí mismo y de ningún modo está encargado de confiar a su propia duración una sucesión móvil de aproximaciones, sino que, por el contrario, debe imponer, en la unidad y la sobra de sus signos, la imagen de una palabra construida mucho antes de ser inventada. ${ }^{11}$

Así que, para hablar de algo hay que nombrarlo y las palabras designan, definen y delimitan lo posible de ser dicho. El arte podrá ser ese "cualquier cosa" que define Danto pero la crítica, aún la "posthistórica", no puede hablar de ella de cualquier modo. Entonces, partiendo del supuesto de que existe o puede existir alguien tan (irresponsablemente) tenaz como para darse a la tarea de criticar videodanza, ¿cómo puede este sujeto analizar algo que no tiene límites a través de un lenguaje que si los tiene?

En otras palabras, la crítica de videodanza podrá ser una escritura que nace de la perplejidad pero no puede nunca ser imprecisa y ambigua sin violentar su mismo carácter de escritura.

Pues bien, aparece un aspecto donde es posible situarse para comenzar a escapar a tales dificultades: la redefinición permanente de los conceptos. ${ }^{12}$

Ya se sabe que la crítica deberá mantener una visión particular para valorizar diferentes "tipos" ya sea obras centradas en la experimentación tecnológica (el afán por descubrimientos sobre nuevas posibilidades del movimiento y la forma, sin perder el carácter estético del todo) o aquellas que focalizan en la expresividad, la poética y el contenido "humanista" o el contexto social, pero incluso sobre cada una de estas líneas estéticas el crítico se enfrentará , cada vez, a una obra diferente en su forma, su gramaticalidad, en su ser único, que al mismo tiempo y sin precisar cómo, es parte de un conjunto (que a priori sólo se puede caracterizar como "todas las obras como ésta"). Aquí es donde el escritor deberá ser capaz de plantear de entrada una serie de conceptos a través de los cuales pueda decir algo verdadero de una obra de videodanza. Se trata entonces de lograr elaborar esos conceptos que sean capaces de transformarse según cada objeto y cada posición que asuma la escritura frente a éste.

La necesidad de precisión se vuelve abismal (pero no por ello impensable) por eso, cada vez que el crítico aborda un nuevo objeto, debe someter permanentemente a examen las nociones que utiliza en sus escritos—desde qué idea de cuerpo interviene en una videodanza hasta que aspectos de la disciplina se destacan al optar por el término videodanza y "danza para la cámara", e incluso mucho más, pues, ciertamente, será necesario preguntarse acerca de los significados de dispositivo, movimiento y espacio presentes en la obra. Y esto, sólo para ingresar al análisis-y muchas veces, crear otras nuevas especialmente formuladas para el caso.

Una señal, entonces: se hace necesaria la reconceptualización permanente de las nociones que definen y definirán al lenguaje de la videodanza, pero antes, la capacidad para generarlas.

\section{Los lugares comunes}

Luego, otro problema a salvar: la libertad del objeto tiende a repercutir en un abuso del "lugar común" y de las metáforas cristalizadas (catacresis). Estos se presentan como síntoma del debilitamiento de la crítica en casi todos los demás lenguajes artísticos contemporáneos del que la crítica de videodanza aún escapa simplemente por carecer 
de sistematicidad. Sin embargo, al tiempo que enturbian la escritura, los clichés y la estereotipia son parte intrínseca de toda reflexión sobre el arte que surge y busca madurar pues sirven al intercambio, al diálogo entre el crítico y el lector ${ }^{13}$ tal como le son útiles los flotadores al náufrago.

Así, los lugares comunes y las catacresis, también se van esbozando en el caso de la escritura sobre videodanza por ende, detenerse en ellas puede resultar una experiencia interesante: ¿Qué se puede decir a través de fórmulas como: "manipulación de la imagen," "exploración del paisaje de la danza," "apropiación simbólica del espacio," "experiencia dancística," "síntesis entre danza e imagen," "experiencia envolvente...donde el público queda sumergido" y el muy frecuentado "diálogo entre cámara y cuerpo"?

Cristalizaciones en sí mismas que también cristalizan un referente, los lugares comunes "son el efecto, en sus apelaciones argumentativas, de la inercia de la memoria cultural,"14 y aparecen, así, como una voluntad que se orienta hacia un pasado y por lo tanto, en dirección contraria al del lenguaje que es su objeto y que se caracteriza por la complejidad y la búsqueda de especificidad en un contexto impredecible situado en alguna parte entre el presente y el futuro.

Se puede incorporar ahora otra señal: la necesidad de una posición de alerta permanente ante los mismos términos y frases que definen el lenguaje de la crítica y que al tiempo que actúan como índices retóricos de género atentan contra su función de época: el decir algo sobre un objeto que se resiste a ser siquiera nombrado.

\section{Balance}

Determinada por una doble contradicción, una relativa a la pervivencia del lugar común (que tiende a eliminar la reflexión particular y la complejidad, al tiempo que no se puede comunicar nada sin él) y otra basada en la ambigüedad de los conceptos (los signos que limitan lo posible de ser dicho, al tiempo que no hay manera de decir sin ellos), se vislumbra así una posible existencia del metadiscurso sobre videodanza que busca persistir más allá de su propia fatalidad no sólo como Escritura sino también como Crítica, al punto de correr el riesgo de encontrarse en un lugar tan trágico como el del silencio frente a una obra de arte.

Las líneas precedentes dan cuenta de una crítica de videodanza que es aún incipiente, casi ausente, pero que ya presenta vestigios de su condición "posthistórica" pues se enfrenta a la difícil, si no imposible, tarea de ejercitar la escritura para valorar algo que a menudo resulta tan novedoso que no existen aún palabras para calificarlo.

Así, la perplejidad y la escritura son los lugares entre los que se gesta la crítica posthistórica y su objeto. Si la videodanza habilita la perplejidad del espectador, está fecundando el suelo de la crítica y si esta logra transmutar hacia otra cosa -de manera tal que pueda modificar los parámetros que la definieron históricamente-, será posible su constitución como metadiscurso acompañante de la Videodanza.

"La única realidad, decía Foucault no está en las palabras ni en las cosas, sino en los objetos. Los objetos son el resultado de ese encuentro entre las palabras y las cosas"15 


\section{Reflexiones sobre la palabra del artista}

Koldobsky señala que

... las últimas décadas del siglo XX son resultado de las redefiniciones sobre la obra de arte, su práctica y su relación con otras prácticas sociales impulsadas en ese período, es decir que a partir de aquí, no resulta extraña la herencia de una palabra acompañante del autor, más allá de la forma que ésta asuma. ${ }^{16}$

Este es, quizás un punto interesante para indagar en la videodanza en su emplazamiento histórico, e incluso, tangencialmente, el rol "posthistórico"17 del artista de videodanza pues, ya se trate de palabra acompañante o del desenvolvimiento de una función novedosa, el hecho es que, en la actualidad, la teoría abocada a reflexionar sobre dicha práctica estética se encuentra casi exclusivamente bajo el dominio de los propios artistas.

Ahora bien, me referiré aquí a la teoría que podríamos definir como "auto-reflexiva" y que se presenta como "clave de lectura" de la propia obra pero también como guía para la comprensión del lenguaje de la videodanza.

Realizando un paneo general por los escritos latinoamericanos de los últimos años surgen dos grandes grupos orientados por una función definida (que puede o no aparecer explicitada en los mismos discursos):

I) Los trabajos, pertenecientes casi exclusivamente a artistas audiovisuales que navegan en aguas de la videodanza, que se proponen como principal tarea la de indagar sobre las posibilidades técnicas de la cámara (encuadres, movimiento, efectos de edición, etc), en referencia a un tiempo y espacio vinculado con un objeto- cuerpo o con un cuerpo como materia que puede ser manipulada. Estos escritos "organizan"las técnicas de la imagen, probadas en sus propias producciones, así como los efectos logrados en su aplicación, de manera tal que aparecen como una suerte de "manuales" legitimados en la propia experiencia y orientados a la búsqueda de nuevas posibilidades de producción y expansión de los límites del videodanza por sobre lo ya hecho y visto.

II) Aquellos escritos, cuya autoría corresponde mayoritariamente a individuos formados en artes del movimiento, que se plantean cuestiones de índole epistemológica y filosófica sobre concepto de cuerpo, su rol de sujeto u objeto en la relación siempre cambiante y conflictiva con la cámara o la esencia de la videodanza como lenguaje híbrido, entre otras. En muchos de estos ensayos se incluyen citas sobre la propia producción e incluso, la experiencia personal del artista ya sea a modo de ejemplificación de las tesis involucradas o a través de la referencia paratextual. ${ }^{18}$ Con respecto a este último grupo -la referencia paratextual de la propia obra genera el efecto genera una inversión en la relación entre teoría y obra pues la cita transforma el escrito en un complemento de la obra de videodanza, y resulta así útil para descifrar las claves que permitan comprender qué concepto de cuerpo, de movimiento y de Videodanza se juegan en ella o al menos, en el pensamiento del artista durante la creación.

Ahora bien, considerando la pervivencia de éstas dos líneas principales de reflexión teórica, tomamos como referencia la formación institucional canónica (escuela de cine o academia de danza) de los autores- artistas que, sin embargo, navegan en aguas de un arte huidizo, caracterizado por el collage y la fragmentación y lo inter y transdiciplinario. 
Entonces se puede dar lugar a la pregunta: ¿Es realmente autorreflexiva la palabra del artista? o dicho de otro modo ¿el artista está ocupando un lugar en la teoría que se puede ilustrar con la metáfora de "la serpiente que se traga su propia cola"?

La respuesta parece en un principio afirmativa, sin embargo, toma relieve como signo o síntoma en la producción teórica actual de Videodanza, la presencia de un nuevo modelo de artista-escritor que, sin negar el molde de gestación primero (el haberse formado en un arte "puro"), se sitúa para escribir, en ese mismo lugar indefinido que le permite moldear sus obras a través de un código propio.

Así, la cada vez más creciente tendencia a los cruces disciplinarios (en el caso que nos ocupa, los artistas que dejan la cámara para ser performers de sus producciones y a la inversa), repercute en la reflexión teórica y habilita al individuo a hablar de su obra pero "desde otro lugar," no sólo desde la vereda del frente a su experiencia en imagen o en danza, sino desplazándose del centro de la escena (este sujeto se permite incluso, reflexionar sobre la obra de otros e incluso sobre la obra de artistas de otras regiones) buscando siempre algo más allá, de sí mismo y de lo que el campo le ofrece a su capacidad de crear.

\subsection{Balance}

La escritura del artista de videodanza deja entrever, a veces, a un sujeto que sobre la formación canónica primera ha adquirido recursos de otras disciplinas artísticas, reflexión teórica, e incluso en desempeños que en nada aparecen ligados con a la esfera del arte y la estética.

Este artista-escritor es más un habitante libre del mundo y de los lenguajes que un erudito disciplinado. Así es que hay una teoría, la que pertenece a este creador de videodanza - uyo emplazamiento no puede definirse del todo, a caballo entre el manifiesto, la crítica o la simple expresión literaria- que "dice mucho más" en ese intento por ubicar a su propia obra en una narrativa cuya existencia está signada de antemano por la ausencia de una narrativa maestra.

\section{Notes}

1. Steimberg, O Semiótica de los Medios Masivos. Buenos Aires. Atuel (1993).

2. Otra es la apuesta que realizan algunos autores de Videodanza al presentar sus obras en festivales de cine independiente como es el caso de 5(cinco) de Jonahtan Perel, presente en el BAFICI 2008 en la categoría Cortometraje. En este caso podemos pensar en la incursión, con cierto éxito, de este arte híbrido en circuitos discursivos cercanos pero no propios.

3. Nos remitimos al rol que ocupa tradicionalmente la crítica, esto es formar parte fundamental de la cadena de producción, distribución y consumo de los productos artísticos y, en este sentido, ser generadora de público. Ver Traversa Oscar Cine: el significante negado. Buenos Aires. Hachette (1984).

4. Arthur Danto (1997), Después del fin del Arte, Buenos Aires, Paidós, pág 26.

5. Danto esquematiza la narrativa maestra de la historia del arte occidental, como una era de la imitación, seguida de una era de la ideología (donde la filosofía explica el arte), seguida de nuestra era posthistórica "... en la cual podemos decir, calificadamente, que "vale todo" porque es el fin de la narrativa maestra.

6. A partir de las operaciones que realiza, esto es "informar sobre la actualidad del arte y clasificar el discurso focalizado dentro de una serie histórica tanto en lo que se asemeja como en lo que se diferencia de él". Daniela Koldobsky (2005) "Sobre la conflictiva metadiscursividad de las artes visuales a partir de las vanguardias" en AAS: Actas del VI Congreso de la Asociación Argentina de Semiótica, Buenos Aires, pág 3.

7. Ibíd., cita 5, pág 65 . 
8. Cuauthémoc Medina y María Minera "Crítica de Arte Contemporáneo. Conversación entre críticos" (www.letraslibres.com) (registro de audio).

9. Barthes, Roland (2005) El Grado Cero de la Escritura (seguido de Nuevos Ensayos Críticos) Buenos Aires, Siglo XXI Editores 1972, pág 25.

10. Pues así como el artista "debe ser sujeto de su tiempo," . . para que la crítica de arte perdure tiene que haber un individuo reflexionando frente al material que le presenta la cultura de hoy y bajo la presión de demandarle espacio a la cultura contemporánea. Demandarle al tiempo una producción de su tiempo y demandarle al sujeto el tratar de ser un sujeto de su tiempo. Esta es una demanda modernista pero que aún involucra a la crítica de arte actual". Ibíd., cita 9.

11. Ibíd., cita 10, pág 26.

12. Paolo Fabbri señala que"Naturalmente no se puede impedir la idea de que existen algunos signos que para ciertos fines se consideran últimos pero. Pero ello no significa que siempre existan signos últimos, como las palabras, cuya combinación produce frases o textos. Si acaso podemos afirmar lo contrario: sólo existen textos, textos de objetos, no textos de palabras o de referencias, textos de objetos complejos, pedazos de palabras, de gestos, de imágenes, de sonidos, de ritmos, etc., es decir, conjuntos que se pueden segmentar según la necesidad o la urgencia". En Fabbri, P., El Giro Semiótico (1999) Barcelona, Gedisa.

13. A propósito, podemos tomar la caracterización que realiza Oscar Steimberg al referirse al discurso de las vanguardias históricas, abundantes en lugares comunes. El autor se refiere al carácter fatal ya circunscripto en la retórica aristotélica, de la apelación a los lugares comunes en la argumentación. Estos son el reservorio de fórmulas ya aceptadas e instaladas en la memoria pública, a la que debe recurrir el expositor para asentar las premisas de la construcción retórica, y en el mensaje de las vanguardias aparecen como una contradicción interna insalvable. Steimberg, 1999 "Vanguardia y Lugar común", SYC Nro. 9/10 Buenos Aires.

14. Ibíd., cita 14, pág 4.

15. Foucault, M. Las palabras y las cosas. Cita parafraseada de P. Fabrri. Ibíd cita 13, pág 40.

16. Las vanguardias históricas arriesgan la posibilidad de comunicación y construcción de un público, en la medida que el discurso artístico pierde toda previsibilidad. Aquí radica la causa de irrupción a la escena artística de los manifiestos, y a partir de allí la crítica encontrará nuevos despliegues y convivirá con un creciente y expandido discurso acompañante lbíd., cita 7, págs. 3 -4.

17. Podemos decir, entonces que el artista que también teoriza se amolda a la caracterización de Danto "Los artistas hoy están al final de una historia en la cual aquellas estructuras narrativas (las que finalizan en la Modernidad) jugaban un papel, y de este modo pueden ser distinguidos de los artistas que de alguna manera imaginé sentimentalmente como quienes primero emergen como especialistas en una temprana división del trabajo que los habilitó como individuos dotados para asumir las responsabilidades estéticas de la sociedad. . . ". Ibíd., cita 5, pág. 68.

18. Genette Genette Gérard (1989) Palimpsestos. La literatura en segundo grado. Madrid. Taurus 1982. 


\title{
Perplexed Writing: Towards a Possible Encounter between Criticism and Videodance
}

\author{
Susana Temperley \\ [Original translation by Mariana Di Silverio; \\ additional translation and editing by Valerie Klorman]
}

$\mathrm{T}$

he following words don't seek to talk about videodance, but about writing on videodance. Interest in this topic emerges from something that begins to take shape as a problem: videodance has found a space and has enjoyed prolific growth in Latin America but, nevertheless, it has not yet succeeded in awakening the interest of critics.

The fact is that criticism, one of the most important metadiscourses for the life of artistic genres and languages, ${ }^{1}$ can be defined as an extreme disconnect between the production and theorizing of videodance. The still incipient existence of critical texts becomes evident as compared with the vitality that its object of study has acquired. We can establish parameters for this situation by considering the context of the location of contemporary art in general, where the possibility of permanence and validity of the museum as a space for the circulation of works of art comprises one of the most current topics of discussion. In the case of criticism, conversely, the issue of validity as a means of circulation does not seem to take part in any discussion.

Thus, in view of criticism's palpable retreat, a question can be formulated in order to contribute to the opening of the debate: do formats of criticism and the questions criticism raises enable it to persist in functioning as a part of the metadiscursive device of contemporary art? The absence of criticism, still underhandedly, of hybrid arts such as videodance, might suggest something about this matter.

On the other hand, we encounter the writing of the artists themselves. The reflective word of the creators of videodance becomes more and more frequent (and fecund) and is oriented towards inquiring into their own pieces or theorizing about the language of videodance, summoning disciplines such as philosophy, epistemology, art history and even politics. The fact is that the different circuits that circulate works (especially festivals) have begun to open themselves up to parallel spaces, directed only at theoretical discussion which, for the moment, only occurs among the artists themselves.

Currently, the existence of these texts is of utmost importance since they constitute the only existing metadiscourse about videodance, while at the same time they point out a structural lack of writings external to the maelstrom of the production of pieces. Thus we can talk about theory coming from the field of artistic production as a means of expression that, though necessary, tends to generate a structural silence in the circuit of circulating works (despite fluid exchange through websites and blogs). Consequently, the possibility of a videodance "market" is still far off, and while many artists find themselves presenting their work independently or via festivals (more and more sophisticated and complete), as well as in itinerant exhibitions, the consumers of videodance that are generated by any of these means remain precisely the artists themselves. This is one of the crucial differences 
regarding video art in general which is, somehow, being exploited in more "profitable" circuits opened up by large corporations in the technology world (mainly telephone companies) through a neo-patronage that, while it may generate controversies, nevertheless seems to take over a place that was empty before.2

To summarize, there is a space within theory that is unoccupied, but there is also another, which has started to mature and become systematized. The crucial point lies in the proliferation of writings stemming from the field of artistic production itself, which implies certain advantages but which cannot replace criticism in the specificity of its role. ${ }^{3}$

The existence of criticism that opens up the field to a professional or at least renewed reflection seems to be crucial. For that reason, and in considering this topic, another question emerges: if a criticism in videodance existed, what role would it have to play in view of this complex and still controversial artistic language? In order to attempt to answer this question, we will have to take into account that the existence of criticism determines to a large extent the importance of a mode of artistic expression in culture, since it contributes to the designation of the status of what it criticizes and circumscribes it as an autonomous space of aesthetic effects.

\section{What Does it Mean to Be a Critic in Videodance?}

\section{Resolutions}

According to Danto, the aesthetic considerations that govern our relationship with the pieces, and even the concept of art itself, are not ahistorical and at the present time we find ourselves in a moment of radical change: "We should think about art after its end, as if we were emerging from the era of art into something else, the exact shape and structure of which remains to be understood" (26). ${ }^{4}$

The author accepts that art is paradigmatically unpredictable, but further, particularly in this moment, we would be facing a structure in which "everything is possible." Thus, contemporary art is too pluralistic in its intentions and realizations to allow it to be captured along a single dimension and, therefore, art criticism should be as pluralistic as post-historical art itself. ${ }^{5}$

How, then, do we understand "post-historical" criticism? Or, we should at least ask ourselves if it is possible to postulate lines of approach to contemporary works that allow us to continue defining criticism as a genre. ${ }^{6}$ If criticism has the task of determining the historical structure to which the piece it criticizes belongs, as well as the meanings it conveys and the intentions it satisfies, then there is an effect of uncertainty that becomes evident from the beginning, since we are facing an historical structure in which anything is possible. That is, we lack a master narrative that serves as a reference to critics to answer these questions.

\section{But Danto makes a proviso:}

Today anything is possible, in the sense that certain things were not possible for a European or an African in 1890. Still, we are locked in history. We cannot have the system of exclusionary beliefs that prevented artists in Europe from making idols and masks... But there are no forms today that are forbidden to us. The only thing that is forbidden to us is if they have the kind of meaning they had when they were forbidden to us. (65) 
According to this thesis, the emergence of a kind of criticism that is specialized in posthistorical languages such as videodance would confront an object of study characterized by freedom of form as well as newness and unpredictability regarding its "meaning," whereas criticism itself would be unthinkable outside of this "everything is possible" regime of beliefs.

This uncomfortable position that is presented to art critics of our time (either we call them contemporary or post-historical, it makes no difference) becomes evident in their own reflection. As the Mexican critic Cuauhtémoc Medina mentions:

Present-day art has to do with a territory that assumed (as an inheritance) a change in creative possibilities and in the dilemmas between those creative possibilities and discourses, images, sounds and social structures... Those of us who are inside this territory (criticism), do not understand more than those who are outside. Rather, we are open to the experience of having to build our relationship with these objects time after time, encountering pleasure in that moment of estrangement and learning.

Nobody teaches us how to develop it. The so-called experts become just as perplexed as everyone else. We probably cannot even do anything with what is being presented to us and precisely in the territory where we can establish dialogues between us, where we share our excitement, where the discourses are set up, is precisely that territory of perplexity...but we are not in a position to reject anything in the face of the condition of practices that are not held to any already known device?

In the face of this scene, videodance critics, upon assuming their role, would confront in first instance the need to "resolve" the dilemma of their own position, since it is possible that they may not be able to do/say anything with what is presented to them as an object of reflection. At the same time, the critic won't be in a position to reject it in order to return to a safe place, to the place of those art forms that are defined by a traditional device.

\subsection{Writing}

\subsection{Concepts}

Now then, writing is the medium where critics resolve their position. And right here another problem appears. Barthes describes the act of writing as a sort of paradoxically tragic gesture:

Without a doubt I can select any such mode of writing today, and in sodoing assert my freedom, aspire to a freshness or to a tradition; but I can no longer develop it for any period of time without gradually becoming a prisoner of someone else's words and even of my own. An obstinate residue, which comes from all previous modes of writing and even from the very past of my own writing, drowns the sound of my present words. Any written trace precipitates like a chemical element, at first transparent, innocent and neutral, in which mere duration gradually reveals a whole past in suspension of increasing density, like a cryptogram. $(25)^{8}$

The matter is that criticism of videodance confronts the task of "accompanying" and valorizing certain objects - which always live in a present characterized by the absence of limits in form - and as we have already seen, it is supposed to do it within that same historical structure. The critic must execute a writing of his own time, a time that is the same as the artist's (Barthes 9) but by means of signs that resist saying what has never been said before. 
Writing is a stale language which is self-contained and is in no way meant to entrust its own duration to a mobile series of approximations, but rather, on the contrary, it must impose, in both the unity of its signs and what is leftover by them, the image of a kind of speech that was constructed far before it came into existence. (Barthes 26)

So, to talk about something it is necessary to name it, and words designate, define and demarcate what is possible to be said. Art could be "anything" as defined by Danto, but criticism, even post-historical criticism, cannot talk about it in any kind of way. So, supposing that there exists or could exist someone so (irresponsibly) tenacious as to undertake the task of critiquing videodance, how could this individual analyze with limited language something that does not have any limits?

In other words, the criticism of videodance could be a kind of writing that arises from perplexity but that can never be imprecise or ambiguous without distorting its own character. With that being said, one aspect appears where it is possible to situate oneself in order to begin to escape from such difficulties: the permanent redefinition of concepts. ${ }^{9}$

It is already known that criticism will have to maintain a particular vision in order to assess different "types," whether those works center on technological experimentation (the eagerness for discoveries about new possibilities in movement and form, without entirely losing the aesthetic character), or on expressiveness, poetics and "humanistic" content or social context. Yet even above each one of these aesthetic lines, however, the critic will face, every time, a work that is different in its form, its grammaticality, in its unique being, that at the same time and without specifying how, is a part of a group (which a priori can only be characterized as "all the pieces like this one"). Here is where the writer will have to be able to propose beforehand a series of concepts through which something true can be said about a piece of videodance. So it is a matter of managing to develop concepts that are capable of being transformed according to each object and each position that writing may assume in the face of it.

The need for accuracy becomes abysmal (but not unthinkable), and for that reason, every time critics undertake a new object, they must subject the notions they use in their writings to permanent examination - from which the idea of a body intervenes in a videodance, in which aspects of the discipline are emphasized by choosing the term videodance and "dance for the camera", and even beyond that, because, certainly, it will be necessary to ask oneself about the meanings of device, movement and space that are present in the piece. And this, just to enter into the analysis - and many times, to create other new ones especially formulated for each case.

A signal then: the permanent reconceptualization of the notions that define and will continue to define the language of videodance becomes necessary, but before that, we must be able to create them.

\section{Common Places}

Now, we are faced with another problem to be solved: the freedom of the object tends to have repercussions on an abuse of the "common place" and on crystallized metaphors (catachresis). These appear as a symptom of the weakening of criticism in almost every other contemporary artistic language, from which videodance criticism still escapes simply because it lacks systematicity. Nevertheless, while they blur the writing, clichés 
and stereotypes are an intrinsic part of every reflection about art that emerges and seeks to mature, since they support the exchange of ideas and dialogue between critics and readers ${ }^{10}$ in the same way that floats are useful to the castaway.

Thus, common places and catachresis, are also being outlined in the case of writing about videodance, hence, pausing for a moment to think about them can turn out to be an interesting experience: What can be said through formulas such as: the "manipulation of the image," the "exploration of the landscape of dance," the "symbolic appropriation of space,"'dance experience,"'synthesis between dance and image,"'an involving experience... in which the audience becomes submerged," and the frequently cited "dialogue between camera and body"?

Crystallizations themselves that also crystallize a referent, common places, "are the effect, in their argumentative appeals, of the inertia of cultural memory" (Steimberg 4) and thus, they appear as a will that orients itself toward a past and therefore, in the opposite direction of the language that is its object and which is characterized by the complexity and the search for specificity in an unpredictable context situated somewhere between the present and the future.

Now another signal can be incorporated: the need for a permanent, alert position in the face of the very terms and phrases that define the language of criticism and that also act as rhetorical indexes of genre, while threatening their function as a period of time: saying something about an object that resists even being named.

\section{Taking Stock}

Defined by a double contradiction, one relating to the continued existence of a common place (which tends to eliminate particular reflection and complexity, while nothing can be communicated without it), and another one based on the ambiguity of concepts (the signs that limit what is possible to be said while there is no way to say anything without them), we glimpse a possible existence of a metadiscourse about videodance that seeks to endure beyond its own fatality: not only as writing but also as criticism, to the point of running the risk of finding itself in a place as tragic as that of silence in the face of a work of art.

The lines above give a report on a criticism of videodance that is still incipient, almost absent, but which already shows traces of its "post-historical" condition because it confronts the difficult if not impossible task of practicing the act of writing in order to assess something that often ends up being so novel that there are not yet any words to qualify it.

Thus, perplexity and writing are the places between which post-historical criticism and its object are developing. If videodance enables the perplexity of the spectator, it is fertilizing criticism's soil; and if criticism manages to change into something else-in such a way that it could modify the parameters that have historically defined it-its constitution as an accompanying metadiscourse of Videodance will be possible.

"The only reality, Foucault used to say, is not in words nor in things, but in objects. Objects are the result of that encounter between words and things" (Paraphrased in Danto 40). 


\section{Reflections on the Word of the Artist}

Koldobsky points out that:

... the last few decades of the $20^{\text {th }}$ Century are the result of redefinitions about works of art, the practice of art and its relationship with other social practices impelled in that period, that is, that from now on, the legacy of an accompanying word by an author does not come to be strange, beyond the form that it takes. ${ }^{11}$

This is, perhaps, an interesting point to explore in videodance in its historical context, and even, tangentially, the "post-historical" role ${ }^{12}$ of the videodance artist since whether it is about an accompanying word or the development of a novel function, the fact is that, at the present time, theory dedicated to reflection about this aesthetic practice finds itself almost exclusively under the control of the artists themselves.

Now then, I will refer here to the theory we could define as "auto-reflexive" and which is presented as a "reading deciphering key" for the piece itself but also as a guide for the comprehension of the language of videodance. If we take a panoramic view of Latin American writings of the last few years, two large groups emerge, oriented by a defined function (which can appear explicitly or not in the discourses themselves):

1. The works, belonging almost exclusively to audiovisual artists who navigate the waters of videodance, which propose, as a principal task, to inquire about the technical possibilities of the camera (framing, movement, editing effects, etc.), with regard to a time and a space tied to an object-body or to a body as a material that can be manipulated. These writings "organize" the techniques of images, tested out in their own productions, as well as the effects achieved by their application. They do so in such a way that they appear as a sort of "handbooks" legitimized in their own experience and directed towards the search for new possibilities of production and expansion of the limits of videodance above and beyond what has already been made and seen.

2. Those writings whose authorship corresponds mainly to individuals trained in the art of movement, which raise questions of epistemological and philosophical nature about the concept of the body, have a role as a subject or as an object in the always changing and troubled relationship with the camera, or the essence of videodance as a hybrid language, among others. In many of these essays, quotations about production itself and even the personal experience of the artist are included, either as a way of exemplifying the thesis involved or through paratextual reference. ${ }^{13}$ Regarding this last group: the paratextual reference of the piece itself generates an inversion in the relationship between theory and works, since the inclusion of quotes transforms writing into a complementary element to the videodance piece. Thus, it proves to be useful for deciphering the codes that allow us to understand which concept of body, movement and Videodance comes into play in it or at least, in the artist's thought in the course of the creation.

With that said, considering the permanence of these two main lines of theoretical reflection, we take as a reference the canonical institutional training (film school or dance academy) of the authors-artists who, nevertheless, navigate the seas of an elusive art, characterized by collage and fragmentation, and the inter- and trans-disciplinary.

So, this can give way to this question: Is the word of the artist really auto-reflexive? Or, in other words, is the artist occupying a place in theory that can be illustrated by the metaphor of 
"the snake that swallows its own tail"? The answer seems to be, initially, affirmative. Nevertheless, it stands out as a sign or as a symptom in the current theoretical production of videodance, the presence of a new model of artist-writers who, without denying the first gestation mould (having been educated in a "pure" art), situate themselves to write in that same undefined place which enables them to shape their pieces through a code of their own.

Thus, the growing tendency toward disciplinary crossings (in the case that we are currently engaged with-artists who leave the camera in order to be performers of their productions and the other way around) has repercussions on theoretical reflection and enables individuals to talk about their works, but "from another place." Not only, that is, from the other side of the street from their experience in image or dance, but moving away from the center of the scene (these subjects allow themselves to reflect on the others' work and even about the work of artists from other regions) always looking for something beyond themselves and beyond what the field offers to their ability to create.

\subsection{Taking Stock}

The writing of the videodance artist insinuates, sometimes, a subject that over the course of a canonical education has first acquired resources from other artistic disciplines, from theoretical reflection, and even from performances that do not appear to be linked in any way to the field of art and aesthetics.

This artist-writer is more a free inhabitant of the world and of languages than a disciplined scholar. So there is a theory, which belongs to this videodance creator-whose location cannot be entirely defined, riding on a horse between manifesto, criticism or simple literary expression - which "says much more" in that attempt to place his or her own artwork in a narrative whose existence is already marked by the absence of a master narrative.

\section{Notes}

1. Steimberg, Oscar. Semiótica de los medios masivos. Buenos Aires: Atuel, 1993. Print.

2. Another one is the bid made by some authors of videodance in featuring their pieces through independent film festivals, as is the case of 5 ( $\mathrm{cinco}$ ) by Jonathan Perel, present at BAFICI 2008 in the category of short film. In this case we can think about the incursion, which is to some extent successful, of this hybrid art in close discursive circuits but not in its own.

3. We refer to the role that criticism traditionally assumes, this being an essential part of the production, distribution and consumption chain of artistic products and, in this regard, being an audience builder. See Traversa, Oscar. Cine: el significante negado. Buenos Aires: Hachette, 1984. Print.

4. Danto, Arthur. Después del fin del arte. Buenos Aires: Paidós, 1997. Print.

5. Danto sketches the master narrative of the history of western art as an era of imitation followed by an era of ideology (in which philosophy explains art), followed by our post-historical era "... in which we can say, with qualification, anything goes" because it is the end of the master narrative.

6. Stemming from the operations it carries out, this is "to inform about the current state of art and to classify discourse focalized within a historical series both in what it resembles as well as in what it differs from it." Koldobsky, Daniela. "Sobre la conflictiva metadiscursividad de las artes visuales a partir de las vanguardias." AAS: Actas del VI Congreso de la Asociación Argentina de Semiótica. Buenos Aires, 2005. 3.

7. Medina, Cuauthémoc and Mar'a Minera. Cr'tica de Arte Contemporáneo. Conversación entre cr'ticos. Web. <www.letraslibres.com> (audio register).

8. Barthes, Roland. El Grado Cero de la Escritura: Nuevos Ensayos Cr'ticos. Buenos Aires: Siglo XXI Editores, 2005 (1972). Print. 
9. Paolo Fabbri points out that "Naturally, we cannot prevent the idea of the existence of some signs that in some cases are considered to be final. But that does not mean that there always exist final signs, such as words, the combination of which produces phrases or texts. Perhaps we can state the contrary: there only exist texts, texts of objects, not texts of words or texts of references, texts of complex objects, pieces of words, of gestures, of images, of sounds, of rhythms, etc, that is, groups that can be segmented according to need or urgency." See El giro semiótico. Barcelona: Gedisa, 1999. Print.

10. Incidentally, we can consider the characterization made by Oscar Steimberg regarding the discourse of historical avant-garde art, abundant in common places. The author refers to the fatal character already circumscribed in Aristotelian rhetoric, of the appeal to common places in argumentation. These are the reservoir of formulas that are already accepted and established in the public memory, to which the exhibitor should turn in order to situate the premises of rhetorical construction, and that, in the message of the avant-gardes, appears as an insurmountable internal contradiction. Steimberg, Oscar. "Vanguardia y lugar común." SYC 9/10 (1999). Buenos Aires.

11. Historical avant-garde movements risk the possibility of communication and audience building, insofar as the artistic discourse loses any predictability. Here lies the cause of the irruption into the artistic scene of manifestos; from there criticism will find new displays and will coexist with a growing and expanded accompanying discourse. Ibid. 7, pp. 3-4.

12. We can say, then, that the artist who also theorizes becomes adapted to the characterization made by Danto "Artists today are at the end of a history in which those narrative structures (those which end in Modernity) have played a role, and thus they can be distinguished from the artists that I have somewhat sentimentally imagined as those who first emerge as specialists in the early division of labor that enabled them as gifted individuals to take on the aesthetic responsibilities of society" (Danto 68).

13. See Genette, Gérard. Palimpsestos. La literatura en segundo grado. Madrid: Taurus, 1989. 


\title{
When Dance is Imagined In Cinema: Disclosure in Dance Practice
}

\author{
Marisa Zanotti
}

m

n this paper I explore scenes from two dance worlds on screen and explore how cinematic and narrative strategies are used that, I would propose, ask us to question the conventions of both cinema and dance, as well as to look again at the "reality" of the world around us. One is a "fiction" about a dance company creating a performance from Bizet's opera, Carmen, in Carlos Saura's 1983 work Carmen;and the other, also released in 1983, is Chantal Akerman's documentary "Un Jour Pina a Demandé," about spending five weeks with Pina Bausch's company.

These films may seem poles apart. Saura's is on the surface a mainstream dancedrama, full of virtuoso camera work and technical polish, which explores Bizet's Carmen using familiar dance narrative tropes: youth over experience, and a female heroine being absorbed into a male vision, punished for her sexuality and ultimately sacrificed. Akerman's typically subjective poetic documentary couldn't be more different aesthetically, replete with long takes, as well as sequences that privilege the moments in-between performances as much as the performances themselves.

What strikes me about these two very different works is that they share scenes of dancers looking in mirrors. Initially this linking theme might appear a conventional strategy, as many films with dance as their subject have such scenes. Through exploring the image of the dancer looking in a mirror, either in rehearsal or in the dressing room, this paper will suggest that these works highlight engagements with the real world as being a product of both Baudrillard's notion of the imaginary and also aspects of what he refers to as the process of symbolic exchange.

For many dance artists and academics active in the twenty-first century, it was not dance in theatre but dance on screen (which, by the late twentieth century, was not always simply a filmed stage work) that constituted the first experience of dance. With this came a notion of not just an audience's perspective on dance, but rather what dance might feel like and its expressive potential. Perhaps more strongly the dance viewer also received messages on how to "be a dancer," to live the life of "a dancer"; or, as D'Lugo suggests in a broader argument about Saura's work, that this (dance) identity"is itself the result of a willed submission to a cluster of artistic and social mythologies" (193).' In Baudrillard's terms, this points to a state where the world is produced by the imaginary, which is "the perspective of the human self, its self identifications through images and objects and its capacity to represent — producing the 'illusion' of the real" world (Pawlett 59). ${ }^{2}$ This becomes particularly interesting when considering dance on screen and its capacity to explore and expand not just perceptions of dance or indeed its cinematic potential, but also perhaps how we consider the practice of dance.

In the twenty-first century, mainstream dance narratives on screen often have messages that depict the dance world offering redemption from a future of crime or poverty (Honey), 
or as a safe haven from racial and class divisions (Save the Last Dance). However, there are also the films of the late 1970s like All That Jazz, The Turning Point,or Argento's classic horror Suspiria, which suggest a different kind of dance world: one of self-sacrifice, discipline, loneliness, manipulation of women by male mentors, and drama or/and death as a kind of punishment/destiny for becoming part of this world. Carmen draws on the conventions of the films of the 1970s; it could be said that these films, like Carmen, echo The Red Shoes, although this paper will not enter into a discussion of the influence of The Red Shoes, as much has been written about Powell and Pressburger's film. Un Jour Pina a Demandé offers an insight into the work of Wuppertal Dance Theatre through a documentary on the work of Pina Bausch that has footage of rehearsal, performance, backstage scenes and interviews with both Bausch and Akerman. Here there is no linear narrative thread created and no attempt to cast the work in line with objectivity, or indeed what might be recognized as documentary realism.

In choosing to discuss Carmen I am revisiting a work that excited me when I first saw it in 1983 as a young dancer. Carmen won ten international awards and six nominations, including the Oscar nomination for best foreign film. Twenty-seven years later I am still as excited by how intriguing and provocative it remains today. I would suggest that it is worth examining some of the subversive strategies at work that may on first viewing not be immediately visible, especially in a filmic space where rehearsal, performance and reality become indistinguishable amongst a company of dancers.

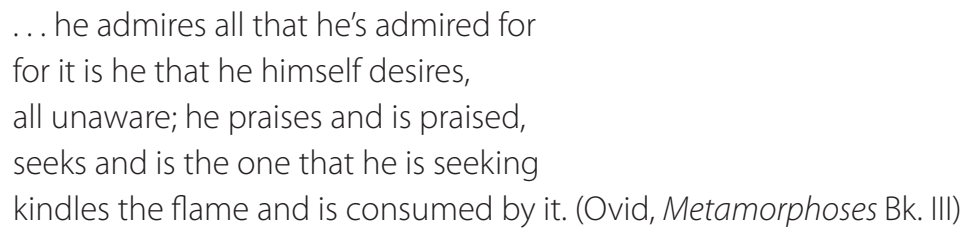

The importance of the mirror in Carmen, and thus its semiotic implications are made evident immediately in the opening of the film. D'Lugo, in his book on Saura, The Films of Carlos Saura: The Practice of Seeing, gives us a detailed analysis of this, and of what he terms the figure of performance (193) as a key theme for discussion. In this book he offers a comprehensive analysis of Saura's Flamenco Trilogy and of the role of the mirror in Carmen. In the filma series of narrative/visual strategies are used through the theme of the mirror and the gaze by way of a contemplation of the image of self and of other dancers. The film foregrounds narcissism and the mirror, and explores the process of looking as an operation that unifies fictional and non-fictional worlds in a state of performance. As the narrative develops, the spectator enters into the world of a play within a play (itself a form of narcissism as the work of art reflects upon itself), with themes of the creation of identities in dance and Spanish culture.

In this context, the question might also be asked, at which point does the dancing body become fictionalized; in dance are we ever really in a fictional body space? The scope of this paper does not permit me to explore all that this question implies but I will begin to consider it as a theme.

Being a dancer is often a process of looking, being looked at by other dancers, and imagining being looked at. Sometimes in the studio the dancer is performing an imagined performance for an imagined spectator. If using a mirror, the dancer might glimpse herself 
performing an imagined performance for an imagined spectator. This addition of another layer of spectatorship is of significance. The sequence from Carmen described below is played in front of mirrors and is intermittently watched by other dancers in the company as they too rehearse.

The character Cristina is pitted against the younger Carmen. Cristina asks to help Carmen demonstrate how to approach a choreographic sequence of elaborate gesture, watching herself in the mirror as she does so. The scene can be read in relation to another familiar trope, exemplified by Antonio the choreographer passing over an older female dancer for a younger woman. ${ }^{3}$ However, what is more interesting in this short scene is the spectator seeing a version of the process of repetition, in this case a reflection on a reflection, a process that is so much part of classical dance practice. There is a depth of understanding here of both dance technique and dance pedagogy. ${ }^{4}$ This scene deals with issues of narcissism, especially when we see Carmen (the character's name) learning that being Carmen (the character in the dance drama of Carmen) is an act that unites mind and body, desire and will. Although Carmen as a character is a fiction, the body of Carmen as Carmen is a reality lived by the dancer. I would in addition suggest that there is a connection for the dancer between the experience of moving accompanied by the simultaneous act of seeing, and being seen in a performance that is both in the present and in the future, an imagined performance.

This is not a separation from the self, but perhaps what the viewer is seeing here is the act of the fictional character Carmen becoming not just Cristina (and there is a hint of that) but also an awareness that she has won out against Cristina. Perhaps it can be suggested that she is becoming "the dancer in the mirror": she is entering a "mirror world" with all the possibilities that this might offer. A mirror world in this context might be defined as a space, which allows the dancer/choreographer to enter into a world, and a process of imagined (and Imaginary) performance. In the mirror world Carmen sees herself in relation to her value in terms of youth and beauty and in her potential as Antonio'sCarmen. However here we might return to Baudrillard who, in "Revenge of The Mirror People" says: "objects, children, the dead, images, women, everything which serves to provide a passive reflection in a world based in identity is ready to go on the counter offensive" (149). ${ }^{5}$ Carmen is no passive ingénue, and whilst the action in the film appears to superficially mirror the Opera's narrative, Antonio tries to create his Carmen and possess herin both the mirror world of the dance he is creating and in the world outside that. She is a modern young woman driven by her own needs and desires. She exists independently of his artistic vision.

Where the film can be read as truly subversive, however, is in showing us that it is Antonio who is in crisis: he is quite literally out of step, a victim of his striving for an authentic, essential truth in a world where there can only be what is produced through representation. This desire is both in relation to his recasting of Bizet's opera and the need to create an ideal, a "real," culturally authentic Carmen. Antonio's vision is of a Carmen that returns the story to its Spanish (as opposed to French) roots. Marshall Leicester, Jr. develops very interesting arguments in relation to Saura's exploration of authenticity in Carmen (something that Antonio Gades was also deeply concerned with in his work with his own company). I will not attempt a full exploration of this argument in this paper but a key point would be that Leicester, Jr. highlights that Flamenco is a recent construction. The dance drama envisioned by the character Antonio is both too close to the clichés of Bizet's opera 
and is also a new form that integrates episodic structure and flamenco, "itself the product of a world where tradition itself is always under construction always being extended to cover and to justify new needs and desires" (256). This would suggest another example of the imaginary attempting to recapture the real. D'Lugo further analyzes the role of the mirror: for example in a scene alone in his studio that not only shows Antonio engaged in a narcissistic display but in the aspect of dance that is critical, contemplative, where thought is visible in the body. On the surface Antonio is choreographing sequences or assessing himself as a dancer, however implicitly in this process of dancing he is also a man struggling to define himself through his body within a culture that is itself being questioned and redefined. I would also add that Antonio's crisis is connected with his performance of another series of roles coming out of the myths of a (screen)dance culture: impresario, jealous lover and aging dancer.

This paper has explored themes of performance through Saura's film Carmen, one of which themes seems to be asking: when does the dancer enter the world of the performance; or rather, when does she leave it? In Un Jour Pina a Demandé (referred to henceforth as Un Jour...) Akerman explores a similar question through images of mirror worlds and in showing rituals around performance and rehearsal. In Un Jour... the still camera in the dressing room shows us what appears to be a familiar image: dancers in the dressing room or in backstage activity, smoking, putting on makeup, sitting around. Here there is sense that, at moments, the dancers, whilst allowing Akerman into their world, do so through a sense of the performance of that world; and that Akerman herself, in her creation of the work, is also engaged in a form of performance.

What Akerman's formal choices create is the possibility to reconsider the significance of these rituals as we move between dressing room/rehearsal and performance. After a while these worlds and these times lead us to explore a space of multiple exchanges. When a dancer sings a folk song to herself in the mirror, is she rehearsing what will happen later in some future Bausch work? We see a couple smoking together; this image gathers momentum when later they perform a disturbing smoking scene. These images reflect one another in different ways in our memory. One remarkable sequence is a montage of dancers applying make-up before and during a show while looking in mirrors: they are powdering their faces, the framing rendering the actions choreographic, the rhythm echoing the rhythm of small gestures in sequences on stage. Akerman playfully draws our attention to the relationship between this ritual of preparation for going on stage, with the rituals of gestures shown on stage.

The film is particularly poignant when she shows us the dancers in quiet moments. We might recognize them from our knowledge of the company on stage, but in comparison to how we see them in a state of performance, when they are driven, physical and vocal, here they appear almost ghostly. The traces of themselves in Bausch's dance works are evident only in what they are wearing; otherwise they seem light, insubstantial. They inhabit in Akerman's world another kind of fiction that of the dressing room versus the "reality" of their personae on stage. Akerman suggests a netherworld that dancers move through; the images hint at them being ghostly figures: looking in the mirror, are they checking they are still present, and if they are, in which world - that of the performance or the real world? Just as in the examples cited previously with respect to Carmen,the space of the mirror again becomes a space for contemplation, both in the repetition of a ritual of preparation and 
as space for gathering the self together again through the narcissistic rituals of grooming. Here the boundaries between fiction and documentary are blurred through Akerman's poetic vision. As in Carmen, looking in the mirror becomes an exchange that takes the dancer and the spectator into another kind of world.

In Akerman's documentary we are not sure (because we are not told) which show we are looking at over the five weeks Akerman spends with the company. ${ }^{6}$ Sometimes we seem to be watching the dancers in a series of altered states, in performance, in rehearsal and in the dressing room. However, through the filmic space she asks the viewer to question fixed ideas about the separation between on and off stage. Throughout the documentary Akerman does not privilege any event as being more interesting or significant than any other. As noted previously it is not unusual for backstage to be a fascinating figure in a film work about dance, but in Un Jour..., where we might expect some kind of revelation that this is where the drama really is, we are instead shown that not too much "happens." Butler quotes from Halbreich and Jenkins in Foster: "hers is a cinema of waiting, of resolutions deferred."When we watch Bausch's dancers in the dressing rooms they appear on the surface to be doing very little. However it becomes clear that we are glimpsing them during not just one performance but also one of a series of performances. Akerman is suggesting something about Bausch's work, an investment by the dancers, and in fact herself, in this process. She immerses the viewer in this world and we are witness to her experience.

It is typical of Akerman that she is interested in mundane activity arising from moments in-between events, and that these non-spaces become events in themselves where time collapses. Here her interests chime with Bausch, for whom duration is an important feature of work. Akerman looks at the work of performance as part of a process, not just one final event. She creates duration where the time of rehearsal, of dressing room and stage overlap. This echoes what we might call "Bausch-time," for Bausch often articulates time in her works as a layering of fictions and memories of childhood, family, adulthood, place, and social and performance rituals.

In this paper I have argued that the cinematic visions of Saura and Akerman invite us to reconsider practice and performance, authenticity and fiction in the context of dance as acts of symbolic exchange. Akerman makes little difference between documentary and fiction, forcing us to question through her radical choices the way in which cinematic conventions create and obscure meaning; this subsequently creates a new lens through which to view familiar scenarios. In Carmen,too, we find radical strategies, perhaps most of all in Saura's treatment of death, wherethe division between the world of the mirror and the world on the other side is removed. Deaths and murders are performed but we are never really sure whether anyone dies or indeed whether Antonio is imagining events. Therefore not only do we have a work that destabilizes us constantly as viewers through shifts of time and space, but also a work where death is rendered as not final.

The subversive potential of performance in Carmen is in turn amplified when that performance is also a performance of death. This resonates with Baudrillard, for whom the separation of life and death is the basis of the power structures and controls produced through binary thinking; and for whom economic/semiotic systems are built on the notion of fixed categories. Performance in this context can also be read in relation to Pawlett's definition of symbolic exchange, being seen in acts which are challenges to these closed systems (48). Or as Baudrillard suggests in The Perfect Crime: "Now the image can no longer 
imagine the real because it is the real" (4). Both Carmen and Un Jour. . . seem to deal in exploring notions of binaries, pointing us towards ideas of performance as a dual form. When Saura and Akerman ask a question in cinema about where dance performance begins and ends, they raise the possibility that dance performance might be both the cut and the suture for a world where Reality is a product of the process of the Imaginary. In these films, dance on screen affords a medium through which complex issues surrounding dance and dancers, performing and performance can be addressed.

\section{Notes}

1. D'Lugo, Marvin. The Films of Carlos Saura: The Practice of Seeing. Princeton: Princeton University Press, 1991. Print.

2. Pawlett, William. Jean Baudrillard. London: Routledge 2007. Print.

3. In the stage version of Gades' Carmen it was Cristina Hoya who played Carmen (muse paper)

4. See Mark Franko on transference in dance pedagogy in: Of the Presence of the Body: Essays on dance and performance theory. Ed. André Lepecki. Middletown: Wesleyan University Press, 2004. 113-123. Print.

5. Baudrillard, Jean. The Perfect Crime. London: Verso, 1996. Print.

6. The final sequences of the work are interviews with both Bausch and Akerman; we find out that the company was performing Bandonen, although there is footage from Nelken in rehearsal and performance filmed while the company was touring, presumably in the five-week period. 


\section{Bob Lockyer}

Bob Lockyer, former executive producer for dance programs at BBC Television and founding chair of Dance UK, was interviewed by Douglas Rosenberg at the University of Brighton in 2008. This interview was transcribed from video.

Douglas Rosenberg: I'll start off with some history-basic stuff: how did you start; what were you thinking; what was your plan; what happened; how did you get to where you are; how did you get to this point here-?

Bob Lockyer: Well, my professional working life was at BBC television. Television at that time (and I should say that when I left it ceased to be) was a creative medium. Writers were writing for television - the television play. It happened in America, it happened in Europe, it happened in England and elsewhere, but the major problem [was] that choreographers making dance programs weren't getting a chance. There was dance on television, but that was mainly either replays, or things that were brought into the television studio. I mean, it's hard to remember when I started; the idea of videotape was very new. The idea of a digital camera - I don't even know if it was Mr. Sony's dream or not-if there was a Mr. Sony. The first bit of videotape, which I would actually keep in my wallet to show people [was] two inches wide. You couldn't cut it directly, and it cost a vast amount of money. But, I really felt that choreographers, if we could find some choreographers, should use the medium of television. A national broadcasting organization was the only way to do it, because you didn't have lightweight equipment.

Actually, the first chance I had as a director was working with Lynn Seymour on a project, which was based on the poem "The Swan." I've actually got [to get] it out to look at tomorrow - just to see how good or bad it is - because I haven't decided whether I am going to screen it at something. It lasted fifteen minutes, was set to a string quartet, and it was totally created for the camera. In fact, it was much more created for the camera than was planned because, for various reasons, we ran out time and, at the last moment, we had to reduplicate shots to make up the time. The thing was, it was being what I call 'washing line.'The washing line is the music, and then we had to fit the visuals to the washing line; the music wasn't written afterwards.

That was the first thing we did and then [because of] various funding difficulties, nothing else happened; we were bringing in works and making work in the television studio of stage works, but we were not making creative works. That chance came at the BBC when Mrs. Thatcher decided, in her crusade against the BBC, that the BBC had to have twenty-five percent of its output made by independents; that immediately allowed us to go to work with the arts council. And so, dance for the camera was born as a result of Mrs. Thatcher's right-wing attack on the BBC, trying to make production companies make work. That was the birth of dance for the camera.

DR: As far as the starting point ... it would be helpful to have a date.

BL: You see, it must be . . I think we're talking the late eighties, I think. I'm terribly bad about dates. I'm just always looking ahead; I'm never looking back. I suppose I should have looked up and seen-but I think it must be the late eighties, early nineties; it's about ten 
years. Where are we now? About ten or twelve years. Out of that collaboration with the arts council, we made over fifty films; which is quite something.

DR: So let me ask you, because you sort of slid into this notion that dance and television went together, or should go together. Can you go back now and talk a little bit about why? First of all, what was your interest in dance? And second of all, why did you think the marriage would be valuable?

BL: Well, I got into dance because I'm dyslexic. In the days of live television, you had to prompt actors. You prompted actors with a little button that you pressed, and that cut out the sound leaving the studio and leaving the transmitters. So, you gave them a prompt from the prompt corner in the theater. And I got that completely up the spout one day and was sent home from the BBC; it was: "Go home at once!" Then I was called back and they said, "Oh, you must work with Margaret Dale," who was sort of an ex-dancer who worked at the $\mathrm{BBC}$ doing dance programs. She mostly brought the Royal Ballet into the studio. But, she worked with [Birgit] Culberg, and various other people, bringing them into the studio to make work, to make television versions of stage works. I started working with her and got involved with Peter Wright, who came in as a television director for a time, before he went back to the theater. I started writing scenarios of short dance films, some of which were made, and some weren't. I just felt absolutely, just strongly, that the choreographic eye was something that was important to bring to the screen. I think there are choreographers who are not interested in it in any way at all; it just does not cross their mind. They don't understand what the camera can do. I mean, I think, it's where the moment of creation happens. In making a dance for the stage — it is in the rehearsal room [first] — then it ends up on stage. In making a film, you have the rehearsal process, the shooting process, and the creation really happens in the cutting room. Certain choreographers are not interested in that process at all. Others of them will just stay there, working away, discovering what one frame, two frames, can do to the whole meaning of the complete film, and are really fascinated by it. That's what we were trying to do-what I was trying to do-was to give them another form of expression.

DR: You're sort of articulating an arc of activity from, more or less, restaging choreographic works for television to — towards the end of your work, which you did at the BBC — creating work out of whole cloth. So, that's quite an arc and the end product is quite different, I think.

BL: Totally different.

DR: So can you talk about how that evolution occurred? And what occurred in that evolution?

BL: Well, I suppose working for a public broadcast . . I absolutely believe the best stage work should be made available to as many people as possible. And, as the touring costs of dance companies increased enormously, the opportunity of seeing work, I felt, was terribly important. That's what I mainly did; most of my time at the BBC, I was a director who brought stage works into the studio, and re-created them. But, what I then discoveredthat I knew-was the whole idea that screen-time and stage-time is something that is very, very different. [When] you are directing something that then already existed, you had to be very careful not to let the cat out of the bag too early, or you were left with a bag. If you're dealing in a narrative, which is a story line, there were needs for reaction, counter-reaction, because everybody by then had a television, and understood the language of television, 
and the screen. They understood the screen language, which didn't necessarily work with the stage work. And that's what I was trying to do, was to give choreographers-directors liked to work with choreographers - the opportunity to understand that. [To] use what the screen can do, and what the juxtaposition of shots can do, because the frame is all you have. Whereas, on the stage, you are sitting there and you have no proof where the audience is actually looking. Some people may be looking into the eyes of the person sitting next to them or looking at the stage, but not looking at the center of what the choreographer was thinking about. In a funny way ... I always said that ... if you ... bring a work into the studio, to film a stage work, you actually don't need all those things with the lighting, because the lighting is there to direct the audience at what to look at, what the choreographer wants people to look at. So, in fact, the lighting and the cutting of the script are almost identical.

DR: So where was the transition point, then, for you?

BL: Well, there was never really a transition point, because they both kind of went along in parallel. I mean, the other problem is one of cost. If you were doing a work that was already created, it's actually the creation costs that have been paid for-the dancers have danced them, and worked them. So, if you take something like a Lloyd Newson or DV8 work, "Enter Achilles," which we did, or "Strange Fish," the film versions, which are totally different from the stage versions, which actually came at the end of the production period. They had been produced, they had worked on the stage, they had toured-perhaps in some cases for a year or eighteen months - and then they were re-made with original performers for a film. That process was very exciting and very different, because what happened was, in both cases, the setting of them became totally realistic. In "Enter Achilles," it moved from a strange stage set into an old disused pub_-in real spaces — and the dancers re-inhabited this old pub with all its furnishings.

DR: So, how did that happen?

BL: Well, that was a decision that Lloyd made with some discussion with me, mainly on his own. He jut knew that what works in the theatrical space would not work in television. You are so used to seeing reality, whether it's a war in Iraq, or you're watching nature programs, it's based on reality. Therefore, that's what he ... that's how he did it. I think that the whole idea of the theatrical would not have worked; a great ramp stage that lifted up like a craggy mountain at the end is a very theatrical thing. So, the whole thing changed, and in the same way, time-wise, it shrunk from ninety minutes to a television hour. So, forty minutes of the material was cut away, for the reason that one close-up can tell you a lot more than a three-minute dance, perhaps. And that, I think, is something that choreographers have yet [to understand] — that you actually, with small gestures, are telling enormous stories.

DR: When you're talking, I'm thinking of the parallels between what you're describing and literary translations from text, books or fiction, to cinema. There's a . . I never thought about this before...

BL: Yeah, there's a great similarity ...

DR: Because you're thinking about dance as the original text ...

BL: Yes...

DR: Which is being translated, in a way, in the same way that any other text would be translated... 
BL: Yes - so yes, I think that's it. Except, often in a dance situation you have ... the music is actually again, the washing line ... and you can't take four bars out of the original piece of music, if it's something incredibly well known. But, you can do it if the music has been written and it can be re-written or re-used. I mean, [that was] the advantage of just using Lloyd's piece, as an example. It was a montage, it had a soundscape; you could play with the links of all those things. Cut out a verse, in other words, and lose the two minutes of that [verse], but shorten it all.

DR: So, were you aware ... was there a consciousness at all of what was going on, what was afoot, when you were making this kind of work? It was a pretty huge change, a pretty powerful cultural phenomenon.

BL: Yeah, I think there was a political move at the BBC at the beginning, which was the BBC as a patron, an arts patron; and that certainly was one of the pushes. Whether that came as a result of what we had done ... they suddenly started writing about it, and it was in the annual report. As the importance of the BBC as a patron of the arts, whether that came first or we were first ... I have a feeling it came after, I think we were leading the way. I mean, I pushed at a slightly open door. I'm not sure that they knew what they were getting, but we succeeded in winning successfully quite a lot of awards with the project, so I think it was quite exciting. But then, politically, it has now completely changed; the whole process of commissioning has changed, and it has sadly fallen off the table.

DR: But, for better or for worse, you created a model.

BL: Yes, yes, we created a model and I was incredibly lucky that I then went around the world talking about it, and teaching it, so I was quite lucky that way. And that, I think, was a bit [of a] strange way, because I was on the staff and getting a salary ... and there were down times. If I could fill the down times by going somewhere, I was out of their minds and out of the way. So, I was incredibly lucky. I went to Australia and worked with various people there, went to Canada a couple of times, and BAMF, where I met Katrina McPherson, [while] working. I mean, so I was incredibly lucky.

DR: As is everyone else in the community. Again, for better or for worse, you created a model.

BL: We created a model, whether it was the right model or not, I'm not sure. The problem was the one model is then taken up, for good or for worse around the world, you might say, almost. But, I mean, it was a model of plurality —if that's the right word-yes, a plurality of funding. It allowed a broadcaster and two major arts funders, or people, and the company itself, to come in with the amount of money you needed.

DR: So let me just state this question again: For better or worse, your activities, left, or created a model that became the dominant model. If you could reflect on that a little bit and start off by describing what this model is, first of all.

BL: I suppose "Dance For The Camera" created a model—the BBC and the Arts Council created a model, which was taken up around the world. [lt] was the idea that teams of people, a choreographer and a director, come up with an idea, a creative idea. They submit that on one side of paper. Originally, they then went away with development money, and if they were lucky with the development [money], they went to the commissioning stage, made the work at the end, and we as the commissioning editors — like in all films - came 
in, looked at it, accepted it, or didn't accept it. That's it, briefly. The idea was that it allowed [us] to have a large number of people coming in, putting in ideas, and then slowly working down to people who were getting the commission. I think, on the whole, that [it] was quite successful. The problem was, over the ten years, more people wanted to come in, and there was an encouragement of the new people. I think if there was a criticism, it was the old stages, or the people on a learning curve of experience [who] didn't get a chance to have another go, or two goes or three goes. You're not going to make a masterpiece- or perhaps, you are going to make a masterpiece the first time. Perhaps not the second, but it's the third, fourth time [you] begin to understand the language you're working with. I think there was, then, the whole problem of the duration. I think we were all very concerned, but certainly the powers that be at the BBC wanted something that would fill the television slots. And to actually make a twenty-minute dance film - twenty-five, thirty minutes, or whatever the necessary slot-takes a lot of time, and a great deal of money. So that's why fifteen minutes, for example, was the maximum we did for the dance on the camera. We did five and we did nine, and I think the sort of ten-minute slot was the best. [It] was manageable in the budget, and in the time, and actually with the people, working with the people, [they] could actually do [it] with the money that they were given. I mean the thing was that we were absolutely insistent that the creative team actually did get some money out of it. So often in arts things, doing things for love becomes so important; but I think it's important that you actually earned your bottom dollar.

DR: Well, I'm using the term "model," but part of the model ... once again, if you could go back and sort of talk about this. You described some formal constraints, which lead to the residual effect of, in a way, this sort of short attention span.

BL: Yes, I think I, yes...

DR: Do you want to just go with that?

BL: Yes, I'm trying to yes, I suppose, for better or for worse, the dance for camera projects set up a formulaic system. It was very much based on television and the whole idea of television, and sustaining how long people could watch television for. I always think that you don't actually watch television-you listen to it. You move out of the room, you go onto this ... it's very rare that you sit there glued to the television. You listen to it while you stroke the cat, have a cigarette, glass of wine, or whatever. So, it was working within the formats of television that these projects were devised. And what was fundable, and what was acceptable would get screen time. So that's why they were a series of short, short films, and not hour-long films. Also, budget-wise, one was never going to get a budget that would allow a choreographer to make an hour-long dance film. In fact, I don't think, even now, there is anywhere a choreographer that could make an hour-long dance film without some training, knowledge of the medium. Perhaps there is now. But I don't know . .. whether they would actually want to is another thing. So, I mean, we built this thing, but the other great regret about "Dance For The Camera" was the actual distribution of it. It was designed for television to have one transmission, or two transmissions. And that's all it got, and they were forgotten. The great problem with dance, with dance itself on stage, is that there's no past. If you are a student who is studying dance now, and you want to know who Martha Graham was, then you can dig out the old movies of Martha, because they are actually available. But if you were looking at dance in the United Kingdom, it's very hard to look 
up, and find footage of the Ballet Rambert, for example, in the fifties, or early Christopher Bruce; all those things are not there for you to look at as a dance student. And I think that is a problem. Also, students of dance for the camera, which now, [there are] seemingly courses are starting up all over the place, they have no idea of the past, or what people have done. The work of David Hinton, and his work "Touch" and "Birds," and those sorts of things, and his work with Lloyd are not really available for study. So, everybody starts new, which I think is one of the great sadnesses.

DR: One of the other things that I wanted to talk to you about a little bit, because I keep coming upon new things, one of the things that I've been thinking a lot about lately, is the nature ... or not nature, of the actual curating in the screendance community. For instance, a festival shows ten or fifteen films - they have nothing to do with each other; there's no relationship, you have to make a relationship. So, it's like walking through a gallery seeing paintings of fifty different people. So again, for me, it's become the status quo; and for me, it's a big concern. I don't know if you want to talk about that. Things like genres in dance films...

BL: I think what we did at the BBC, at the arts council ... we made a number of films, fifty films; and the development of the work in Australia, in New Zealand, in Canada. Everyone was so excited that they actually made their five films. They were very proud and then showed them, and the idea of dance screen exhibits, and dance screen festivals opened up. And everyone said "how wonderful" or "gosh, how not wonderful." We've now got to the stage where there is a body of work, a considerable body of work. I have no idea how much, but I suppose there must be 5-10,000 small dance films around. But, there's really no one who knows anything about them, or who can get a hold of them. You know, there are a number of curators who curate the festivals, but often their festivals are just screening what has happened in the latest films. They're not saying, well what l'd like to do is a film series about the work of one particular choreographer/director or however; or one period of time. There is a sense that being able to look at your past, no one is actually looking, and writing, and talking about the art form. And, it's funny that that's what we need to do. We need to be proud of our past and be extremely critical of the work that has gone-but creatively critical about it. We just can't say it's all rubbish, but why we think it is rubbish . . . and writing about how people are using the language, the choreographic language, and the filmic language, and that's not happening. Well, it's not happening as far as I know in the UK, I don't think it's happening anywhere, and that is a great loss. Because, whatever it is, it's actually having a body of work that you can read about things. You can say to people, "here, have you seen this article by somebody?"You can print it off; it may be on the web, but when you print it out and read it, the art form has come of age. At this moment, I don't think we have come of age; we're still in the playroom I think.

DR: It seems to me that much of the feeling, in general, now is simply based on circumstance. So in other words, there's funding for this or that, the circumstance is that it produces some films; or we started a festival, and they've gotten entries from a hundred people. So, the circumstance is that they show these. It's reactive rather than proactive.

BL: Well yes, it's much ... yes ... are you going to be proactive, or are you going to be reactive, as you say. I think, you know, it's much easier, in a funny way, to be reactive than it is to be proactive. You know, it's easier to say, "look I've got these twenty-five films which 
I've discovered, which are wonderful, and we've got to have some money to screen them." That's [more] possible to get together [than to] say"I want to commission these twenty-five people to make films based on - "or whatever the thing, you know the idea, the concept is: loneliness, oneness, whatever; to find that kind of money to commission work, is incredibly hard. It's also the same thing of not having a past; you if you can't get hold of people's films to say, "look this is Laura Taler: I'd very much like to get Laura to make a film about being a refugee, or about being a stranger in a new city." Or whatever the concept is, it's very hard to get, very, very hard - certainly in the United Kingdom. Looking at the cinema, and more and more in television as well, it's a totally written medium, the whole understanding of funding is for the written word. It is the script; everyone can have their opinion on a script it can be re-written-people can talk for hours about 'ands' and 'buts'; and should scene 14a come before14c; and what about if we transport it all to New York, wouldn't that be better because I don't think we can sell it in the Midwest if it's Ipswich in the east part of England, it's got to be in America, and we can give you more money for it. They've got something in their hands that they can work on, but if you're working on a choreographic idea, which is a physical idea, it is incredibly hard to explain what it is. To explain to somebody who has no knowledge of movement, no knowledge of the person you're fighting for, that's the difficult thing. Choreographers, some are wonderfully articulate about their work, and some aren't, and that's the really difficult thing. How do you describe a dance film if you're going off to raise funding for it?

DR: Which would bring up the question, how do you describe a dance?

BL: Yeah.

DR: Once you begin to describe movement, you demystify it, and it becomes...

BL: Well, well you know, I was just thinking, Pina Bausch was in London a few months ago with "Café Muller." I think everybody in that audience had a different view about what it was all about. What were those people pushing their way through those chairs, opening those big doors and making their way into the room? What was it all about? Why was it gray, strange, and what was it? That's the wonder of it, is that it's actually working. You know, you switch on the telly and there are the mean streets of New York and the hallowed police car, you are immediately there, knowing where you are. The excitement about pure movement, I think, is that you're not quite sure where you are; although, we might understand so much more than people realize, by how people sit, what they do, how they walk. We know so much about people from that; I mean, body language tells all. Body language is ninety percent of communication. We do know what people are feeling if you go somewhere; you can see whether people are happy or sad; you can tell through body language, and that's what you can certainly do, I think, on film. Dance film is not about dancing on the screen, it's not Fred Astaire and Ginger Rogers, it's something other than that. It's interesting how little dancing, dance-screen work may have in it. I mean, you [can] choreograph with an eyebrow as excitingly as you can with a grande jeté across the stage; in fact, more powerfully. I think there are various moments in big movies where, if you start looking at them, there are sequences where there is no language at all. I'm getting ready to deliver this lecture, I was looking at the The Leopard, Visconti's film, and there's this party at the end, which lasts about twenty-five minutes. There's very little dialogue, and what dialogue they have doesn't matter to the story at all. You get the whole collapse of this man, the Prince 
going down, and suddenly discovering that old age is taking over, and youth is coming in, and the society that he has been brought up in is slowly beginning to collapse. It ends with, well it doesn't end but ... with a wonderful scene, in close up of Burt Lancaster with a tear just coming into his eye. It is an amazing screen work. I've also looked at Mon Oncle, the Jacques Tati film. [In that film], the language doesn't matter; it's not mime, it's the use of real movement, in these cases, real historical settings that are coming to tell you things — telling you a great deal.

DR: So if you were now to describe any situation you want to describe, and see it through, what would you imagine dance film to be? If you could imagine a new era ... maybe it's the same as before. If you could make it all up, what would your vision be?

BL: I'm not sure what my vision would be. I'm not sure if my vision would be very different from when I started out, which was giving people the opportunity to use the medium, and explore the medium in a new way. I think I would like-if I was given a million- or five-million dollars, or whatever - is to work with two or three people who I admire [and] to carry forward an idea which we could work towards in a different way, which may lead to something, to finding out something new. But, I think it takes time, and it takes creative time, and I think that's certainly, in choreography and in dance screen time, that's not what's there; there is not a possibility of really sitting down and thinking of ideas and storyboarding ideas, which you can then take somewhere. That's what I would like to see. I would like to be given three, twenty-minute films or something; to commission three people who I admire enormously to make three different projects. I think it might take us into different areas.

DR: I'm also thinking about the transition. Your work was made for television.

BL: It was made for television because that's where I worked, and that's where the opportunities were. Television is this monster that ate material, and instead of showing another ballgame, why don't we show a bit of art? That's really why, I mean, I felt very strongly that the arts should get, and dance in particular, should get their moments of glory on telly.

DR: That's fine...

BL: I think what has changed now, is that with multi-screens, with everything, with the digital age, with the lowering of the common denominator, it's become very different. The problem is, you know, the worldwide web and being able to download projects. But, whatever you can do, whether you're pay-to-view or [however] you are going to get that money, that initial money [must come] from someone to make the project. Whatever happens, you may open up the possibilities of screenings. [Wherever] you do it, it's there, and you can see it on your telly, or wherever you watch it: on your mobile phone or your computer. The initial funding has got to be there to make the film. Or, you can go away and of course make something, shoot it on your mobile phone and transmit it on YouTube, or however you do it. Some of it is, I'm afraid, crap; a lot of it is crap. But, it's giving people time, really, to think. Thinking time and development time, which is most important.

DR: So at the beginning, the translation issue ... for instance, Laurence of Arabia was made for the wide screen; it suffers when it's viewed on television. So, the opposite of that: the work that's made for the television screen has been taken, again, fully formed and...

BL: Put on the big screen ... 
DR: But when brought into the festival situation and projected really large, there's not much thought about what happens in that translation. Do you know what I mean? I wonder if you have any thoughts about that; the way that dance film has just migrated from one venue to another without some sort of context or consideration; if that's an issue.

BL: I don't mind where it's [screened], as long as it's screened well. I don't mind whether it's appearing on the small screen or a big screen. I object if it's clipping bits off the top, or if it's slightly out of focus, or those things. I'm very surprised sometimes at how good something made for the small screen appears on the big screen. Then again, the amount of what you can get away with when it's only being the tiniest amount of space on your television screen ... when you blow it up, there becomes, suddenly, a bloody big hole in it or something. You know, continuity goes to somewhere- I don't know. You don't necessarily notice on a television screen, but you do notice when it's blown up large. In the wonderful world of high definition, [there are] going to be even more of those changes; things are going to be made clearer. You know, as the technology gets better, it shows everything. Whereas in the days where the technology was very simple and very straightforward, it was black and white, or perhaps in color, you could hide an awful lot of things behind it. Now you can see it, if you look at old movies and things. We're now so used to wanting to see it all-warts and all-but that all costs a great deal of money.

DR: You mentioned earlier the Lloyd Newson, the DV8 stuff, which was rife with content-I mean it was deep work. Again, what seems to happen in most, in many, movements, as more and more people come to the form, what lasts is form. So it seems like you might see a hundred dance films now-and in my opinion most of them would be more formal: a dancer in the rain, a dancer in a building — without any sort of depth ... .

BL: Yeah I think there is a danger, but I think this has to do with being young, and growing from things you want to do with your friends. You think, "gosh, isn't it wonderful? Where can we go film?" I think if I see another disused factory, where everyone clomps along in a disused factory, everyone seems to have to make their film in a disused factory. A lot of it, no thought is given to it. What is the disused factory bringing to what you're dancing about? You could just take the dance, and put it on stage, and it would be just as viable. In fact, it might be better because what you're doing is just filming a piece of dance. You're not using the film camera to say something different in the editing process. When people say, "Let's record my dance," that's what a lot of people are doing. You've got to make the first dance step you make believable. If it's not believable in the context that you're dancing it in, you've lost your audience straight away. If you lost them, then it's no more than a pop video.

What we are trying to do is something that has more meaning, which requires thought, rather than sitting watching a pop video. I think that's not what people are being taught, or thinking about - the actual contextualization of their movement, and their film-and what the idea [is]. Is there really a true idea, and is theatric movement the way to express this idea, on film or on the screen? And often, that's not it; often, you just have a very nice piece of dance that could have happened on the stage, which people film. What Lloyd Newson did, was take a stage work and the ideas - intellectual ideas - behind the stage work, which may have been two to three years of intellectual study and thought, and rehearsal, and then 18 months of performance with a group of actor dancers, which then was squeezed 
out and made, condensed down to a piece of screen work. In that condensing downbecause that's what the screen does, it condenses down-all you want is a shot of me and a shot of somebody, and there is an interaction taking place that we don't necessarily have to express in a dance way or in a melodic way; so it's actually what dance movement, dance screen movement is...

Where does the art form fit in, if it is an art form? It doesn't fit in the world of the cinematic literature. It doesn't fit in the world of television criticism because there isn't any around the world. It doesn't fit with British Film Institute cinema or all those things because it's not cinema. It's not in the movement of the art film business, which is the big business at the moment really. So it has its practitioners, but it doesn't have its supporters and that's the major problem. I think in the next two to three years, [we have] to find a way, [by] finding supporters who will write about it, talk about it and be able to screen it. And then I think it'll be able to grow.

DR: It's, ironically, kind of a blank screen right now ...

BL: Yeah. Dance film comes out of, and it's part of, the television and the movie business and the role of the producer and the executive producer, in that business is a very creative and important one. And I think that the role of the independent artist working alone in his garret, or her garret, making this product, is quite difficult. I mean, I think if you're a writer, you may well send chapters of your book to somebody you trust to look at. On the screen, I think that there is a sense that you have got to share as a dance filmmaker. If you're making dance film, you've got to share that work with other people in the creative process. Film is a shared creative process. In a funny way, you can now do it on your computer at home in one room. When I started, it was always a community that you were working with-your film editor or your video editor-who were working together. He would suggest things and you would suggest things, and you say, "Well I don't like that, but I like that. What if we combine those two?" I think that dance making, films and television programs have always been a community activity... And, I think that there is a danger of becoming just a one-man band, a solo thing. You get so focused in on what you want that you cannot necessarily, we say, see the wood through the trees. I think that the use of somebody coming with a clean eye to it is terribly important and that [it] would help a great number of films that I see. I mean, the theater in Europe has dramaturges and things like that, and I think that it's not just an isolated form. It's a people, it's a form where you need input all the time, and I think as much input as you can get makes your film that much better.

DR: We could talk forever. Let me ask you, is there anything that I haven't addressed that you...

BL: No, I can't think ... can I think? No, I don't think there is. Leave that for another time. 


\title{
Re-view
}

\section{Cutting Rhythms: A New Perspective on the Rhythmic and Choreographic Nuances of the Edit}

\author{
Cari Ann Shim Sham*
}

Cutting Rhythms: Shaping the Film Edit. By Karen Pearlman.

Burlington, MA: Focal Press, 2009. Pp. 269. \$39.95 (paper).

$\mathrm{R}$

olled corners, post-it note covered, writing in the margins and dog-eared pages are the signs of a well-used book. When I look at my copy of Karen Pearlman's 2009 publication Cutting Rhythms I realize that I might need to get another copy. After just one pass at this book, it looks as if I've spent a lifetime with it. I must admit that while reading it, I had a very hard time putting the book down and couldn't quell my excitement whenever I came upon a cohort in the world of editing, filmmaking or dance for camera, blurting out "you've gotta read this book!" Cutting Rhythms seeks to deepen the understanding and definitions of rhythm in the shaping of the edit. It also investigates how the body of the editor experiences the physical act of cutting. The book's author is interested in undoing the mysticism of the craft by explaining in layman's terms over-used or undefined words in the field such as "intuition." In her Preface, Pearlman states, "the idea was to base my research on words that are frequently used, but infrequently defined in the regular course of editing a film, such as 'structure,"montage,'and 'rhythm"' (ix). And she does just that.

In twelve chapters Pearlman gracefully covers a wide range of issues and technical definitions for more deeply understanding the practice of editing. Chapter 1, as its title implies, addresses "Rhythmic Intuition" by discussing intuitive thinking. She bravely explores, breaks apart and examines the topic of intuition. She begins by quoting Donald Schon, who writes: "When people use terms such as 'art' and 'intuition,' they usually intend to terminate discussion rather than to open up inquiry" (2). Pearlman argues that "intuition" is commonly used as an excuse, as a means to avoid technical or scientific explanation of an editor's craft, thus allowing editorial practice to remain mysterious. She challenges this by defining intuition on several levels, and ventures into the unclaimed territory of topics ranging from explicit knowledge, implicit learning, and kinesthetic empathy to, finally, my personal favorite, mirror neurons (a new and exciting subject that is springing up in science and dance scholarship). She finishes the chapter by explaining how rhythm is perceived, learned, practiced, and applied in editing. 
In Chapter 2, "Editing as Choreography," Pearlman draws on her movement experience to explain the art of the edit as "a dance," a move that illuminates Pearlman's ability to weave her perspective and experience as a dancer into understanding rhythm in editing. Chapter 3, "Timing, Pacing and Trajectory Phrasing," and Chapter 4, "Tension, Release, and Synchronization" are clear and straightforward in their content, and support her introduction of a new concept: "Trajectory phrasing,"' Pearlman writes, "is a term I have devised to cover an area of editing rhythms that is not precisely addressed by the terms 'timing' and 'pacing'" (52). Pearlman, however, can also come across as heavy-handed at times. For example, in Chapter 4 she presumes to speak out for all editors in a personal tirade: "Editors hate it when directors snap their fingers or hit the table to indicate where they want a cut because these gestures, as well as expressing a kind of dictatorship or distrust of the editor's intuition, can actually jump between the editor and her own feeling for the material" (70).

Chapters 5 through 8 explore different types of rhythm found in traditional film editing, including physical, emotional and event rhythms. In these chapters the author analyzes popular film scenes as visual tools to explain various editing conventions and stylistic choices, staying within the familiar territory of classics such as The Godfather and Gone with the Wind, to name two.

Chapter 9, "Style," discusses collision, linkage, montage, and decoupage. Her definitions of the latter two alter the French use of the words, "drawing on the common understanding of the term among English-speaking editors," and might be considered biased among nonWestern audiences. Chapter 11, "Common Scenes," is a breakdown of two-handers and chases; I found it to be the least interesting section in the book.

Pearlman's twelfth chapter is the conclusion of the book and my favorite piece of writing. Through definitions, explanation and reassignments of meaning, Pearlman constructs an apparatus of rhythm theory that suggests similarities between choreography and editing - why, that is, the two make good bed partners. This speaks deeply to me and helps me to better comprehend how l've found myself understanding the edit through my own dancing body's experience. Pearlman writes: "Choreographers make dance phrases, and editors make cine-phrases, but both are shaped by the tools of timing, pacing and trajectory phrasing ... consideration of the choreographic possibilities for shaping movement and energy over time is one way of understanding and possibly expanding the craft of cutting rhythms" (248).

Being a filmmaker and editor who teaches in the field of dance, I find Cutting Rhythm to be a great addition to the classroom or reading list for anyone teaching or studying the form. Pearlman includes helpful exercises and role-playing assignments throughout the book that would be useful in workshop or classroom situations. Considering there are few books written on the topic of the edit in relation to rhythm and movement, Pearlman is a big fish in a small pond. This text forges new territory of multi-disciplinary analysis that serves as an enlightening resource for editors, filmmakers, and choreographers working in dance and or film. Pearlman's rigor and the specificity with which she explores her topic, the shaping of the edit, is unmatched. She so thoroughly explores, explains, and demonstrates varying ideas on rhythm and the shaping of the edit that any editor, amateur to professional, will come away with new and useful information.

If I were to offer any critique, I dare say, I was very distracted by her choice of only using the gender specific pronouns "she" or "her" throughout the entire book. It seems to me an 
unnecessary and distracting gender politicking in an otherwise brilliant piece of writing. Congratulations to Pearlman for tackling such a mysterious subject and contributing a strong new addition of material to our libraries, studios, classrooms, and bedrooms, as well as to all who collectively share the love of dance and camera, movement and screens, rhythm and the edit. 



\title{
Re-print
}

\section{Toward a Definition of Moving-Picture Dance}

\author{
Noël Carroll
}

[Ed. note: This article was originally presented as a paper at the "Dance for the Camera Symposium" at the University of Wisconsin-Madison in 2000, and subsequently published in the Summer 2001 issue of Dance Research Journal.]

Imost since their inception, moving pictures have often featured dance. The obvious
reason for this is that the natural subject of moving pictures is movement. And
dances_-along with hurtling locomotives, car chases, cattle stampedes, tennis matches, intergalactic dogfights, and the like-move. Thus, a significant portion of the history of moving pictures involves dance movement. Many moving-picture makers have devoted admirable amounts of effort and imagination to portraying dance in or through media as diverse as film, video, and computer animation. The purpose of this essay is to attempt to offer a philosophical characterization of this field of activity; that is, I will try to define moving-picture dance.

Many readers, learning of my intention, are apt to groan, "labeling again, how boring." To a certain extent I can sympathize with that sentiment. It is far more interesting to talk about work than it is to set about classifying it. The concrete achievements of the field are more important than abstractions about it. Nevertheless, and despite my ready acknowledgment of this, I will persist for several reasons.

First, whenever festivals of this sort of work are held, it is very likely that at one time or another almost everyone present will be tempted to say of some work that it doesn't really belong on the program. Everyone complains about labeling, but sooner or later most people feel compelled to invoke some favorite definition of their own. For human beings, categorizations are unavoidable, even if we like to pretend indifference to them. And most of us can feign indifference only for so long; most of us have a breaking point. Thus, it seems to me a good idea to get this issue out in the open and to discuss it abstractly — to compare and contrast the various categorizations in play and to develop dialectically from them a comprehensive framework that makes sense of our practices and that resonates with our intuitions about its compass.

Second, though defining things can be a tedious affair, it is also a very powerful way to learn about the contours of a field. For when we attempt to define the strengths and weaknesses of alternative and even rival proposals, we come to recognize the complexity of the field, since different definitions will highlight certain tendencies in the work in question, even if they obscure others. Definitions, that is, even when they are unsuccessful, as I suspect mine might be, can be illuminating. For definitions do not merely demarcate the 
boundary of a field from other fields, but they can reveal the intricate landscape within a field as well.

Definitions, in short, have a heuristic or pragmatic use, often perspicuously flushing out data and complications previously neglected, ignored, overlooked, or unappreciated. This is true even where the definition turns out to be ultimately unsatisfactory. So even though my definitions may appear either too narrow or too broad, I offer them as a way of advancing the discussion.

Another reservation about definitions, popular in the humanities today, is the suspicion that all definitions are covert exercises of power, privileging some work and disenfranchising other work. I am skeptical of this general position about definitions and, in the concluding passages of this paper I will try to show why my definitions of motion picture dance are not an ideological brief in favor of some stylistic practices rather than others. Thus, though I will not be in a position to defend that view until you have read my proposals and arguments on its behalf, let me at the outset of this definitional exercise at least register the plea that my intention here is not to create a definition that is stylistically exclusive; rather, I will attempt to craft a category that is as broad as possible, while at the same time being something we are willing to count as a genuine category.

Indeed, I am motivated to construct a broad category of moving picture dance just because I think that existing ways of defining the field are too narrow-too narrow especially in ways that cause friction, as creative artists attempt to exploit new technologies. For example, those who classify the field in question as cine-dance wonder whether computer animations of dance should be at the same festival or on the same program or in the same historical overview as works by Maya Deren. Many ways of construing the field, that is, are wedded to certain moments in the development of moving-picture technology, such as the heyday of film. But conceiving of the field only in terms of film stands athwart historythat is, it blocks the prospects, conceptually and sometimes practically, of an innovative engagement on the part of makers of dance images with new technologies.

It seems obvious that alternative technologies for the creation of motion picture dance will continue to proliferate. In order to facilitate experimentation, we will need a broad conception of the field, one that will make the exploration of previously undreamtof possibilities easier, rather than closing down options. It is in that spirit that I have offered the present definition - to invite change and development, rather than to defend the status quo. In fact, I see my definition, in contrast to existing alternatives, as a means of emancipating creativity, at least in terms of promoting openness to the inevitability of technological change, rather than as a strategy for canonizing entrenched stylistic practices. Perhaps someone will discover a way in which my proposals serve some hidden dance-world agenda. But one must spell that out in letter and verse. One cannot presume a priori that all definitions serve the interests of some vaguely defined establishment. Some may even liberate.' Whether mine does or not remains to be seen.

Undoubtedly, you will have already noticed that I have introduced a new name, "Moving-Picture Dance," for the field under discussion. I have opted for this conceptualization rather than other, more familiar ones, such as cine-dance, film dance, video dance, camera dance, and even screen dance. One way to begin to approach the problem of defining the field is to articulate the reasons for preferring one mode of nomenclature rather than others. 
Traditionally, the area has been called cine-dance or film dance. Since cine-dance is probably the most popular way of referring to the field, it is worthwhile to spend some time explaining its limitations. The problem with characterizing the field in terms of cine-dance is that it is too narrow. Obviously, it is too medium specific. It restricts the phenomenon to work made in cinema or film. It is, so to speak, a celluloid-based conception. It also perhaps belies the modernist bias behind much early work in this area. That is, it seems to suppose that each artistic medium has its own peculiar limitations and/or potentialities, and that it is the duty of the artist to foreground those unique features of the medium in her work. Thus, many have thought that for a candidate truly to belong to the corpus of cine-dance it would have to exploit the unique features of cinema, where those are customarily understood in contrast to the possibilities and limitations of theater, including theater dance.

Cine-dance or film dance, under this construal, is always avant-garde, inasmuch as it is implicitly allied to modernist commitments to the purity of the medium. For example, Ed Emshwiller claims:

To me there are characteristics that distinguish cine-dance from a straight dance film. When the dancer is used in filmic terms, rather than dance terms, space, and time are flexible. The images projected on the screen may seem to move forward and backward in time, may be discontinuous, in fast motion, slow motion, frozen, repetitious, or simultaneous. The dancer can appear to shift instantaneously from one location to another, can be compressed, elongated, distorted, or seen from widely varying perspectives. These manipulations are some of the means the filmmaker has to choreograph his work. By means of the camera and the editing table, he creates image movements and relationships different from those of the dance choreographer. $(25)^{2}$

Though this view was once extremely enabling, this conception of the phenomenon is at present clearly obsolete for two reasons. First, by now the work that we all agree belongs to the field in question includes all sorts of work in media other than cinema. Video is the most obvious exception. But also, work which no one would deny falls into the category that concerns us can be achieved through computer processing, such as the technique known as motion capture, which was used in the production of Bill T. Jones's Ghostcatching (1999).

If film was the medium in which endeavors of the kind that concern us first appeared, that fact can be regarded, in one sense, as an accident of history. For the visual culture established in the film medium has evolved and been refined by other media, and is likely to undergo even further development in media not yet imagined. This is why, rather than speaking of film studies or cinema studies, I prefer the concept of moving-image studies, which includes as its object not only film, TV, video, laser discs, and CD-ROM, but also whatever else is to come as future technologies abound and generate descendents of our current moving-image practices. ${ }^{3}$ Similarly, this is why I think that we should speak of moving-picture dance rather than cine-dance, film dance, and, for the same reason, video dance, since these categories insofar as they are each medium specific, are too restrictive. The phenomenon at hand crosses media, and, therefore, calls for a label that reflects this fact.

A second reason to eschew medium-specific characterizations of the field is related to the implicit modernist prejudices concerning the purity of the medium that often come in tandem with this way of speaking. In the modernist conception, a cine-dance should be uniquely cinematic, or uniquely videomatic — that is, something realizable only in film (or video), and not by means of some other medium of expression, notably theater. Thus, Talley 
Beatty's famous leap in Maya Deren's A Study in Choreography for the Camera (1945)-a legendary example of Doug Rosenberg's notion of recorporealization ${ }^{4}$ —is regarded as a quintessential example of cine-dance, for a grand jeté of that length would be humanly impossible on stage, but is rather an artifact of what some might call film-space and film-time. ${ }^{5}$

But this modernist bias is overly exclusive. On the one hand, what is called "film-space" and "film-time" are realizable in other media, including, if not theater, then at least video. ${ }^{6}$ And, on the other hand, it is far from evident that whether or not something is realizable theatrically is the relevant criterion here. This approach, as we saw in the previous quotation from Emshwiller, seems to favor editing and special effects as the true tests for membership in the class of cine-dances. But, as Roger Copeland has pointed out, we may wish to include in the relevant category dances, such as some numbers by Fred Astaire and Ginger Rogers, that, though made for the camera, are executed in long-take, deep-focused shots that capture movement in a continuous space (11)?

Do we wish to exclude these-which might be called "Bazinian cine-dances"—from our perspective, just because it is conceivable that they could be staged in real time on the space of a theater stage? ${ }^{8}$ Likewise, something like David Woodberry's Invisible Dance (1981), a Tati-like exercise in discovering dance amidst the flow of everyday life could be refashioned as an instance of street theater. ${ }^{9}$ But still, the version of Invisible Dance that we possess on film, I think, is something that most of us would agree is a cine-dance or, at least, whatever we wind up calling this category.

Indeed, the same point might be made with respect to Elliot Caplan and Merce Cunningham's Beach Birds for Camera (1993), since not only is it artistically impure, given its self-avowedly painterly ambitions, but also, with enough money, enough elaborate set machinery (including rotating stages), and an arsenal of lighting effects, something very like it could arguably be realized theatrically. And yet it belongs to the category that concerns us.

Of course, by arguing that this category should not be tied to a specific medium, I do not mean that the artist should ignore the medium in which she is working, but only that the medium and certain favored uses of the medium should not be the test of class membership here. The artist is well advised to understand the capabilities of her materials, including the lenses, film stocks, chromakeys, and the like which she intends to deploy. The point is simply that which of these media and their capabilities she chooses does not determine whether her work is an instance of what I call moving-picture dance.

My dismissal of the physical medium as criterial in this regard may strike some as too hasty. For the notion of a medium can refer not only to the materials from which an artwork is constructed, but also to the implement used in constructing it. Not only sounds, but also musical instruments, like clarinets, can be referred to as musical media. And, in this sense, it may seem that everything in the category of moving-picture dance shares a mediuman instrument through whose agency they are all contrived. And that instrument is the camera. So why not call the category camera-dance or dance for the camera?

There are several problems with this proposal. The first is that there are so many different kinds of cameras that one hesitates to say that we've got hold of a single medium here. Further, one can imagine moving-picture dance imagery generated not by a camera but by means of sound - sonograms, after the fashion of radar. But, as well, in a less science-fiction 
vein, we may worry that thinking in terms of camera-dance is too restrictive. Are there not animated dances, which, though they depend on cameras to be mass-produced, are primarily the result of drawing rather than photography? And would a dance composed exclusively in the realm of CD-ROM by computer animation and exhibited on computer monitors be discounted from a festival of work of the relevant sort, merely because it was not camera generated? This is another reason why I prefer the label moving-picture dance to the alternative label camera-dance.

The notion of screen dance, which I myself once found very promising, may seem to avoid the kinds of problems we've encountered so far. For it might be supposed that it is not medium specific; screens, it might be said, are shared by films, video, TV, and computer monitors. But, though this may seem perverse on my part, I think that this supposition is false, if we take the notion of a screen literally.

A screen, in the pertinent sense, is a support upon which we project an image. But, in this respect, a screen is not a necessary condition for a showing even a film. As is well known, Edison originally had the idea that films would be shown at peep shows, on devices that we would now call movieolas. It remained for the Lumieres to project films onto screens. Thus, early dance films like Annabelle the Dancer (1894-1895) and possibly Crissie Sheridan (1897) were not examples of screen dance. Moreover, the movieola/peepshow circuit did not end with the Lumieres. From my adolescence I remember peepshows of exotic dancers and strippers, available on coin-operated movieolas in amusement parks and adult bookstores. Nor were these films only single-take documentations of prior theatrical performances: many were made for the camera and edited. Films do not need to be literally screened or even to be destined for screening in order to count as films, and, therefore, there can even be film dances that are not screen dances.

Another problem with the notion of screen dance is that the concept of a screen does not really apply to television, though certainly televised dance should not be automatically excluded from our catch area. Televisual images are not projected onto a screen. We look directly into them; we do not look at their reflections or projections on a screen. Standardly, film scholars attempt to distinguish between film viewing and TV viewing this way. Because of movieolas, I do not think that this distinction is as ironclad as they do. But still, they make a legitimate point about the typical TV viewing apparatus (rather than, say, cassette projectors): in the usual case, we look into the projection and not at a reflection of the projection. The same can be said about looking at moving images on computer monitors.

Denying that TV images of dance are literally cases of screen dance may strike some as outlandish. After all, we talk about TV screens all the time. But what does this mean? Is the TV screen the front glass on the monitor-the thing that people clean with Windex and sometimes call a screen? But this is not a screen properly so called. That is, it is an entirely different animal than a film screen. For first of all, the TV image is projected through this glass and not onto it. And second, this glass is not a necessary feature of the TV image. You can remove it and there will still be a moving image. Try it, if you don't believe me.

Perhaps what people have in mind when they talk about the TV screen is the phosphor screen in the cathode ray tube. This lies between the shadow mask and the front of the glass of the picture tube. It is coated with phosphor strips that glow when different colored beams of light hit it. But the phosphor screen is part of the picture tube-which is to say that it is part of the projection mechanism, i.e., once again, part of the picture 
tube. It is not a screen onto which the image is projected. It is a device for generating the image; it is a device for projecting the image. Typically, there is no screen onto which the projector beam throws the image. In television, we usually look directly into the projection mechanism rather than at a screen onto which something is projected. Thus, most televised dance, including, for example, Twyla Tharp's Making Television Dance (1977) with all its special effects, does not literally count as screen dance.

Here I can imagine some complaints. On the one hand, some of you might say that even if the television screen is not equivalent to a film screen, it is like another sort of screen, namely the wire mesh on a screen door. Yet, if this is how you understand the notion of screen in "television screen," then you must admit that the category of screen dance is much more heterogeneous than it sounds, since the way in which one applies the concept to film dances versus TV dances is radically different, and, in some respects, contrary. The locution "screen dance" thus blurs important distinctions and muddies the waters, rarely an admirable tendency when trying to craft a concept. In addition, the analogy with the wire mesh on screen doors may not be a felicitous one to adopt here, since I assume that we would not want to call a live, three-dimensional dance, executed by live bodies, that is staged on the opposite side of a screen door an example of screen dance in the relevant sense.

Another complaint that some may have with my rough treatment of the idea of screen dance may be that when composing a film dance, a video dance, or a computer dance, one must be attentive to the dimensions of the picture plane on which one works. If it is a square or a rectangle, if it is in cinemascope or Todd-AO, the image composer must be aware of this - if only to make sure that viewers get to see what the composer intends them to see. And, more than that, if one hopes to make a genuinely effective dance image, one should study the shape of the visual expanse upon which one is working.

This is all true. And yet it is, I think, to be really talking about the frame, rather the screen, since it is the frame whose exact dimensions make certain compositions more efficacious than others. That is, for example, with film we are not actually talking about the surface onto which the image is projected, but the shape of that surface. Likewise, with regard to $\mathrm{TV}$, we are talking about image ratios and their relevance to placing figures saliently inside their borders. Though we may speak of sensitivity to the screen here, it is really just a shorthand way of referring to framing, whether what is framed appears in a phenomenologically deep space or a shallow one.

And finally, if you remain unmoved by any of the previous objections to the notion of screen dance, there is also the problem that the concept does not seem well prepared for the future. For we can readily imagine holographic dances and dances in virtual reality that we might wish to regard as part of our evolving tradition of moving-picture dance, but which will not require screens. And what of the developments that we cannot foresee? In the future there may be no screens, yet the practice of moving-picture dances may (and probably will) still be with us.

Given the problems with previous designations of the field, it seems useful to try a new tack. As already indicated, I propose to call the field moving-picture dance. This conceptualization has three components: "motion," "picture," and "dance." First, in order to belong to this category, an example must be a moving image. This requires that the work in question be made by a technology in which the possibility of movement is at least feasible. Most dances of this sort will either contain figures that are moving, or images that elicit the 
impression of movement by means of devices like fast editing or special effects. Though this covers a lot of ground, some of you may say it is not broad enough, since there are still dances, like Douglas Dunn's 101 (1974), and therefore that we shall want to count as part of the field images thereof. ${ }^{10}$ But if we make motion one of the criteria here, such efforts will be excluded.

This would be a problem if the requirement were that the image had to be moving; however, that is not how I've stated it. I've only required that it be made by means of a technology where movement is possible. So a film of a still dancer will nevertheless fall into the category, since movement is a possibility in film. It is not, on the other hand, a possibility with slide projections. So a slide of a still dance will not be counted in the category of motion-picture dance, though a comparable still film, even if it appears to be perceptually indiscernible from the slide, will so count.

Is this an arbitrary distinction? I don't think so. For in the film case, since movement is a possibility, the fact that the image has no movement is a pertinent stylistic choice. In order to plumb the significance of what the artist has done, we need to ask why she has chosen to make a still image. We need not ask that question about a slide, since movement is necessarily impossible in a slide. If the image could move, it wouldn't be a slide. Movement is not a possible choice with respect to a slide—all slides must be still—-so there is no point in asking why the slide is not moving. But if a film shows no movement, that is an unavoidable question, since in that case the artist eschews one of the fundamental possibilities of her technology.

Thus, because of its relevance to artistic choice, style, and significance, the choice of movement versus no movement is a defining feature of film, and other forms of moving images, whereas it is not a conceivable choice with respect to slides, or, for that matter, paintings and photographs of dance. That is why I state the motion condition so broadly in terms of the possibility of movement. Of course, most moving-picture dances move: either their figures move or devices like editing and special effects convey the impression of movement. This is what immediately differentiates them from other visual forms, such as paintings, sculptures, and photographs of dance.

The notion of moving-picture dance also requires that the moving images in question be pictures of dance. But this raises the question of what is meant by dance. Richard Lorber has attempted to define dance as "the sum of all non-functional movement behaviors" (8)." This does not seem quite right, however, since the mattress-moving in Yvonne Rainer's Room Service (1963) should count as dance movement, but it is functional. Indeed, the exploration of ordinary movement by the early postmodern dancers at Judson Church might appear to render the concept of dance utterly indefinable, since if ordinary movement is dance, then it would appear that any kind of movement could be dance. That is, dance cannot be defined in terms of its internal movement properties, like expressivity or rhythm.

That sounds persuasive, but it does not mean that we lack the wherewithal to differentiate dance from other sorts of behavior. Specifically, we may be able to identify something as a dance historically, even if we are unable to define it essentially. That is, dance, like the concept of a biological species, may be a historical concept-a concept whose members we determine, as we determine membership in a biological species, by telling narratives or genealogies of descent. So, something counts as a dance movement (or a dance stillness) if it is an example of a historically identifiable dance form or a recognizable descendent thereof. In 
order to establish that a candidate for membership in the category of dance is a recognizable descendant of a previous dance form or a combination of previous dance forms, we need to tell a plausible historical narrative of its evolution from bona fide origins, as we do when we explain how postmodern dance evolved dialectically from modern dance.

I will not deny that the notion of a historical concept deserves more attention than I have just given it. ${ }^{12}$ However, even the little that has been said should give you an inkling of how I propose to tackle the problem of whether or not we are dealing with a specimen of dance. Of course, if you have a better way of identifying dance, you are welcome to use that for the explication of the idea of moving-picture dance which, at this point, I am defining as an image array composed of movement from a recognizable dance vocabulary, where a dance vocabulary is identified either historically or by whatever means you have discovered.

But this is not yet the complete definition, since I have called the field "moving- picture dance" rather than "moving-image dance."What, if anything, hangs on talking about pictures rather than images? Pictures are things whose referents we recognize simply by looking. ${ }^{13}$ Pictures are of the kinds of things we find in the world - specific objects, events, persons, and actions. "Image" is a broader term of art, signifying any form that is visible. An image can be what is called nonfigurative, or nonobjective, or abstract. Jackson Pollock, Wassily Kandinsky, and Frank Stella are famous for their images, not for their pictures, since pictures are of recognizable things or, at least, recognizable kinds of things.

Thus, the term moving-picture dance narrows the field to visualizations of recognizable things, specifically to dances, which, it would seem, are necessarily composed literally of humans and human movement, or personifications thereof. So, at least according to me, when I claim that the concept of moving-picture dance describes our field of interest, I am saying that something belongs in our area if and only if it is a moving visual array of recognizably human movement or stillness (or a personification thereof) drawn from an identifiable existing dance vocabulary or a descendent therefrom. Or, more simply but less accurately: a moving-picture dance is a moving picture of dance movement.

Let me call this the central concept of moving-picture dance. As we shall see, it needs to be supplemented with another concept-what I will call the extended concept of moving-picture dance. But before we get there, allow me to say a few things about the central concept. I'm sure that some of you have already formulated objections to this characterization of what I allege to be the central concept of the field. These objections may take at least two forms: that the notion of moving-picture dance so defined is, in certain ways, too narrow and, in other ways, it is too broad. For some of you, it will be too narrow because it excludes too much, since it excludes what are called ballet mécaniques like Fernand Leger's and Oscar Fischinger's, on the one hand, and abstractions, such as Doris Chase's Circles I (1971), Rocker (1976), or Pelexi Radar (1981), on the other. I hope to deal with these shortcomings when I introduce the extended concept of moving-picture dance.

At the same time, the category, as I've sketched it, may seem too broad, since it includes things like film-dance documentations, sans editing, taken from a fixed-camera position. And many of you will argue that that is just not the kind of thing with which we are concerned. Even the notion of cine-dance gets closer than what I am calling the central concept of moving-picture dance.

This is a fair point, and it calls for immediate comment. From my perspective, the concept of moving-picture dance, as defined so far, only marks the genus of the things that 
concern us. Anything that centrally concerns us must fall into this genus as I've defined it. However, this genus includes several species, notably: moving-picture dance documentations, moving-picture dance reconstructions, and moving-picture dance constructions. As these labels perhaps already indicate, it is primarily moving-picture dance constructions that we generally gather to honor at festivals. So the preceding objection is an apt one to the definition of the genus of moving-picture dance, but the damage can be repaired when we categorize the subtending species in the genus and take note that one of themmoving-picture dance constructions - is the category that most interests us.

What exactly are these species? In order to get a handle on this, it pays to recall that moving-picture dance is a hybridization of two forms: motion pictures and dance. Thus, one way to differentiate these species is to examine the way in which each species relates these two constituents. One relation is that in which the dance is the predominant or lead element-where the motion picture subserves the dance element. That is moving-picture dance documentation. Another possibility is where the motion-picture component calls the tune. That is moving-picture dance construction. Between these two, there is the possibility where the motion-picture elements and the dance elements are co-equal determinants in the results; moving-picture dance reconstruction fills this category. ${ }^{14}$

In order to be a little less abstract, I will say something about each of these categories. Moving-picture dance documentations take advantage of technologies like cinema and video in order to imprint records of the past chemically, mechanically, and/or electronically in their medium. Documents of this sort are invaluable to dance historians and to choreographers involved in reconstituting the classics; they supply a temporal telescope into dance history. Traditionally, the preferred style of these documents is the frontal long-take single fixed-camera-position approach. Examples would include Virginia Brooks's 1983 video of the Dayton Contemporary Dance Company at the Riverside Dance Festival, Talley Beatty's 1948 bench piece from Jacob's Pillow, and the video documentation of the stage version of Li Chiao-Ping's Yellow River (1991).

Recently, moving-picture documentations have received a great deal of bad press, especially from dance notators. They argue that moving-picture documentations-or docudances - are not very good records, especially of historic choreography, because they restrict themselves to single performances, with a single cast of dancers replete with their personal mannerisms, taken from a single angle which may not always be the best one from which to notice, understand, and appreciate the relevant movement qualities. That is, docudance is a poor instrument for telling the dancer from the dance.

In this regard, notators have a point, though it may not be precisely the point they have in mind. For the complaints they voice really only pertain to a certain style of docudance, albeit a very pervasive style, but not to docudance as such. That is, the limitations they point to belong to one style of docudance and can be remedied easily by movingpicture dance documentators through countervailing stylistic strategies.

Undoubtedly, there are a great many examples of docudances that are too selective, that are restricted to a single performance, or that favor medium-long shots from a single camera position, and which, thereby, lose important details and dance qualities. But it is certainly within the resources of the moving-picture dance documentator to transcend these difficulties.

Despite appearances to the contrary, the notator has certain films and videos in mind when she chastises existing films and video records of dance. She has not really thought 
about the possibilities of docudance as such. For example, she has in mind the great many examples of films of a single performance where the camera holds back to a respectful long shot. But there are no grounds to think that a moving-picture dance documentation needs to be restricted to a single performance. A film can show many different ballerinas performing the character of Giselle, as one finds in the film A Portrait of Giselle (1982). Or, if one does not wish to interrupt a performance, one can provide alternative versions of the scenes in the sorts of appendices that are becoming more and more popular in laser discs, or one can nest the alternatives in the hypertext of a CD-ROM, or one can place them on the alternative tracks of a DVD. Indeed, in the 1980 docudance of Doris Humphrey's Two Ecstatic Themes (1931), two soloists, Carla Maxwell and Nina Watt, perform the dance in full_one after the other - thereby enabling the viewer to begin to discriminate the personal from the choreographic (the dancer from the dance).

The problem of the medium-long shot can be overcome by similar devices. If long shots obscure details, then take shots from many angles, including close shots, and locate them in appendices. This is not only a conceptual possibility. Sally Banes and Robert Alexander do just this in their document of Yvonne Rainer's Trio A (1978). And, of course, there is no reason why a moving-picture dance documentation cannot show a dance more than once from different angles, or at different camera speeds. Babette Mangolte's film of Trisha Brown's Water Motor (1978) presents the dance first at 24 frames per second and then in slow motion, affording what Vertov calls a microscope in time that enables one to attend to the dance in fine detail.

Once we realize that it is only a stylistic choice that limits moving-picture dance documentation to showing us a continuous stretch of choreography-once we realize that either parts or the entire performance can be taken from different vantage points for different reasons - then a solution to the problem of selectivity is within our reach. The notator presents the documentarian with a dilemma: either select variable camera positioning and editing, thereby doctoring the record, or go for the problematic medium-long shot, thereby occluding significant detail. But this is a false dilemma. For the documentarian can do both. She can shoot the dance from end to end from a medium shot, thereby rendering it in all its integrity, and then show us alternative views from more suitable angles of details of the dance, and even alternative views of parts of the dance as performed by different principal dancers. These alternative views can be presented either sequentiallythat is, in appendices following the dance proper-or as insets in medium-long shots via segmented or split screens, or, again, they can be nested in the hypertext of a CD-ROM. In short, the notator's argument against moving-picture dance documents rests upon exaggerating the limited imaginations and stylistic approaches of past documentarians. The notators, I believe, mistake such examples as inherent limitations of moving-picture dance documentation as such. But dance documentators, as we have seen, can surpass those limitations effortlessly, at least if they have enough money. This is not said in order to argue against the production of Labanotation scores of dance; in the best of all possible worlds, we should want such scores and moving-picture dance documentations.

If in the case of moving-picture dance documentations, the motion picture component is in the service of the dance, in the case of moving-picture dance reconstructions, the dance component and the motion picture component are more like co-contributors to the result..$^{15}$ The point of a dance reconstruction of this sort is to make the dance and its 
qualities accessible to the viewer. To this end, the reconstructor will deploy multiple camera positions, editing, close-ups, and the like in order to recreate the impression of the dance. Examples of what I have in mind include productions of the "Dance in America Series," such as the reconstruction of Western Symphony in the 1993 production Balanchine Celebration: Part II, directed by Matthew Diamond.

In these cases, I suggest that the moving-picture dance reconstruction is best understood as an interpretation of an already existing dance. Perhaps an analogy will be useful here. Just as the performers of a piece of music execute what we call an interpretation of an already existing work, so the moving-picture dance reconstructor, employing her complement of visual resources, makes an interpretation of a pre-existing dance or dance performance (which is itself already an interpretation).

The aim of musical performers is to make the musical work accessible to an audience; likewise, the moving-picture dance reconstructor aims at making a pre-existing theatrical performance of a dance accessible to an audience by, in effect, showing them how and where to look at a pre-existing dance, and how to organize the dance and its important patterns in their temporal experience. In effect, the moving-picture dance reconstruction is an interpretation of an interpretation, where the pre-existing performance is itself generally an interpretation of a pre-existing dance. Moreover, as there can be many acceptable performative interpretations of the same piece of music, so there can be many different, though acceptable, moving-picture dance reconstructions, each, in turn, making different aspects of the dance accessible to viewers.

In moving-picture dance reconstructions, the dance component and the motion picture component are co-equal in the sense that, though the reconstructor is constrained by the need for respecting the identity of the dance in question, the desired result is to render the dance accessible visually (and aurally) in a motion-picture format, thereby requiring that the dance be adjusted to the exigencies of the pertinent motion-picture mode of representation. This will often require interrupting and reorienting the movement of the dance in a battery of takes for maximal camera exposure. Moving-picture dance reconstruction requires a tender balance between the choreographer and the reconstructor, but it is not an impossible one to achieve.

Whereas the reconstructor is involved in remounting a past dance via motion pictures, the moving-picture dance constructor is aiming to produce a new work. To see what I'm getting at, it is useful to begin by recalling the modernist notion of cine-dance. There the idea was that a cine-dance is made for the screen, and that the way to test for success is to ask whether the dance could be realizable by theatrical means. Where it is not, that is taken as evidence that a new work has been created, one that relies essentially on the camera for its provenance. So a work like Hilary Harris's 9 Variations on a Dance Theme (1967) is a paradigmatic cine-dance in this tradition, since it is supposed that its penetrating geography of the body is not something obviously realizable on stage, dependent as it is on cinematic close-ups and framing.

Now, I have criticized the modernist bias of this conception, arguing that comparable theatrical realizability should not be the test of whether something counts as a moving-picture dance construction. Nevertheless, a piece of the notion of cine-dance may still be useful to us, namely that such a construction be a new work, one brought into being and shaped by the agency of the resources of the motion picture, such as editing, 
camera movement, camera placement, special effects, digital processing, motion capture, computer animation, and so on. This does not mean that the moving-picture dance constructor cannot use pre-existing dance material, as presumably Hilary Harris did, in the process of constructing something new by cinematic agencies; it only requires that the constructor be attempting to produce a new dance work in the process, rather than documenting or reconstructing one. Speaking of her work with Douglas Rosenberg entitled De L'Eau (1995), Li Chiao-Ping put this point nicely when she said that De L'Eau was not a translation of a work, but rather was the work. ${ }^{16}$

So the test of whether we have a moving-picture dance construction is whether the constructor intends to produce an autonomous work of art, using either pre-existing dance material or dance material expressly composed for interacting with whatever motion picture resources the constructor has at her disposal. On this construal, it makes no difference if a comparable dance work could be realized by other means, such as theatrical ones; what makes the difference is that new work in question was in fact produced through the agency of the motion picture, for example, by cinematic or videographic means. These means, moreover, need not be unique to the relevant medium. Thus, a long-take duo by Astaire and Rogers, composed for the camera, though perhaps in some sense realizable on a stage, still counts as a moving-picture dance construction, because it is a new work, a new dance, brought into existence by the agency of motion pictures. The issue is not whether the new work could have been produced in another art form, like theater, but whether it was brought into existence by the art form of motion pictures.

Earlier I said that with respect to moving-picture dance constructions, the motion picture component is dominant. The sense of "dominance" that I had in mind is that the choreographic ingredients involved, whether designed specifically for the occasion or derived from pre-existing material, are not transfigured into an integral, autonomous, original work of art until they are articulated in the idiom — whether essential or not — of motion pictures.

But then how are we to tell the difference between moving-picture dance reconstructions and moving-picture dance constructions, in cases where the dance construction is employing pre-existing dance material? Here we need to consider the artist's intention in producing the work: was she intending to create a new work or to re-interpret an already existing one? In the latter case, we have an instance of reconstruction, whereas in the former case, we are looking at a moving-picture dance construction.

Because of this reliance on authorial intention, it may be imaginable that we could have three perceptually indiscernible moving-picture dances: one a document, one a reconstruction, and one a construction comprised of pre-existing dance materials. How do we say which is which? It depends on whether the author intended to make a document or a reconstruction of an existing dance, or whether she intended to make something new, something with different qualities and different significations than any pre-existing dance. Is this a problem? I don't think so, since for art in general, it is the creator's intentions that fix the pertinent category of an artwork (Levinson 188); ${ }^{17}$ and, furthermore, where a constructor intends to create a new artwork but produces nothing more than what functions, upon reflection, as a document of a pre-existing dance, then, unless (like Warhol with his Brillo Boxes) she is making a reflexive comment, we will say that she has failed to realize her intention to construct a new artwork — which, all things being equal, is a reason to find her moving-picture dance construction unsuccessful. 
So far I have defined the genus of moving-picture dance and then further subdivided it into three species, of which the last, the moving-picture dance construction, is undoubtedly the one that we most care about, since it is the source of original artworks in this field. I claim that this is the central concept of motion dance, because most of the work that one will encounter at festivals devoted to this sort of work fall into this genus and, as well, one can expect to find examples of all three of its species on the program. Though, of course, one expects to find more moving-picture dance constructions than the other sorts, nevertheless, when some documentations and reconstructions appear, one is unlikely to hear too much grumbling, since, I submit, all three species coincide roughly with our intuitions about what fits naturally into our field of interest. That is, we all understand why documentations, reconstructions, and constructions have all found their way onto the program.

However, even if my formulations suit the least controversial examples of what concerns us, they do not cover everything. As indicated previously, by invoking the requirement that motion-picture dances be comprised of dance material-however straightforward that makes our scheme of categorization-it fails to accommodate the sorts of ballet mécaniques and nonfigurative movement abstractions that are also often regarded as part of the tradition of moving-picture dance. In order to deal with cases like this, I suggest that we introduce a second, extended (rather than central) concept of moving-picture dance, thereby hypothesizing that our field is really governed by two concepts rather than only one.

That is, the central concept of moving-picture dance needs to be supplemented by the extended concept of moving-picture dance. My suggestion for this second concept is that something is a moving-picture dance in the extended sense if the image component includes a significant amount of movement presented because it is interesting for its own sake. ${ }^{18}$ This movement may be of elements inside the frame or it may be an impression of movement generated by technical means, such as editing or special effects like pixilation (such as one finds in the work of Pooh Kaye). Where that movement is interesting in its own right, we have a case of moving-picture dance in the extended sense. For in these cases, we are apt to describe the movement as dance-like just because dance is the art form that specializes in the exhibition of movement for its own sake.

This is not all that dance does, of course, but when one is asked which of all the art forms specializes in the exhibition of movement for its own sake, dance seems the likeliest candidate. That is, dance is the pre-existing category under which we subsume movement presented because of its intrinsic interest as movement. Consequently, when we encounter a motion picture that exhibits a significant amount of movement in a way that is interesting for its own sake, we are naturally inclined to say that it is dance-like, or, in my terminology, an instance of moving-picture dance in the extended sense.

Here I must hasten to add that a set of movements may not only be interesting for its own sake, but interesting for other reasons as well. Thus, the aerial ballets in Bruce Lee's kung-fu films, what Douglas Rosenberg calls recoporealizations, are narratively interesting at the same time that they are interesting, indeed delightful and compelling, to watch for their own sake. My requirement is simply that the movement be at least interesting for its own sake, but it need not be exclusively so. Because, as well as being interesting for its narrative content, Bruce Lee's martial cine-choreography is also interesting for its own sake, we can call it a case of moving-picture dance in the extended sense. 
Moreover, if we accept the notion of motion picture dance in the extended sense, I think we can deal with the kinds of cases the central concept of motion picture dance leaves out. Ballet mécaniques present nonhuman movements as interesting for their own sake. Abstract movement pieces — such as Doris Chase's — can also be counted as movingpicture dance constructions in the extended sense, where they picture movement that is interesting for its own sake. Even constructions comprised of ordinary movement-such as Amy Greenfield's Tides (1982), Elaine Summers' lowa Blizzard (1973), Silvina Szperling's Bilingual Duetto (1994), and Ami Skanberg's warm-up Etude (1996) — may count as movingpicture dance movement in the extended sense, if the ordinary movement is exhibited in the context of a new artwork in a way that renders it interesting for its own sake. ${ }^{19}$

If we employ these two concepts of moving-picture dance-the central concept and the extended concept — I think that we can assimilate all the cases of dance-relevant motion pictures we want. Is there a problem with employing two concepts to define the field, rather than one? Perhaps some might worry that there is, because they fear that one concept, the central concept, is being implicitly privileged hierarchically over the other. But there is no reason to suppose that this must be the case. It is perfectly consistent with what I've proposed to agree that many moving-picture dances in the extended sense are superior to moving-picture dances more centrally in the category, including moving-picture dance constructions. Indeed, none of my categories are evaluative; they are all classificatory. A well-done moving-picture dance reconstruction can be aesthetically better than a lackluster or inept moving-picture dance construction.

In conclusion, I have developed a family of definitions designed to capture the range of things that I believe we feel intuitively drawn to include in the corpus of what I am now calling moving-picture dance, a label that I believe better encompasses the extension of things that concern us than do the more popular alternatives. Some readers, I know, have genuine reservations about definitional projects like mine because they fear that definitions, like Aristotle's definition of tragedy, have a tendency to turn into prescriptions - attempts by theorists to legislate what will count as art or art of a certain genre, like moving-picture dance. But I do not think that this definitional exercise has been legislative, because the framework I've offered is rather compendious: even if the central concept limits experiments to dance movement, the extended concept opens it to any kind of movement. This allows that anything can be grist for the artist's mill, so long as it has something to do with the possibility of movement. Can any conception be more liberal? Does anyone wish to include in the category something that has nothing whatsoever to do with movement? And, in any case, my definitions are not overly exclusive from the artistic point of view, since, of course, even if someone makes a work that somehow falls outside my framework, there is no implication in what I've proposed that it cannot be art or that it cannot be of great value.

So what's the problem?

\section{Notes}

1. For instance, to use a political example, certain definitions of what it is to be a human being have long been emancipatory instruments in struggles against racism and sexism.

2. Emshwiller, Ed. "Artist's Statement." Dance Perspectives 30 (Summer, 1967): 25. Print. 
3. This argument is developed in Noël Carroll, "Defining the Moving Image," in Theorizing the Moving Image. New York: Cambridge University Press, 1996. Print.

4. See Rosenberg, Douglas. "Recorporealizing the Body Via Screen Dance." Dance for the Camera Symposium. University of Wisconsin-Madison. 11 February 2000. Lecture.

5. Similar reasoning would pick out Cunningham's Blue Studio (1976) as a quintessential video dance, since in the chromakey segments, Cunningham, through the agency of video, is able to "dance across" an impossible series of landscapes.

6. For example, the creative geography that is so important in Shirley Clarke's A Dance in the Sun (1953) could be easily duplicated through video.

7. Copeland, Roger. "The Limitations of Cine-Dance." Filmdance: 1890's-1983. Ed. Amy Greenfield. New York: Filmdance Festival Catalogue, 1983. Print.

8. Andre Bazin was an influential French film theorist of the nineteen-forties and fifties who advocated the use of long-take, deep-focused shots - shots that allow the spectator's eye to rove across the image. Such shots approximate the conditions of seeing in real space and time, rather than breaking events apart by editing. Bazin defended this style in the name of realism. But clearly the kind of reliance on blocking in the single shot that he preferred could also be replicated in theater. See Andre Bazin's What Is Cinema? Vol. I. Berkeley: University of California Press, 1971. Print.

9. Jacques Tati was a French filmmaker who specialized in comedies_-such as Play Time (1967)_of everyday life, finding humor in its mundane events. One could say that he isolated comic moments in the stream of daily living, plucking laughs out of the quotidian. He also employed Bazinian techniques to this end, encouraging viewers to discover comic interactions in scenes, much as we find Waldo in the games of the same name. Woodberry's Invisible Dance (1981) shares a congruent sensibility, staging bursts of dance activity amidst the rush of Wall Street lunch breaks, and inviting us to find pre-staged dance moments in the seams and on the margins of the workaday hustle and bustle.

10. N.B. Amy Greenfield made a film of 101, though since I have unfortunately not seen it, I cannot say how still it actually is.

11. Lorber, Richard. "Experiments in Videodance." Dancescope 12.1 (Fall/Winter, 1977/78): 7-16. Print.

12. For further discussion of this historical approach (with respect to the issue of identifying art in general), see Chapter Five of Noël Carroll, Philosophy of Art: A Contemporary Introduction. London: Routledge, 1999. 249-264. Print. Also, see the suggested readings at the end of that chapter for more references.

13. For a defense of this view of pictures, see Noël Carroll, "The Power of Movies," in Theorizing the Moving Image (cited above), pp. 75-93.

14. Abstractly, there is a fourth possible permutation here: where the dance element and the motion picture element have nothing at all to do with each other. But if they have literally nothing to do with each other, then we are not dealing with a case of hybridization, but, rather, with two numerically independent works. Consequently, this possibility will never be realized literally in any moving-picture dance, where dance and image are physically imprinted in one object, and, therefore, should be of no concern to us.

15. In order to avoid terminological confusion here, let me emphasize that by "reconstruction"I am talking about reconstructions of existing dances by means of moving-picture technologies; I am not referring to things like Millicent Hodson's reconstruction of Le Sacre du printemps (1987) for the stage.

16. See Chiao-Ping, Li. "The Director/Choreographer Dialectic." Dance for the Camera Symposium. University of Wisconsin-Madison. 10 February 2000. Lecture.

17. Levinson, Jerrold. The Pleasures of Aesthetics. Ithaca: Cornell University Press, 1996. Print.

18. We will say that movement is interesting for its own sake, at least if the movement itself, apart from whatever other functions it performs, is delightful, arresting, fascinating, pleasurable, compelling, or riveting to look at (as movement), or because it is stimulating to think about (as movement), perhaps for theoretical reasons. Admittedly, this does not supply us with a definition of what it is for movement to be interesting for its own sake, but it should give the reader of an idea of the relevant ballpark.

19. Though the central concept of moving-picture dance is comprised of three species, I suspect that, when it comes to the extended concept, we are only dealing with the category of constructions. That is, I do not think that people are usually inclined to count documents of non-dance movements or even motion picture reconstructions thereof as moving-picture dance, even in the extended sense. The temptation only arises where the moving-picture dance work in question has some claim to being an autonomous, movement artwork. Some evidence for this is that one does not usually find such movement documents or reconstructions included in festivals for or catalogues of moving-picture dance works. 



\section{Artists' Pages}

\section{Simon Ellis}

[The following is a text-based adaptation of the performance-presentation, Watching, presented at OpenSource\{VideoDance\} 2007, Findhorn, Scotland on November 23, 2007.]

Watching

Video (available to stream at http://vimeo.com/11016394)

This video was screened simultaneously with one other video.

Both videos had only one audience member each.

The videos were rear-projected on screens that were $1.5 \mathrm{~m}$ away from their respective viewers.

What lies outside of the frame?

In dance-on-screen writing and thinking there has been an invaluable emphasis on overcoming the problems of framing and screening movement. The language is strong: "the rigid, rectangular window"

(Nagrin 33), "the often-deadening space of the screen"

(Rosenberg 13). ' Within this screen we witness the body's "flattening" (Preston 79). ${ }^{2}$ The screen topples three dimensions into two. This flattening, powered by what André Lepecki calls the "reductive operation of the camera as perspectival machine" (75), has occupied our thinking, acting as a reason to engage with screendance (and a reason to avoid it). ${ }^{3}$

At the heart of this language is an overwhelming concern for what the camera sees, and consequently, what is produced on screen. Doug Rosenberg describes the phenomenon of camera-looking as an act that "implies a reverence for that which is framed and eschews all that is outside the frame" (14-15). However, to (over)emphasize what is within frame (or onscreen) is to run the risk of joining conventional cinema in presupposing the viewing experience. Our shared performance heritage - itself a critical aspect of screendance hybridity-necessitates an acknowledgement that screendance content also lies beyond the frame.

There were also two live performers.

Both audience members watched their "own" performer

(but were able to see the other if they chose to).

But before I talk about aspects of the nature of content, I need to back up a bit. 
In 2000, I was teaching choreography to final year dance students at the Victorian College of the Arts in Melbourne. We were dealing with a rather formalist approach to choreographic ideas, and the question of form-content existing on some kind of continuum was raised. That night I was talking about this with my girlfriend at the time (that's the love story part) — a visual and installation artist called Elizabeth Boyce - who suggested a small book by Thomas McEvilley: Art \& Discontent (1991). Actually, she didn't recommend the book so much as give me an old photocopied handout of a section of the book called Thirteen Ways of Looking at a Blackbird. The book's language is plain, and clear, and is an excellent example of arts theory writing that is inclusive, provocative and evocative. Better still, McEvilley appears to hold no fears in tackling many of the 'givens' in arts theory. That is, to discuss in detail the things we might believe are self-evident (or even obvious), but so easily forget, ignore or avoid. "Every critic should give indication of the sources and limits of his knowledge" (Pound 56). ${ }^{4}$

Some confessions:

This paper is heavily based on McEvilley's writing. I am not suggesting that I am an expert on questions of form and content. Occasionally I read art theory because I feel a little obliged.

Each audience member was located on a viewing platform.

The ambient sound of the live performance (prior to the video performance) was miked and sent to the audience's headphones.

The principle concern for McEvilley in Art and Discontent is to forcefully debunk any notion that works of art_-of any kind — exist in a formal vacuum. In other words, that the formalist dream of excluding non-audiovisual elements from how work is experienced is implausible. To attempt to deprive work of content probably sounds a little bizarre considering our contemporary awareness for the cultural imprinting of how (and what) we watch, but this is what formalists desired. In 1966, Susan Sontag wrote: "It is the habit of approaching works of art in order to interpret them that sustains the fancy that there really is such a thing as the content of a work of art" (11). ${ }^{5}$

But, for McEvilley, such formalist ideals are seriously compromised simply because he wonders how, when viewing works of art, we can ever avoid the "associative habit" (45) of the human mind. ${ }^{6}$ The question becomes not whether content is present, but rather the 
nature of its relationship to form. Here, McEvilley uses semiological terms to clarify the form/content relationship as being either

motivated or unmotivated.

If the relationship is motivated, then content is inherent in the formal properties of the work. If the form-content relationship is unmotivated then content is added to the work by the work's audience - including the artist or artists (McEvilley and Denson 38).?

Each audience member had a pillow under the head.

Each audience member wore high quality headphones.

It was all very comfortable.

The distinction is more subtle than it first appears. Many things that are "outside" of a work can easily_ and intuitively_be placed within it. Examples might be the reputation of the artist, her record of earlier work, or even the assumption that an artist has seen a certain work (McEvilley and Denson 37-8).

"What is content, anyway? And, are we involved?" (McEvilley 69)

In this paper I am going to consider some aspects of content in dance on screen that are typically (and easily) forgotten as being content. These are derived from a selection of McEvilley's Thirteen Ways of Looking at a Blackbird (70), and are: content added to a work over time; content arising from the genre or medium of an artwork; and content arising from context.

Before the videos were played, audience members watched their "own" performers live. This performer was also the "subject" of that audience member's video.

Content added to a work over time

"Whatever occurs to a work as its history unfolds becomes part of the experience of the work, and part of its meaning, for later generations" (McEvilley 79).

An example of this is the German-born, Australian-based choreographer and dancer, Tanya Liedtke, who died tragically in Sydney in August 2007. The 30 year old, known in the UK for her work (in particular) with DV8, was about to take over the artistic direction of Sydney Dance Company_an extraordinary challenge, and one she clearly was excited about. Content is accrued to her work as its "destiny" is added to through time. Tanya's work becomes the work of "the emerging choreographer whose life ended tragically at age 30." In effect, and I mean this with sensitivity and a certain amount of sadness, her death has added to the content of the work 
she has made, and impacts on how it is experienced and viewed as it continues to be presented around the world.

A more banal (and less terrible) example might be a screendance work that is re-edited some years after its first cut. In much the same way as Ridley Scott has treated us to various versions of

Blade Runner (1982), it is not so much that footage (or voiceover) has been added to or removed, but that a reedit has occurred that contributes to and becomes part of the meaning of the work through time. Of course, the edits also shift the content of the work—but that goes without saying.

Content arising from the genre or medium of the artwork

Implicit in the notion that genre adds content to an artwork is the categorization of artworks as existing within particular genres (and not others). Such categorization invariably leads to questions about popular versus elitist works of art. In screendance, this, perhaps, is evident in the rather fraught relationship that contemporary dance practices have with music videos.

I am currently editing a project called Tuesday that could, in effect, be described as a music video. Recently I was working on an application for a festival and read the following guidelines: "Illustrative or interpretive work, (e.g. music videos), will not be suitable" (Threshold). ${ }^{8}$

Is this what I am doing? Illustrating a song? Indeed, is this all that music videos do-illustrate or interpret songs? Don't some genres of dance performance do precisely this? Is this bad? Are there rules?

How do I get a copy of the rulebook?

When asked, "What is taste?" Marcel Duchamp replied "habit."

Spike Jonze's work is wonderfully unsettling in this respect. His video work in the late 1990s with the fictitious Torrance Community Dance Group simultaneously parodied modern dance and dance video clips. And in How They Got There (1997) ${ }^{9}$ Jonze creates what might be described as a familiar screendance scenario, including a delightful little ditty between two dancing strangers, only to have the 3-minute

film end in a massive out-of-nowhere car crash sequence.

In order to watch the videos, both platforms were manually rotated from vertical until they were almost horizontal.

And what about questions of format? To shoot on film unquestionably adds content to a project. But then, so too does shooting on my camera phone. Another example of genre adding content to artwork might be a screendance director deciding to return to a single fixed camera setup 
filming live performances in a proscenium-arch theatre. Considering screendance's origins in documenting live performance, for a choreographer/director to work this way adds political and cultural significance and content to the project, and the screendance field more generally.

Content arising from the context of the work

Katrina McPherson's DVD_Five video dances $(2006)^{10}$ exemplifies this idea. Billed as a companion to her book Making Video Dance (2006), "1he DVD effectively "bundles" these five works together, encourages them to be viewed together, and compared with one another.

But, perhaps more importantly, by connecting the DVD with the book, the works take on pedagogical content: Tools for the aspiring screendance artist to watch, learn, and even imitate.

The five video dances are no longer the same works when first presented: not only has the physical format of their presentation been altered, but they have taken on alternate contexts and are now reframed as essential undergraduate screendance viewing.

The presence of screens above the audience (as they were tilted backwards)

was a surprise to them.

Whilst the videos were playing, the two performers remained active

in the (peripheral) performance space.

As a Physical Education undergraduate in the late 1980s, when

Bobby McFerrin sang Don't Worry, Be Happy and U2 was still reasonably cool, our most feared Professor would occasionally, at the conclusion of a student oral presentation, lean back in his chair, stroke his cleanly shaven chin, and ask that most dreaded of all questions: So what?

To remember, to examine, and to consider how content is developed and accumulated in the construction, presentation and watching of screendance, invites newness.

"By foregrounding an element of content usually taken for granted and invisible, a whole new artistic mode or direction can be discovered" (McEvilley 187-88).

At the end of the video(s) the platforms were (slowly) tilted back to vertical.

This experience of being tilted (very slowly) had a major impact on the watching.

One audience member commented: "At the end I felt I had passed through

something, and had a strong sense that something had been done to me." 
If one of the current concerns in screendance research and thinking is

to articulate the medium and form clearly, then in this paper I have been interested in broadening and roughening the edgesin threading movement (or uncertainty) into our critical engagement with the form-and in questioning the in/stability of the screendance viewing process in the emergence and development of content. Actually, there's one other of McEvilley's thirteen ways of looking at a blackbird that is perhaps worth considering:

Content arising from verbal supplements supplied by the artist

McEvilley quotes Edward Said, and although Said is talking about literary texts, I have transposed this word with a more general term: "art works."

"[Art works] impose constraints and limits upon their interpretation ... because as artworks they place themselves. . . they are themselves by acting, in the world. Moreover, their manner of doing this is to place restraints upon what can be done with (and to) them interpretively" (Edward Said, cited in McEvilley 48). To add content, to constrain the interpretive process. The most blatant example of "verbal supplementation" is the title given to a work by an artist.

The project's title is Inert (Ellis, Corbet et al. 2006). ${ }^{12}$

www.skellis.net/Inert.

\section{Notes}

1. Nagrin, Daniel. "Nine Points on Making your Own Dance Video." Dance Theatre Journal 6.1 (1988): 33-36. Print; Rosenberg, Douglas."Proposing a Theory of Screendance." Screendance: The State of the Art. American Dance Festival. Duke University, Durham, NC. July 6-9, 2006. Talk.

2. Preston, Hilary. "Choreographing the frame: a critical investigation into how dance for the camera extends the conceptual and artistic boundaries of dance." Research in Dance Education 7.1 (2006): 75-87. Print.

3. Lepecki, André. Exhausting Dance: Performance and the Politics of Movement. London: Routledge, 2006. Print.

4. Pound, Ezra. Literary Essays of Ezra Pound. Ed. T. S. Eliot. New York: New Directions, 1968. Print.

5. Sontag, Susan. Against Interpretation. New York: Vintage, 1994. Print.

6. McEvilley, Thomas. Art \& Discontent: Theory at the Millennium. New York: McPherson \& Company Publishers, 1991. Print.

7. McEvilley, Thomas and G. Roger Denson. Capacity: History, the World, and the Self in Contemporary Art and Criticism. London: Routledge, 1996. Print.

8. Threshold Studios. Critical Mass: Hypnos. Northampton, UK, 2007. Videoproduction commissioning proposal.

9. Jonze, Spike. How they got there. USA: Palm Pictures, 1997.3 minutes. Video.

10. McPherson, K. Five Video Dances. Goat Media Ltd., 2006. Video.

11. --. Making video dance: a step-by-step guide to creating dance for the screen. London, Routledge, 2006.

12. Ellis, S., D. Corbet, et al. Inert. Melbourne: Dancehouse, 2006. 


\section{Contributors}

\section{Ann Cooper Albright}

A performer, choreographer, and feminist scholar, Ann Cooper Albright is Professor of Dance and Theater at Oberlin College. Combining her interests in dancing and cultural theory, she is involved in teaching a variety of dance, performance studies and gender studies courses which seek to engage students in both practices and theories of the body. Most recently, she finished a year-long project of dancing and writing which resulted in a new book Encounters with Contact: Dancing Contact Improvisation in College (2010). She is the author of Modern Gestures: Abraham Walkowitz Draws Isadora Duncan Dancing (2010); Traces of Light: Absence and Presence in the Work of Loïe Fuller (2007); Choreographing Difference: the Body and Identity in Contemporary Dance (1997) and co-editor of Moving History/Dancing Cultures (2001) and Taken By Surprise: Improvisation in Dance and Mind (2003), all from Wesleyan University Press. Her work has been funded (among others) by the National Endowment for the Humanities, the American Council of Learned Societies, the Camargo Foundation, and the Ohio Council for the Arts, from which she has received five Excellence in the Arts Awards, the most recent in 2009. Ann is the founding director of Girls in Motion, an after-school program for middle school girls, and co-director (with Ann Dils) of a web-based teaching initiative entitled: Accelerated Motion:Towards a New Dance Literacy in America, which is funded by the National Endowment for the Arts and NITLE.

\section{Harmony Bench}

Harmony Bench recently received her PhD in Culture and Performance from the UCLA Department of World Arts and Cultures. She holds an MA in Performance Studies from NYU as well as a BA in Women's Studies and a BFA in Ballet from the University of Utah. As both dancer and scholar, Harmony divides her time between dancing, writing, and teaching. Her dissertation, entitled Choreographing Bodies in Dance-Media, considers the ways in which dances created for screen reconceptualize dancing bodies and choreography. She is beginning a new research project that includes mobile media, video games, and social media as sites for choreographic inquiry and analysis. Dr. Bench has just joined the faculty at Ohio State University as an assistant professor.

\section{Noël Carroll}

Noël Carroll is a distinguished professor of philosophy at the Graduate Center of the City University of New York. He is past President of the American Society for Aesthetics and a Guggenheim Fellow. He has worked as a dance and film critic and he, along with Sally Banes, wrote a documentary program on motion-picture dance, called Dancing with the Camera,for National Public Television in the nineteen-eighties. His work also encompasses the philosophy of literature, the philosophy of visual arts, and social and cultural theory, and he has served as president of the American Society for Aesthetics. Carroll has been a regular contributor of journalistic reviews of dance, theater, and film in publications such as 
Artforum and TheVillage Voice. His most recent book is On Criticism (2008). Carroll joined the Graduate Center from Temple University. He holds a Ph.D. in Cinema Studies from NYU, and a Ph.D. in Philosophy from the University of Illinois at Chicago.

\section{Simon Ellis}

Simon Ellis is a New Zealand born independent performance maker and performer with a broad practice founded on choreographic traditions. He has a practice-led PhD (investigating improvisation, remembering, documentation and liveness) from the University of Melbourne, and is currently senior lecturer in dance (practice-based) at the University of Roehampton in London. His choreographies have included site-specific investigations, screendance, installation, webart, and more conventional black box works. His research interests: include improvisation and investigations of presence, memory/remembering, practice as research, and processes of mediation in performance and screendance.

\section{Claudia Kappenberg}

Following a career as professional dancer, Claudia Kappenberg completed an MA Fine Art/ Film and Video at Central Saint Martins College of Art and Design, London UK in 1998. She is Senior Lecturer in Performance and Visual Art at the University of Brighton, UK and leads the MA Performance and Visual Practices. In 2009 she was awarded a sabbatical from the University of Brighton and a Network Grant from the Arts and Humanities Research Council. Claudia is principal investigator for the AHRC Screendance Network and editor of The Internationl Journal of Screendance. In 2010 she co-curated the What If . . . Festival, London. Her projects comprise single screen work as well as screen-based installations and live site-specific events and have been shown across Europe, the US, and the Middle East. Claudia founded the Lost Parade performance company in 2008 which has toured the UK and Ireland. Publications include a chapter for Anarchic Dance (Routledge 2004) and conference papers on the history and theorization of performance practices and Screendance, including the recent International Journal for Performing Arts and Digital Media, Volume 5, Issue 2/3.

\section{Bob Lockyer}

Bob Lockyer worked for over 40 years at the BBC where he was responsible for the dance programs on BBC Television. Working with the Arts Council of England he created Dance for the Camera. This is a series of short dance works made especially for the camera and to date over fifty videos have been made and seen in the UK and around the world. The programs have been screened at festivals worldwide and won numerous awards. Programs he has produced have gone on to win major awards such Prix Italia, International Emmys and the Prague d'Or. In 2002 the series he originated with Deborah Bull, The Dancer's Body, was broadcast on BBC TWO and went on to win the Dance Screen Award for that year. Among the choreographers he has worked with over the years include Frederick Ashton, Merce Cunningham, Robert Cohan, Peter Wright, Kenneth MacMillian, Lloyd Newson, Christopher Bruce, and Siobhan Davies. 
As well as his work for the BBC, Bob Lockyer was for ten years the first chair of Dance UK, a program that invests in research and publishes reports and papers to improve the health and welfare of dancers. For many years he has also lectured around the world and taught "Dance for the Camera" workshops in the UK, South Africa, Canada, Australia, New Zealand, and most recently, in June 2004, at the Dance Department of the University of Utah in the United States.

\section{Kyra Norman}

Kyra is a choreographer and video maker, with a background and training in contemporary dance and visual art, and a particular interest in screendance. In 2005 she initiated The Light Fantastic, through which she has developed her practice in writing and curating as well as making screendance work. She is currently researching a practice-based PhD exploring the screen as a site for choreography, within the University of Bristol's Department of Drama: Theatre, Film, Television. Kyra has a BA (Hons) in Dance Theatre (Laban, London) and an MA in Visual Performance: Time-Based Media (Dartington College of Arts, Devon). From 2006-2010 she was an Associate Lecturer at Dartington, where she led the Dance on Screen module. At Bristol, she has contributed to several Screen Research and departmental events, and in April 2009 she ran a two-day screendance research event for artists, curators and others engaged in the field from around the UK, "The Screen as a Site for Choreography." Kyra is Administrator for the Screendance Network.

\section{Douglas Rosenberg}

Douglas Rosenberg is an EMMY nominated director and the recipient of the Phelan Art Award in Video. He received the Director's Prize at the International Jewish Video Festival for his film, "My Grandfather Dances" with choreographer Anna Halprin, and is well-known for his collaborations with choreographers including Molissa Fenley, Sean Curran, Ellen Bromberg, Joe Goode, Li Chiao-Ping, Eiko and Koma, and others. A project with Ellen Bromberg, "Singing Myself A Lullaby," funded by a fellowship from the Soros Foundation, won an Isadora Duncan Dance Award (IZZIE) and he has also received fellowships from the Wisconsin Arts Board (Fellowships in Performance and Media Arts), and his work has been funded by the National Endowment for the Arts, the Zellerbach Foundation and the Rockefeller Foundation among others. His numerous residencies include: Stanford University and STARLAB Institute, Brussels; selected screenings include: The Contemporary Art Museum in Buenos Aires, Dance on Camera Festival, New York, Mostra de V'deo Dansa de Barcelona, Spain, the Brooklyn Museum of Art and recently retrospectives at the International Festival of Video Dance in Buenos Aires, Argentina and Agite y Sirve Festival in Mexico. Rosenberg was the director of the Video Archival Program at the American Dance Festival for a decade and is the founder and director of ADF's Dancing for the Camera Festival. He has served on numerous panels and juries and is currently at work on a book addressing the theory and practice of dance for the camera. His most recent publication is The International Journal for Performing Arts and Digital Media, Volume 5, Issue 2/3, and he is currently finishing a book on the theory of screendance that is under contract with the University of Oxford. He is a professor of Art at the University of Wisconsin-Madison. 


\section{Cari Ann Shim Sham*}

Cari Ann Shim Sham* is an award winning filmmaker noted for her surreal visual style and precise manipulation of the edit. She has presented work at the Joyce Soho, \& Danspace in NYC, Highways Space, Redcat, The Brewery, The Henry Huang Theater and Bergamot Station in Los Angeles. She has recently collaborated with Lionel Popkin, Rachael Lincoln, Kyle Ruddick, Jia Wu, John Bishop and Lynn Dally. She works in the mediums of Dance for Camera, Multi Media, Installation and Documentary film. Her films are screening internationally. EMPAC Dance Movies Commission short-listed her in 2009, 2008 \& 2007 grant cycles and she was the recipient of the Surdna Arts Teachers Fellowship in 2007. She is a member of the screening committee for Dance Camera West. Having taught workshops in Dance for Camera in Malaysia and in Los Angeles and guest lecturing on Dance for Camera at UCLA and UC Riverside in 2008, she is starting a media class for street artists, Prestidigitation, in Los Angeles with co-conspirator Anna B. Scott.

\section{Susana Temperley}

Susana Temperley is a Specialist in Art Criticism, and has a Licentiate Degree in Social Communication from the University of Buenos Aires. She is a professor at the transdepartmental area of Art Criticism in the National University Institute of Arts, BA where she teaches the subjects Semiotics and Communication Theory, General Semiotics and Art Society and Criticism. She has given seminars about semiotics and videodance in Buenos Aires and Mexico and she has published articles on videodance, dance criticism and semiotics in both national and international press media. Since 2007 she has organized the International Symposium on Videodance within the frame of the Videodance Festival of Buenos Aires.

\section{Sarah Whatley}

Sarah Whatley is Director of Research for ICELAB in the School of Art and Design at Coventry University. Specializing in dance analysis and the interface between dance and digital technologies, she led an AHRC-funded project to create the Siobhan Davies digital archive and is now working in partnership with Surrey University to enhance user-engagement with online dance resources (also AHRC-funded). She is also part of an AHRC-funded Network project "Screendance" and researches pedagogical practices for disabled dancers. She is an international associate for a pan-European research cluster, Inside Movement Knowledge, and edits the international Journal of Dance and Somatic Practices, published by Intellect.

\section{Chirstinn Whyte}

Chirstinn Whyte worked throughout Britain as a performer, choreographer and teacher for twenty years, and completed a PhD in 2008 at Middlesex University, London, researching choreographic practice for screen. Her work has been shown at screendance and short film festivals worldwide, with writing featured in publications including RealTime, Dance Theatre Journal, Film International and Filmwaves. 


\section{Marisa Zanotti}

Marisa Zanotti is a filmmaker, choreographer and writer. She began her career in dance, training at the Laban Centre and working as a dancer creating work for stage and screen with The Cholmondeleys, Wendy Houston, Laurie Booth and Anders Christiansen. As a choreographer she has been commissioned by Tramawy, CCA, Tron and Dance Base touring these commission in the UK and abroad. She has worked extensively in theatre in new writing on plays by David Greig, David Harrower, Abby Morgan, Mark Ravenhill and Nicola McCartney as a movement direcor and director, in productions by The Traverse Theatre, The Citizens, Paines Plough, Edinburgh International Festival and The TronTheatre. She received a Creative Scotland Award in 2000 and since then her professional practice has been in screenwork in installation, dance film and most recently film drama. She has directed three short dramas and produced and directed four dance films; her current interest in dance for the screen lies in the area of experimental and lo-fi work, she is developing a project on screendance driven by narrative. She works as part of a writer/director team with David Greig and together they are currently writing the feature "The Warren." Their first short film, At the end of the sentence, received BAFTA and BIFA nominations and won the UK Film Council Audience Award and Best Short at The Hamptons Film Festival. She is a trustee of South East Dance and a Movement 12 artist. She leads the MA Choreography at University of Chichester. Her doctoral research entails examining the critical implications of her practice. 


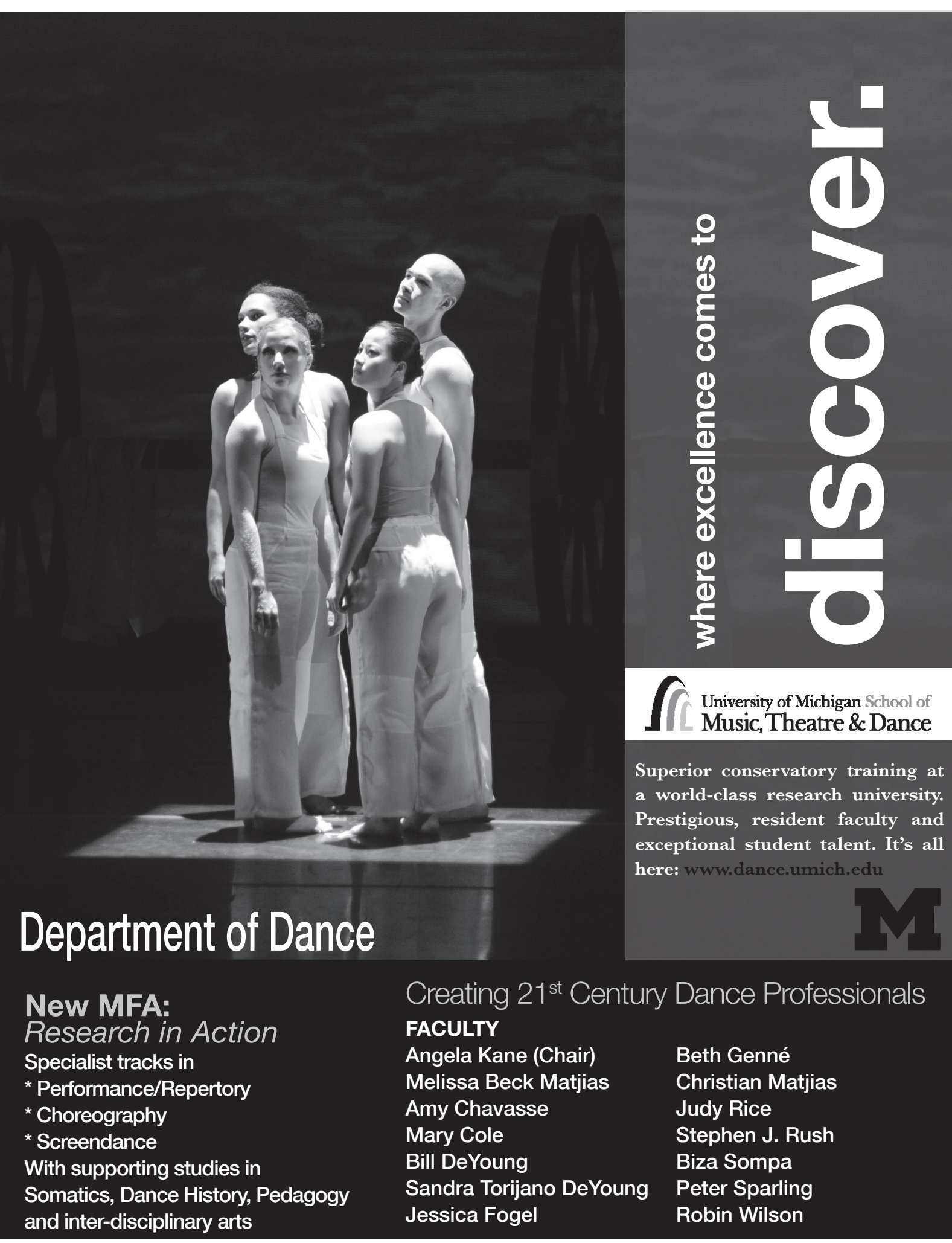

